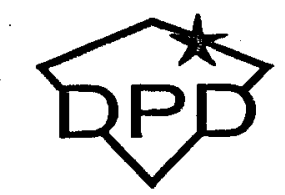

Report DPD-00-107

\title{
Materials Development and Field Demonstration of High-Recycled-Content Concrete for Energy-Efficient Building Construction *
}

\section{DPD, Inc.}

2000 Turner Street

Lansing, MI 48906

USA

Phone/Fax: 517-349-5653

Email: dpdinc@aol.com

- This project was sponsored by the U.S. Department of Energy Under Contract DE-FG02-97ER82359.

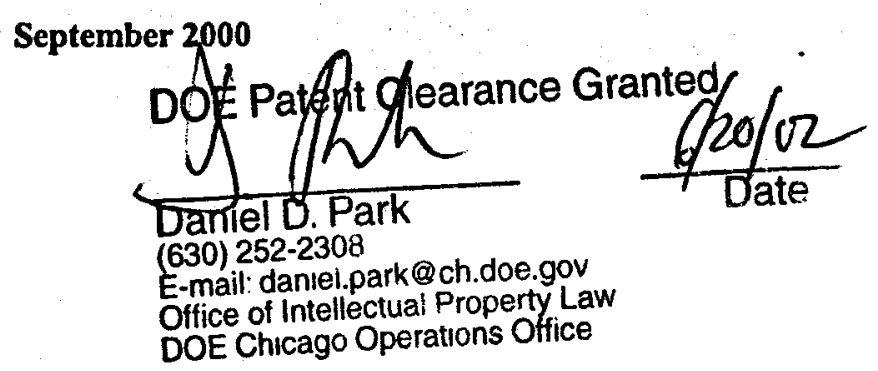




\section{DISCLAIMER}

This report was prepared as an account of work sponsored by an agency of the United States Government. Neither the United States Governmeat not any agency thereof, nor any of their employees, makes any wartanty, express or implied, or assumes any legal liability or responsibility for the accuracy, completeness, or usefulness of any information, apparatus, product, or process disclosed, or represents that its use would not infringe privately owned rights. Reference berein to any specific commercial produet, process, or service by trade name, trademark, manufacturer, or otherwise does not necessarily constitute or imply its endorsement, recommendation, or favoting by the United States Goverament or any agency thereof. The views and opinions of authors expressed herein do not necessarily state or reflect those of the United States Governmeat or any agency thereof. 


\section{DISCLAIMER}

Portions of this document may be illegible in electronic image products. Images are produced from the best available original document. 
$\begin{array}{ll}\text { Acknowledgments } & 2\end{array}$

Summary 3

1.0 Selection and Characterization of Recycled Materials 4

1.1 Introduction 4

1.2 Characterization of Recycled Materials 4

2.0 A New Approach to Concrete Mix Proportioning w/ Recycled Aggregates 11 2.1 Introduction 11

2.2 Description of Mix Proportioning Procedure 11

2.3 Proportioning of Concrete Mixtures w/Selected Recycl. Materials 12

3.0 Mechanical and Physical Attributes of High-Recycled-Content Concrete 13

3.1 Experimental Program and Procedures 13

3.2 Experimental Results 13

4.0 Thermal Properties of Durability of High-Recycled-Content Concrete 39

4.1 Thermal Characteristics 39

4.2 Durability and Related Properties $\quad 42$

5.0 Development and Characterization of High-Recycled-Content Masonry 48

5.1 Introduction 48

5.2 Mix Proportioning, Processing, and Experimental Program 48

5.3 Experimental Results $\quad 55$

6.0 Field Evaluation of Energy-Efficient Building Construction with High-Recycled-Content Concrete $\quad 65$

6.1 Description of the Field Project 65

6.2 Energy Analysis of Buildings 66

6.3 Construction and Instrumentation of Buildings 69

6.4 Field Performance Data $\quad 80$

$\begin{array}{ll}7.0 \text { Conclusions } & 90\end{array}$ 


\section{Acknowledgments}

The research project presented herein was sponsored by the U.S. Department of Energy under Contract No. DE-FG02-97ER82359. This support is gratefully acknowledged.

The National Renewable Energy Laboratory made valuable contributions towards performance of the project. These contributions were of tremendous value to the quality of the project and its findings.

The highly valuable contributions of Todd Gruhn to experimental efforts in this project are gratefully acknowledged. 


\section{Summary}

The main thrust of the research reported herein was to develop new concrete mixtures which incorporate relatively high volume fractions of recycled materials to provide a desirable balance of thermal and structural attributes for use in energy-efficient building construction. The following recycled materials were considered as replacements for coarse aggregate in concrete: granulated plastics (HDPE, PVC, PP and mixed plastics), chipped hardwood, granulated tire, steel, and crushed concrete. As replacement for coarse aggregates, the recycled materials occupy about half of concrete volume. Crushed limestone and birdeye stone were used as control (virgin) normal-weight coarse aggregates in normal and masonry concrete, respectively. Expanded clay was use as control light-weight coarse aggregate in both normal and masonry concrete mixtures. The recycled and control aggregates were characterized based on their dry-rodded bulk density, bulk specific gravity, particular geometry, and particle size distribution (sieve analysis). A refined procedure was developed and verified for proportioning of concrete mixtures with recycled coarse aggregates and natural sand fine aggregates; this procedure requires some basic attributes of recycled materials, and requires final adjustment of water content to achieve the targeted fresh mix workability. Recycled plastic, tire and wood coarse aggregates yield light-weight concrete materials; crushed concrete and recycled steel coarse aggregates yield normal-weight and heavy-weight concrete materials. Water absorption capacity per unit volume of all concrete materials incorporating recycled and virgin coarse aggregates were comparable except for wood coarse aggregates which yielded relatively high levels of water absorption. Flexure, compression and impact tests performed on control and high-recycled-content concrete mixtures provided a basis to judge the structural value of different high-recycled-content concrete mixtures when compared with control normal- and light- weight concrete materials. Recycled plastic, wood and steel coarse aggregates were effective in restrained shrinkage crack control. Thermal conductivity and specific heat measurements on control and high-recycled-content concrete mixtures provided the basis to determine the value of various concrete mixtures in energy-efficient building construction. Major gains in specific heat resulted from the introduction of recycled plastic, wood and tire coarse aggregates. The high-recycled-content concrete materials considered in this investigation exhibited desirable levels of durability when exposed to repeated wetting-drying and temperature cycles, and also to elevated temperatures. An energy-efficient reinforced concrete building was designed, from both structural and energy points of vies, and was constructed with concrete incorporating recycled mixed plastic coarse aggregate. A control building was also constructed with normal concrete. Comprehensive measurements on the energy performance of these buildings confirmed the high value of recycled plastic concrete as a materials for energy-efficient building construction. Concrete masonry materials incorporating recycled coarse aggregates were also developed and characterized. High-recycled-content concrete masonry materials generally provided desirable levels of mechanical, physical and durability characteristics combined with desirable combined with highly attractive thermal attributes for energyefficient building construction. 


\subsection{Selection and Characterization of Recycled Materials -}

\subsection{Introduction}

The project targeted high-volume and market-limited components of waste stream with potential for use as coarse aggregate to tailor thermal attributes of concrete. Recycled plastics, tire, wood, concrete and steel were considered in this investigation. Except for recycled steel, other waste materials considered can be categorized as market-limited. While three different types of plastics were considered throughout the material development part of project, eventually mixed plastics (with limited existing markets) proved to be a viable source of coarse aggregate for concrete in energy-efficient building construction. Recycled steel is the only waste material considered here which cannot be categorized as market-limited; its distinct thermal attributes, however, could be of great value in certain applications. All recycled materials were subjected to size reduction in order to achieve maximum particle size of less than about $20 \mathrm{~mm}$ suiting utilization as concrete coarse aggregate.

\subsection{Characterization of Recycled Materials}

The following recycled aggregates have been acquired and subjected to comprehensive laboratory tests:

- Granulated plastics (HDPE, PVC \& PP)

- Chipped hardwood

- Granualted Tire

- Steel

- Crushed Concrete

We used crushed limestone and expanded clay as the control virgin (normal-weight and lightweight, respectively) coarse aggregates in concrete, and natural birdeye stone as the control coarse aggregate in masonry units. Figure 1 shows the recycled and virgin aggregates considered in this investigation for use in concrete. The fine aggregate used in all mixes is natural sand. The recycled aggregates are considered here as replacement for coarse aggregates in concrete and masonry units. This accounts for approximately $50 \%$ replacement by volume of concrete aggregates with recycled materials. 

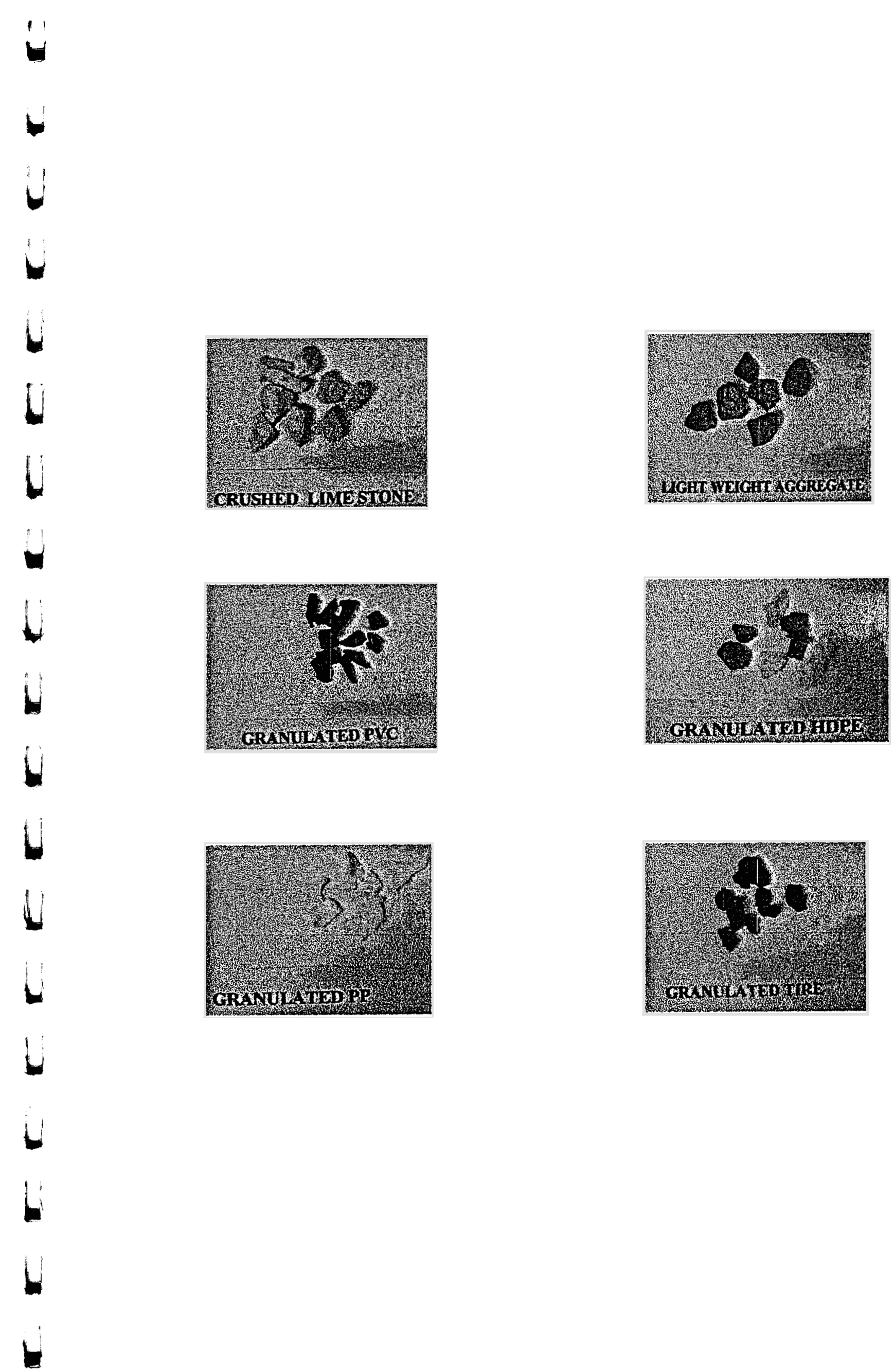

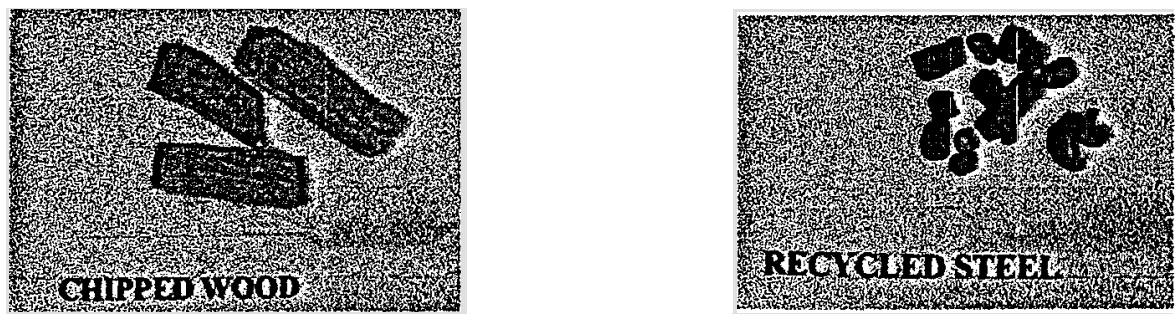

Figure 1. The Recycled and Virgin Aggregates Considered for Use in Concrete.

In order to evaluate the recycled aggregates for use in concrete and masonry construction, they were subjected to the following tests:

- Dry-rodded bulk density

- Bulk specific gravity

- Particular geometry

- Particle sieve analysis

Figure 2 presents the dry-rodded bulk density and bulk specific gravity of different recycled and virgin aggregates. It is obvious that a wide range of dry-rodded bulk densities and specific gravityes are covered here, partly reflecting on the wide range of thermal properties and geometric attributes considered. As will be noted later, dryrodded bulk density has emerged as a primary criterion in our refined mix proportioning techniques for recycled content concrete.

Figure 3 presents the cumulative distributions of the length, width and thickness of various recycled materials. Fifty particles of each recycled or virgin material were considered in the development of these cumulative distributions.

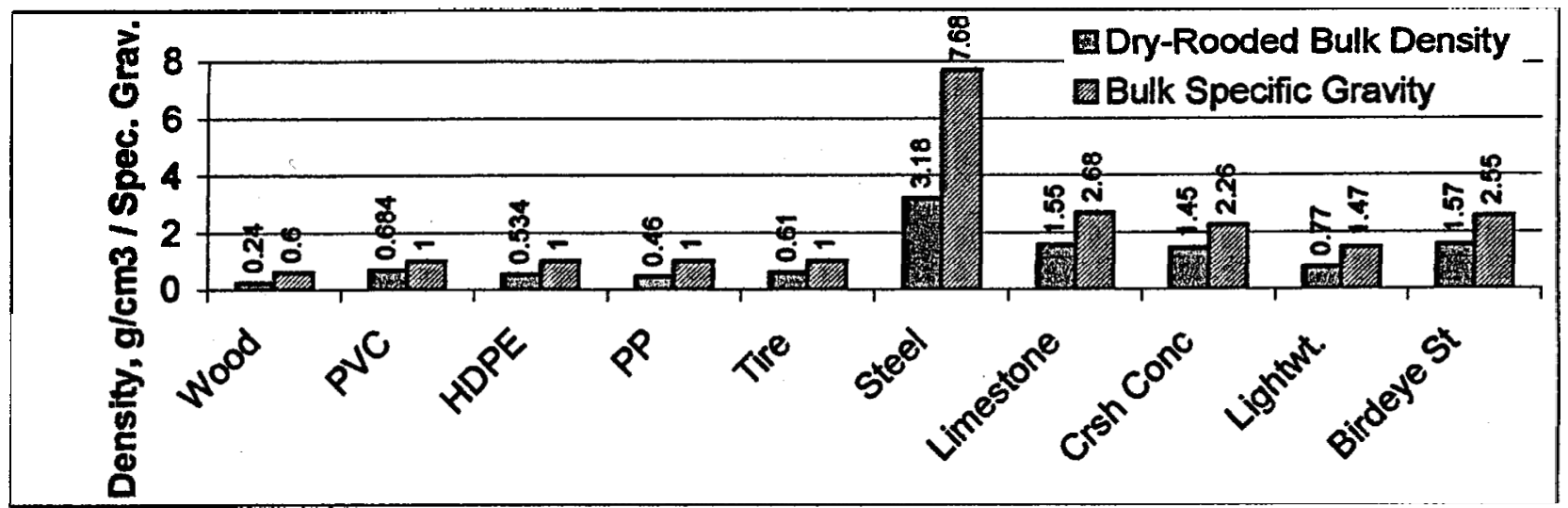

Figure 2. Dry-Rodded Bulk Density of Different Recycled and Virgin Coarse Aggregates. 


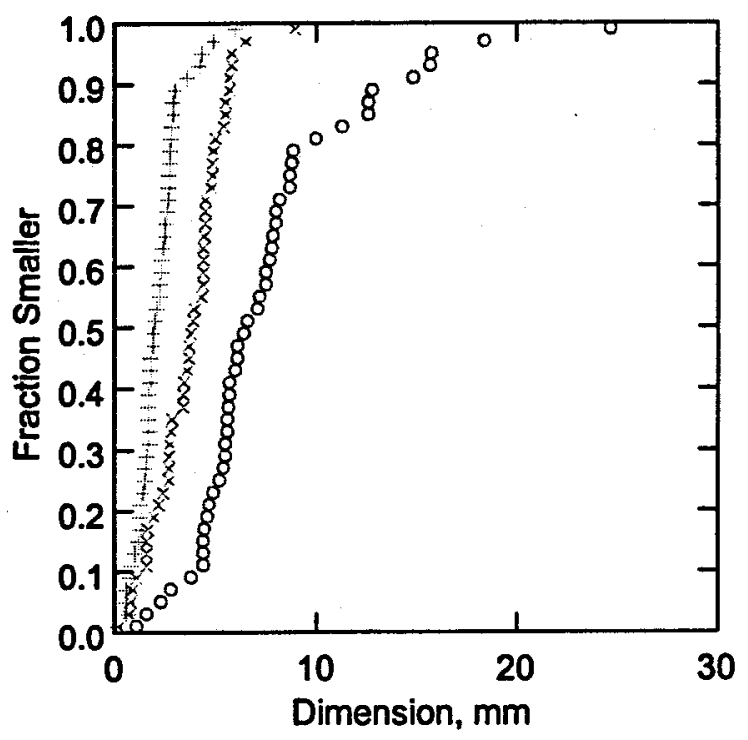

+ PVCTHICK

$\times$ PVCWIDTH

○ PVCLENGTH

(a) Granulated PVC

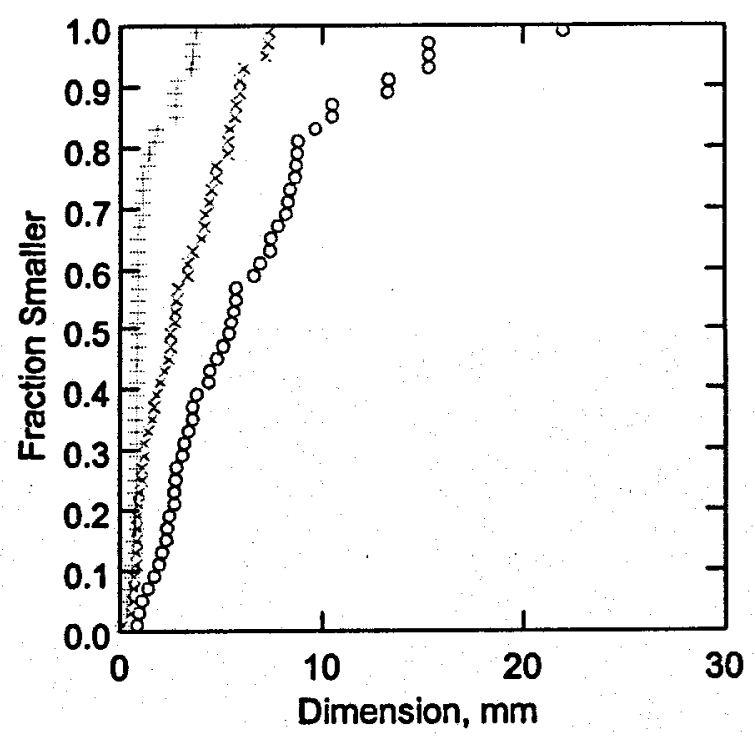

+ PPTHICK

$\times$ PPWIDTH

○ PPLENGTH

(b) Granulated Polypropylene 


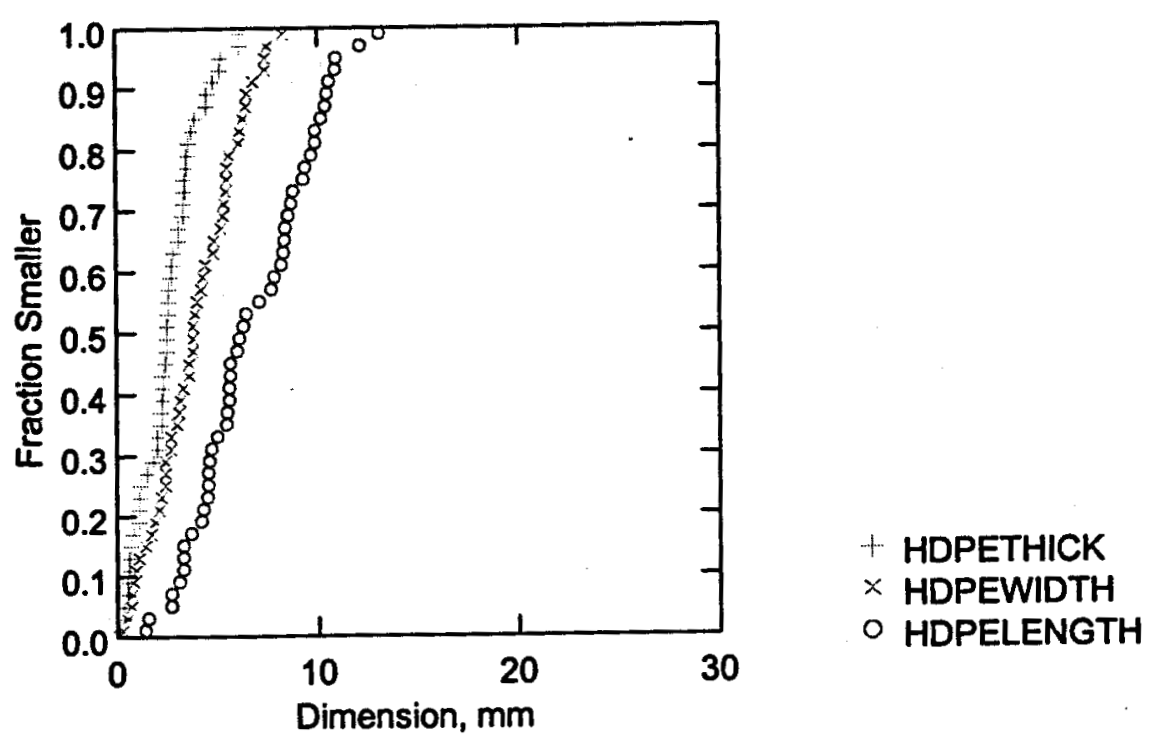

(c) Granulated High-Density Polyethylene

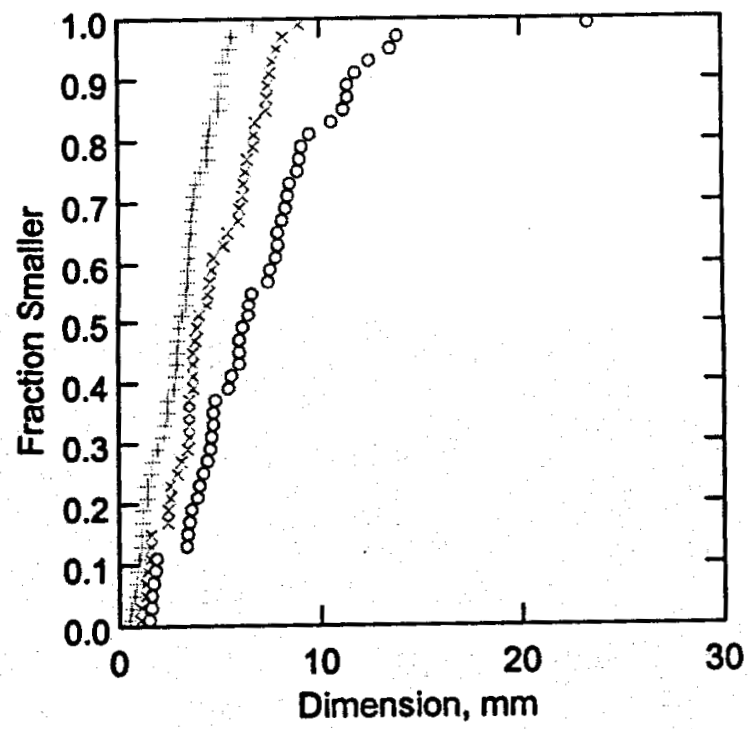

+ TIRETHICK
$\times$ TIREWIDTH
$\circ$ TIRELENGTH

(d) Granulated Tire 


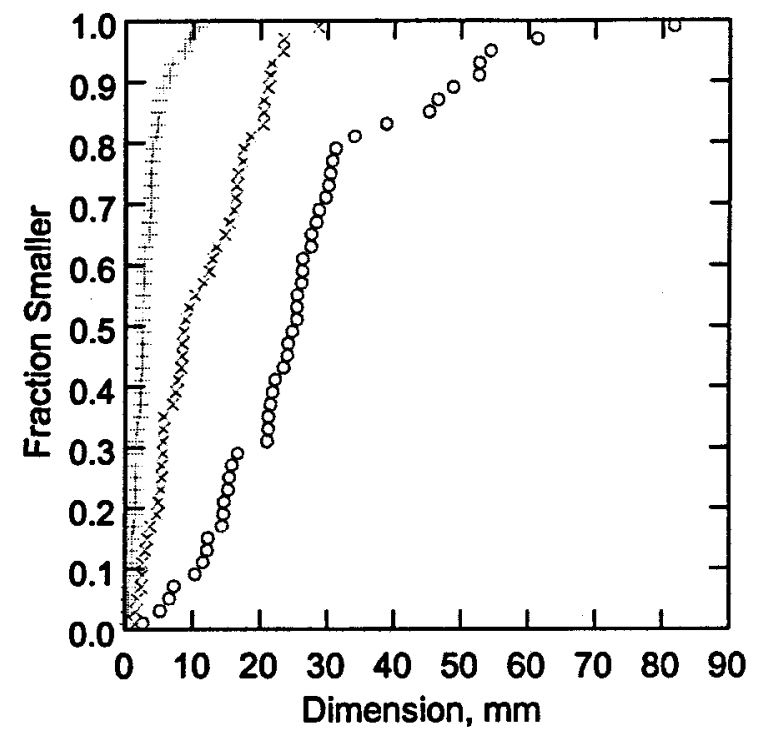

+ WOODTHICK

$\times$ WOODWIDTH

○ WOODLENGTH

(e) Chipped Hardwood

Figure 3. Cumulative Distribution of Different Recycled Materials.

In the case of virgin crushed limestone, birdeye stone, virgin lightweight aggregate, crushed concrete, and steel, which had roughly comparable lengths, widths and thicknesses, we used sieve analysis in order to characterize particle dimensions. Table 1 presents the results of sieve analysis for these and also for other recycled aggregates used in this investigation. Recycled wood has the coarsest gradation, followed by crushed concrete and limestone. Size gradations of granulated tire, plastics (HDPE, PVC and PP) as well as steel are relatively fine. 
Table 1. Particle Size Distribution of Different Virgin and Recycled Aggregates.

\begin{tabular}{|c|c|c|c|c|c|c|c|c|c|c|}
\hline \multirow{2}{*}{$\begin{array}{c}\text { Sieve } \\
\text { Size, } \\
\mathrm{mm}\end{array}$} & \multicolumn{10}{|c|}{$\begin{array}{c}\text { Cumulative Percent Retained for } \\
\text { Aggregate Type }\end{array}$} \\
\hline & $\begin{array}{l}\text { Crush. } \\
\text { Lmstn. }\end{array}$ & $\begin{array}{c}\text { Birdeye } \\
\text { Stone }\end{array}$ & $\begin{array}{c}\text { Virgin } \\
\text { Lightwt }\end{array}$ & $\begin{array}{l}\text { Crush. } \\
\text { Conc. }\end{array}$ & $\begin{array}{c}\text { Recycl. } \\
\text { Steel }\end{array}$ & $\begin{array}{l}\text { Granul. } \\
\text { Polypr. }\end{array}$ & $\begin{array}{l}\text { Granul. } \\
\text { PVC }\end{array}$ & $\begin{array}{l}\text { Granul. } \\
\text { HDPE }\end{array}$ & $\begin{array}{c}\text { Granul. } \\
\text { Tire }\end{array}$ & $\begin{array}{l}\text { Chipp. } \\
\text { Wood }\end{array}$ \\
\hline 38 & & & & & & & & & & 0 \\
\hline 25 & & & & & & & & & & 9.0 \\
\hline 19 & & & & 1.3 & & & & & & 38 \\
\hline 13 & 19 & & 14 & 25 & & & & & 0.1 & 72 \\
\hline 10 & 29 & & 64 & 43 & & & & & 0.4 & 84 \\
\hline 6.4 & 51 & 27 & 97 & 66 & & 1.4 & 0.06 & 7.5 & & \\
\hline 4.7 & & 59 & & & 5.8 & 18 & 7.2 & 38 & 30 & \\
\hline 3.4 & 80 & 88 & & 90 & 77 & 58 & 63 & 73 & 52 & \\
\hline 2.0 & 91 & 99 & & & & 97 & 94 & 93 & 87 & \\
\hline 0.84 & & & & & 100 & 99 & 95 & 97 & & \\
\hline
\end{tabular}




\subsection{A New Approach to Concrete Mix Proportioning with Recycled Aggregates}

\subsection{Introduction}

Due to the variability of recycled aggregates, there is a need for versatile concrete mix proportioning techniques which can accommodate various properties of recycled aggregates which could be encountered in practice. We have developed such mix proportioning techniques based on the principles devised by Portland Cement Association in document entitled "Design and Control of Concrete Mixtures".

\subsection{Description of the Mix Proportioning Procedure}

The mix proportioning process comprises five steps described below.

1. Targeting a normal compressive strength (with normal-weight aggregate) of $31 \mathrm{MPa}$, water/cement ratio should be 0.45 .

2. with $12 \mathrm{~mm}$ maximum coarse aggregate size (roughly applicable to the aggregates under consideration here) and fine aggregate fineness modulus of 2.7 , the dry-rodded volume of coarse aggregate (or recycled materials) per unit volume of concrete is 0.56; the weight of coarse aggregate (or recycled material) per unit volume $\left(\mathrm{m}^{3}\right)$ of concrete would thus be 0.56 times the bulk density of coarse aggregate (or recycled material): $\quad W_{\text {coarse agg }}\left(\mathrm{kg} / \mathrm{m}^{3}\right)=0.56 \times 1,000 \times \mathrm{BD}_{\text {coarse agg }}\left(\mathrm{g} / \mathrm{cm}^{3}\right)$

3. With $12 \mathrm{~mm}$ maximum size of coarse aggregate (or recycled materials), considering air-entrained concrete (with 6 vol.\% air content) and a slump of $140 \mathrm{~mm}$, one arrives at $200 \mathrm{~kg} / \mathrm{m}^{3}$ water content for the concrete mix.

4. With a water/cement ratio of 0.45 and water content of $200 \mathrm{~kg} / \mathrm{m}^{3}$, one arrives at a cement content of $444 \mathrm{~kg} / \mathrm{m}^{3}$.

5. The fine aggregate content should be selected to compensate for the total volume (1 $\mathrm{m}^{3}$ ) minus the total volume of cement, water, coarse aggregate and air:

$$
\text { Sand Volume }=1-\mathrm{W}_{\text {water }} / \mathrm{SG}_{\text {water }}-\mathrm{W}_{\text {cement }} / \mathrm{SG}_{\text {cement }}-\mathrm{W}_{\text {coarse agg }} / \mathrm{SG}_{\text {coarse agg }}-0.06
$$

where, W and SG refer, respectively, to the weight per unit volume $\left(\mathrm{m}^{3}\right)$ of concrete and the apparent specific gravity of coarse aggregate or recycled material, and 0.06 is the volume of air per unit volume of concrete.

Replacing the previously selected values of $\mathrm{W}$ in the above equation and noting that the apparent specific gravity of water and cement are 1 and 3.15, respectivey, and considering that Sand Weight is equal to Sand Volume times the apparent specific gravity of sand (2.64), one arrives at the following expression for calculating the weight of sand per unit volume $\left(\mathrm{m}^{3}\right)$ of concrete:

$$
\begin{gathered}
\mathrm{W}_{\text {sand }}=2.64 \times 1,000 \times\left[0.94-0.444 / 3.15-0.2-0.56 \times \mathrm{BD}_{\text {coarse agg }} / \mathrm{SG}_{\text {coarse agg }}\right] \\
=1,584-1,478 \times \mathrm{BD}_{\text {coarse agg }} / \mathrm{SG}_{\text {coarse agg }}
\end{gathered}
$$


In the above equation, $\mathrm{BD}_{\text {coarse agg }}$ is the dry-rodded bulk density $\left(\mathrm{g} / \mathrm{cm}^{3}\right)$ of the (virgin or recycled) coarse aggregate. In practice, given the variations in inter-particle friction and other properties of different recycled materials and coarse aggregates, the value of slump may change (at constant water content) depending on the type of virgin or recycled coarse aggregate. The water content should also be adjusted in light of changes in the water absorption capacity of (virgin or recycled) coarse aggregates, and considering that we use oven-dried aggregates in all our laboratory mixtures. We thus chose to adjust the water content of different mixtures to yield comparable levels of slump (140-200 mm).

\subsection{Proportioning of Concrete Mixtures with Selected Recycled Materials}

The above mix proportioning procedure was applied to concrete mixtures incorporating our selected recycled (and virgin) coarse aggregates. The resulting mix proportions are presented in Table 2. This table also presents the fresh mix properties (slump and air content) of various concrete mixtures.

Table 2. Mix Proportions of Concrete Materials with Different (Virgin or Recycled) Coarse Aggregates (with oven-dried aggregate and $444 \mathrm{~kg} / \mathrm{m}^{3}$ cement content).

\begin{tabular}{|c|c|c|c|c|c|c|c|c|}
\hline Coarse Agg. & $\begin{array}{c}\mathrm{BD}_{\text {coarseag }} \\
\mathrm{g} \\
\left(\mathrm{g} / \mathrm{cm}^{3}\right)\end{array}$ & $\begin{array}{c}\mathrm{SG}_{\text {coarse }} \\
\text { agg }\end{array}$ & $\begin{array}{c}\text { Water/ } \\
\text { Cement }\end{array}$ & $\begin{array}{c}\text { Coarse } \\
\mathrm{Agg} / \mathrm{Cem}\end{array}$ & $\begin{array}{c}\text { Sand/ } \\
\text { Cement }\end{array}$ & $\begin{array}{c}\text { AirEnAg } \\
\left(\mathrm{ml} / \mathrm{m}^{3}\right)\end{array}$ & $\begin{array}{c}\text { Slump } \\
(\mathrm{mm})\end{array}$ & $\begin{array}{c}\text { Air Cont. } \\
(\%)\end{array}$ \\
\hline Limestone & 1.55 & 2.68 & 0.475 & 1.96 & 1.66 & 130 & 60 & 6 \\
\hline Lt. Wt. Agg. & 0.77 & 1.47 & 0.475 & 0.975 & 1.84 & 130 & 150 & 13 \\
\hline Crushed Conc. & 1.45 & 2.26 & 0.475 & 2.0 & 1.44 & 130 & 125 & 8 \\
\hline Rec. Steel & 3.18 & 7.68 & 0.475 & 4.35 & 2.12 & 130 & 145 & 12 \\
\hline Chipped Wood & 0.24 & 0.6 & 0.63 & 0.313 & 1.94 & 130 & 124 & NA \\
\hline Gran. Tire & 0.61 & 1 & 0.475 & 0.773 & 1.55 & 130 & 90 & 10 \\
\hline Gran. PVC & 0.684 & 1 & 0.475 & 0.868 & 1.3 & 130 & 110 & 14 \\
\hline Gran. HDPE & 0.534 & 1 & 0.475 & 0.675 & 1.8 & 130 & 12 & 7 \\
\hline Gran. PP & 0.46 & 1 & 0.475 & 0.583 & 2.05 & 130 & 12 & NA \\
\hline
\end{tabular}

${ }^{1}$ A higher water/cement ratio of 0.56 produced a slump of $140 \mathrm{~mm}$. 


\subsection{Mechanical and Physical Attributes of High-Recycled-Content Concrete}

\subsection{Experimental Program and Procedures}

Three replicated mixes were prepared for each of the compositions introduced in Table 2. Three compression (100 mm diameter by $200 \mathrm{~mm}$ height cylinders), three flexure (prisms with $100 \mathrm{~mm}$ square cross section and length of $350 \mathrm{~mm})$, and three impact $(150 \mathrm{~mm}$ diameter by $50 \mathrm{~mm}$ height cylinders) were prepared from each mix. These specimens were demolded at 24 hours of age, moist cured at $100 \%$ relative humidity and $22^{\circ} \mathrm{C}$ for 13 days and then air dried at $50 \%$ relative humidity and $22^{\circ} \mathrm{C}$ for another 14 days for testing at the age of 28 days. The compression, flexure and impact tests were performed following ASTM C 39, ASTM C 78 and ACI Committee 544, respectively. The ruptured flexure specimens were used for the assessment of the water absorption capacity and apparent specific gravity (ASTM C 642) of different concrete materials. Figure 4 presents a view of the flexure test set-up.

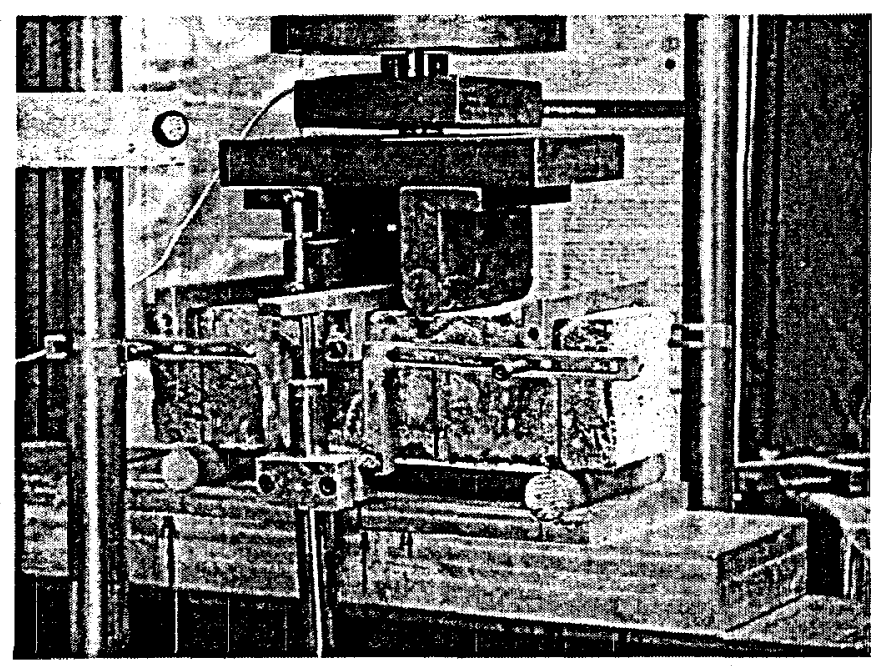

Figure 4. The Flexure Test Set-Up.

\subsection{Experimental Results}

Examples of flexure specimens ruptured after test are presented in Figure 5. The compressive strength, flexural strength and impact resistance test results (mean values and standard errors) are presented in Figures 6,7 and 8, respectively. Concrete mixtures using limestone as coarse aggregate are the control materials in this investigation. 


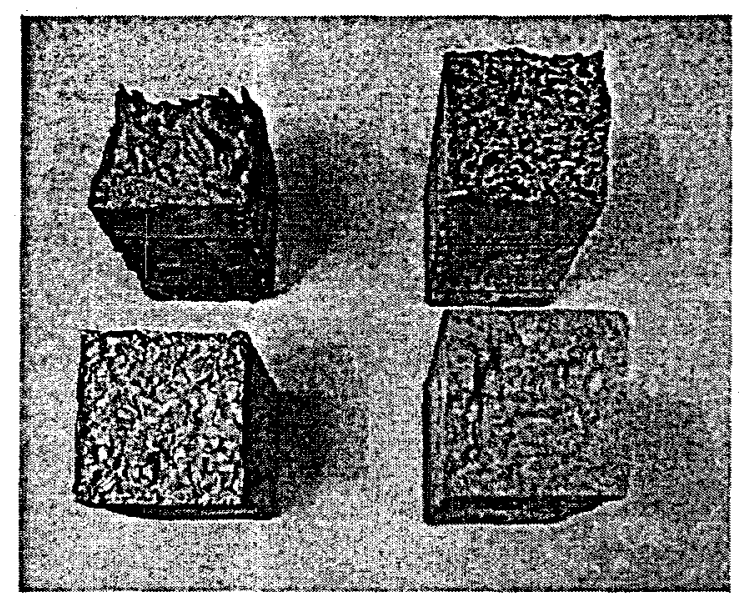

Figure 5. Examples of Ruptured Flexure Specimens.

While Figure 6 indicates a sharp drop in compressive strength when crushed limestone is replaced with plastics and especially with tire and wood, Figure 7 suggests that concrete materials with recycled plastics and even with recycled wood as coarse aggregate provide reasonable levels of flexural strength. The failure mode in concrete materials incorporating recycled plastics, wood and tire was quite ductile (while that in control concrete was brittle). Instrumented flexure tests were thus performed to quantify the ductility (and energy absorption capacity) of high-recycled-content concretes in flexure; the results of these instrumented flexure tests are presented at the end of this chapter. Concretes with recycled (crushed) concrete and recycled steel as coarse aggregate perform somewhat similar to the control concrete in compression and flexure. Concrete with lightweight coarse aggregate, on the other hand, exhibits compressive and flexural strength levels comparable to those of recycled plastic concretes.

Concrete materials with recycled (crushed) concrete as coarse aggregate provide impact strengths comparable to those of control concrete with limestone coarse aggregate (Figure 8a). Recycled plastics, when used as coarse aggregates, also provide reasonable levels of impact resistance. Concrete materials with recycled tire, wood and steel as coarse aggregate, and also concrete with light weight coarse aggregate provide relatively low levels of impact resistance (see Figure 8a). When considering the difference between impact resistance to first crack and failure (which reflects on the post-cracking ductility of the material), Figure $8 \mathrm{~b}$ suggests that use of recycled plastics, tire and wood as coarse aggregates yield improvements in post-cracking ductility of concrete.

Figures 6 and 7 indicated that the compressive strength of recycled content concretes does not necessarily reflects on their flexural strength. With the introduction of relatively low-modulus (plastic, tire and wood) coarse aggregates, there is generally a larger drop in compressive strength than in flexural strength (which is the dominant mode of behavior of concrete slabs). Figure 9, which shows the ratios of compressive strength to flexural strength, confirms this observation. In general, concrete materials with recycled plastics, tire and especially wood provide higher flexural strength-to-compressive strength ratios 
than concrete materials with limestone, crushed concrete, recycled steel and lightweight coarse aggregates. An evaluation of the flexural and compressive strengths in different mixtures also indicated that, unlike normal concretes of different compressive strengths, the ratio of flexural strength to the square root of compressive strength is not constant for different recycled aggregate concrete materials.

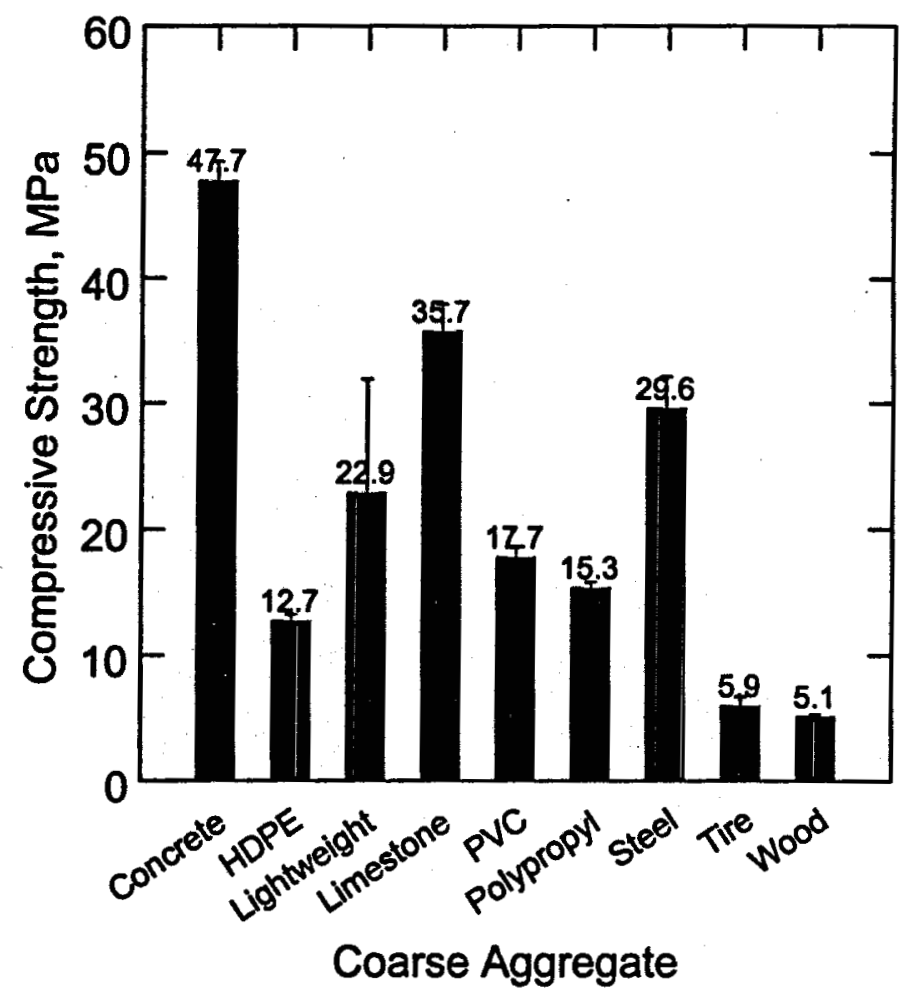

Figure 6. Compressive Strength Test Results. 


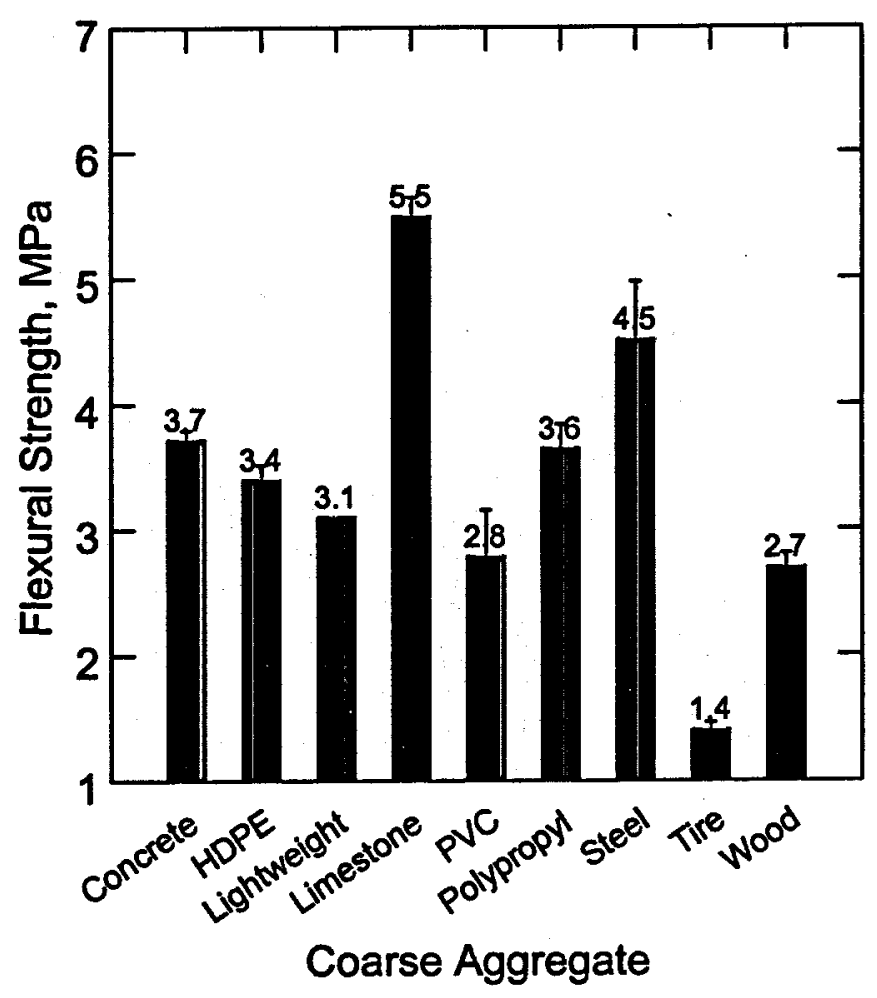

Figure 7. Flexural Strength Test Results. 


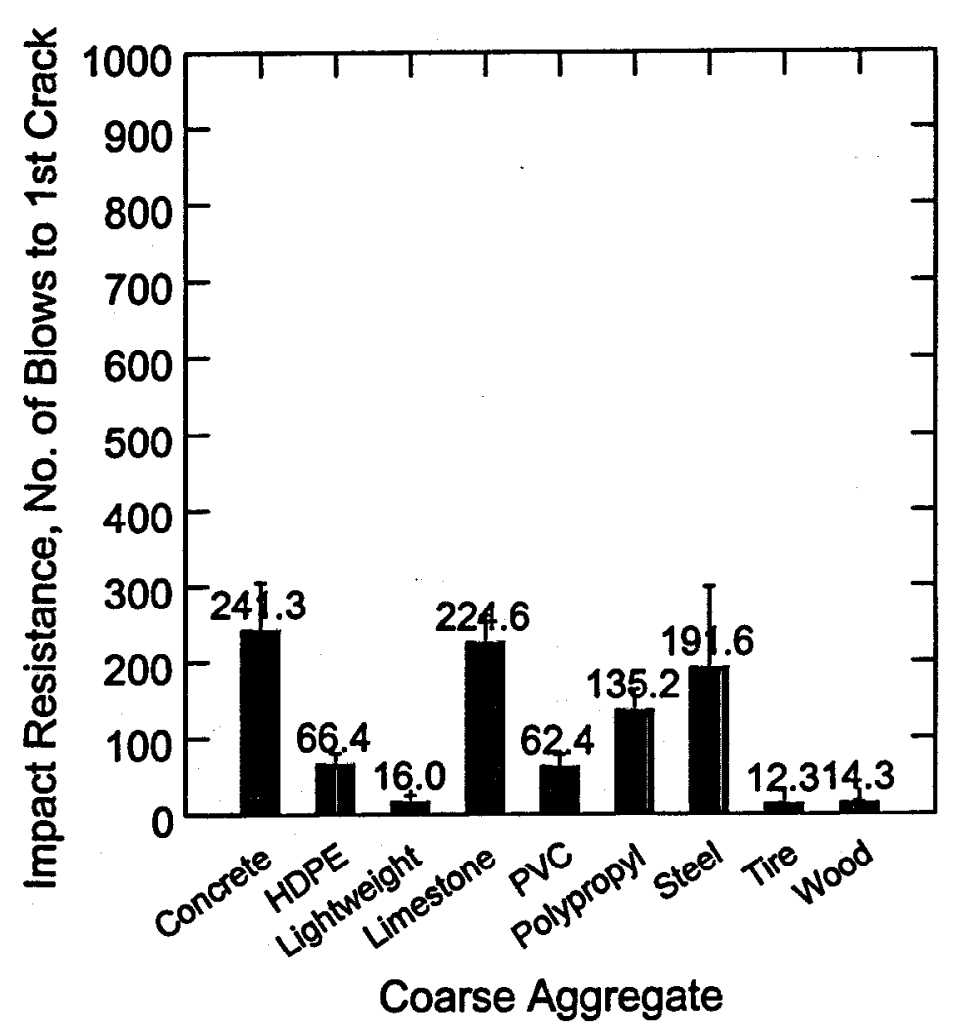

(a) First Crack 


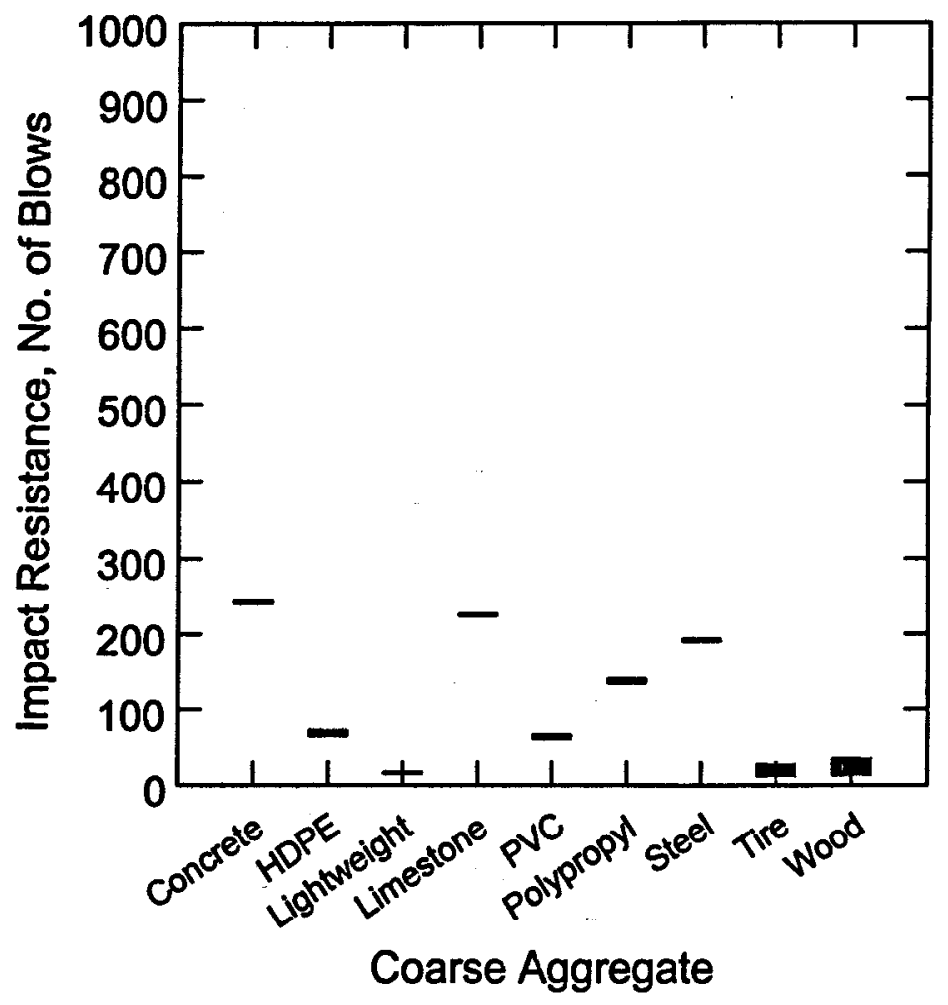

(b) Range Between First Crack and Final Impact Resistance

Figure 8. Impact Resistance Test Results. 


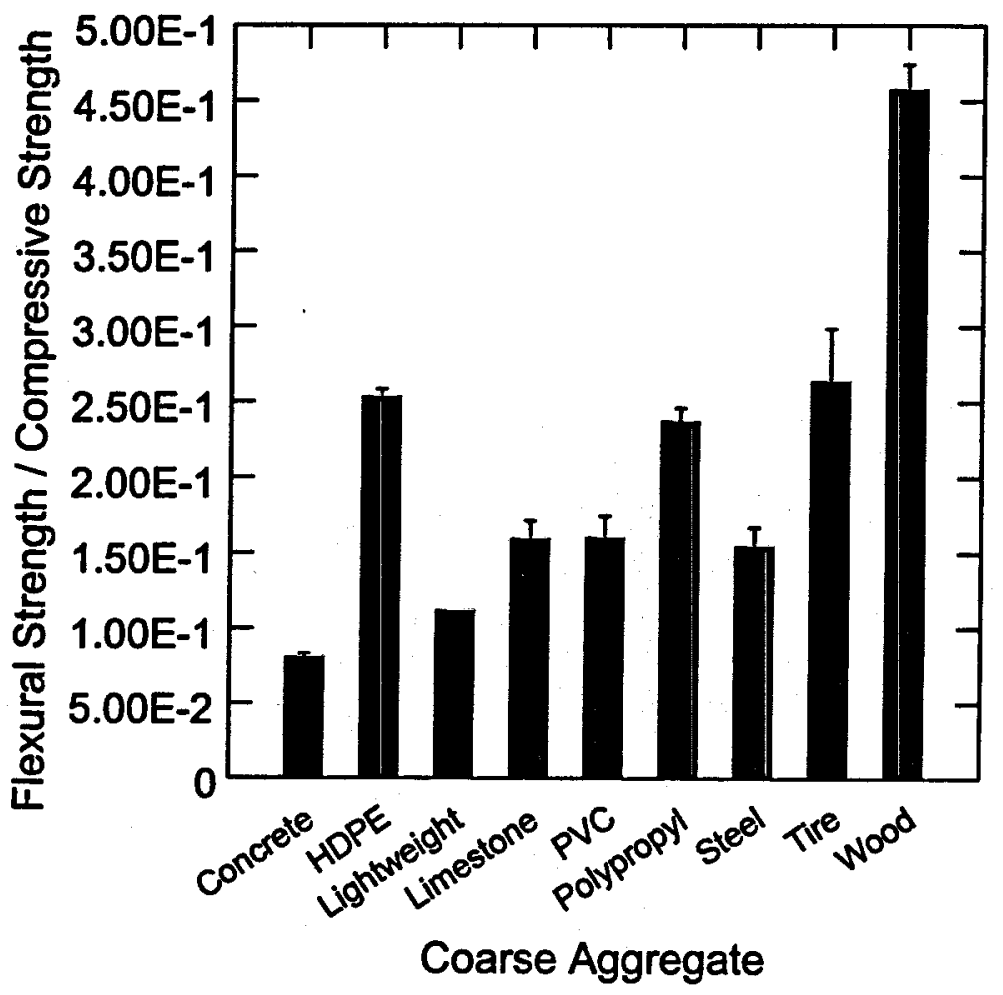

Figure 9. Ratios of Flexural to Compressive Strength.

The water absorption and apparent specific gravity test results (means and standard errors) are summarized in Figures 10 and 11. Figure 10 suggests that water absorption capacity (on a weight basis) is distinctly high in recycled wood aggregate concrete. As far as the apparent specific gravity is concerned, Figure 11 indicates that the concrete materials investigated here can be categorized as follows: normal-weight (with limestone and crushed concrete as coarse aggregate); light-weight (with recycled plastics, tire and wood as coarse aggregate, and also with lightweight coarse aggregate); and heavy-weight (with recycled steel as coarse aggregate). When comparing the water absorption capacity of different concrete materials on a volume basis (Figure 12), they provide comparable levels of water absorption except for wood which exhibits a relatively high water absorption per unit volume. This observation suggests that the matrix, which is the key absorber of water in all mixtures except wood concrete, has comparable levels of porosity in concrete systems with different virgin and recycled aggregates. 


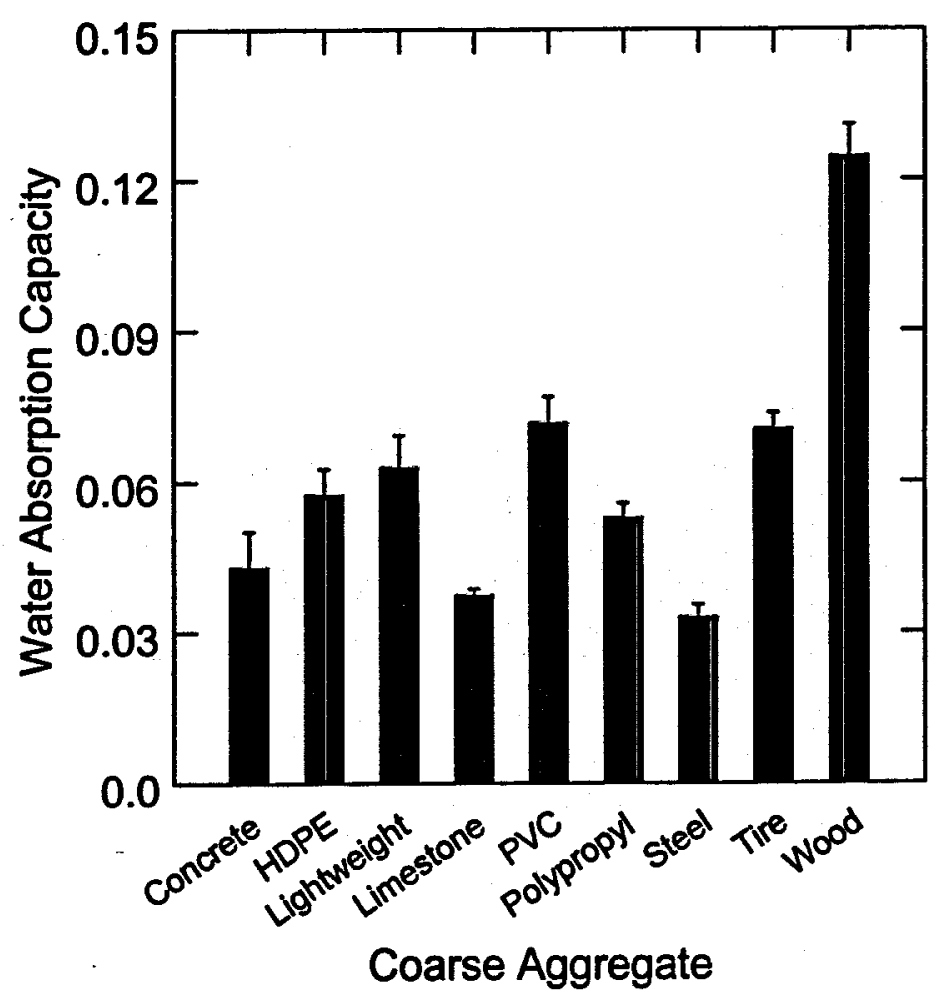

Figure 10. Water Absorption Capacity On a Weight Basis. 


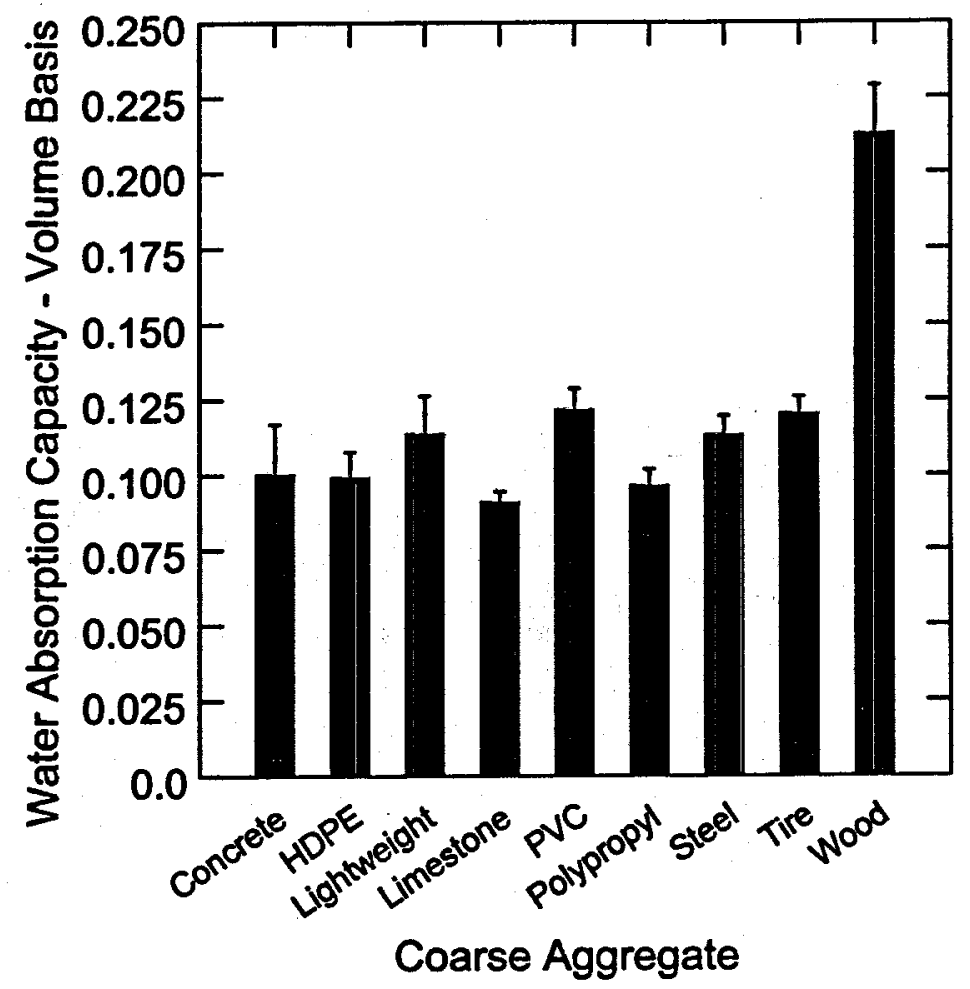

Figure 12. Water Absorption Capacity On a Volume Basis.

Figures 13a and 13b present the relationships (data points as well as regression line and $90 \%$ confidence interval) for compressive and flexural strengths, respectively versus apparent specific gravity when excluding concrete materials with recycled wood, tire and steel and coarse aggregates. These figures suggest that strength and apparent specific gravity are somewhat correlated in concrete materials with recycled plastics, crushed concrete, virgin limestone and lightweight aggregate. However, this correlation does not exist when all concrete materials (including those with recycled wood, tire and steel coarse aggregates) are considered (see Figure 14). 


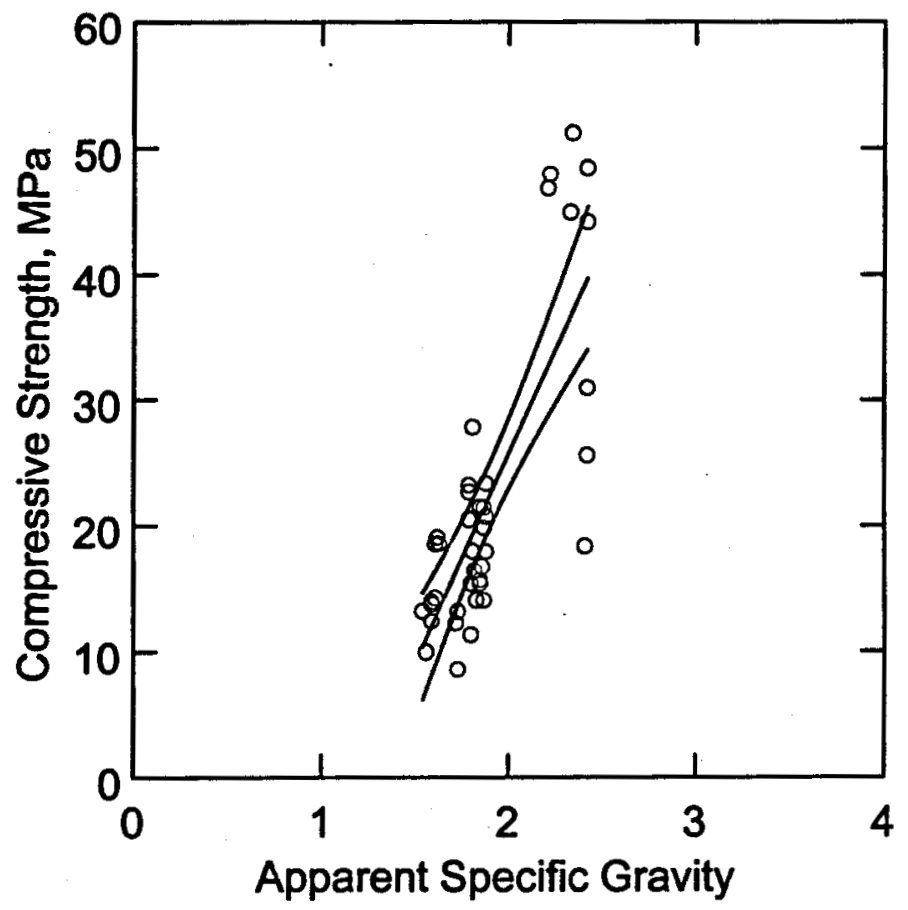

(a) Compressive Strength Vs. Apparent Specific Gravity 


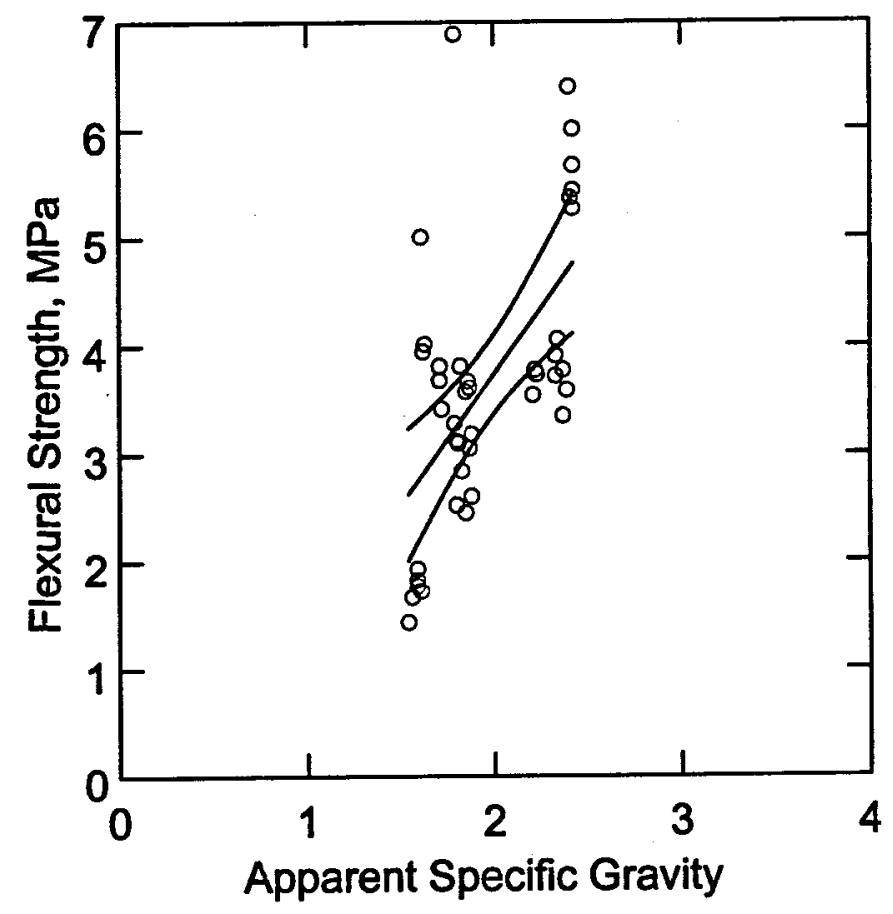

(b) Flexural Strength Vs. Apparent Specific Gravity

Figure 13. Strength Vs. Apparent Specific Gravity (with regression line and $90 \%$ confidence interval) Excluding Concrete Materials with Recycled Wood, Steel and Tire Coarse Aggregates. 


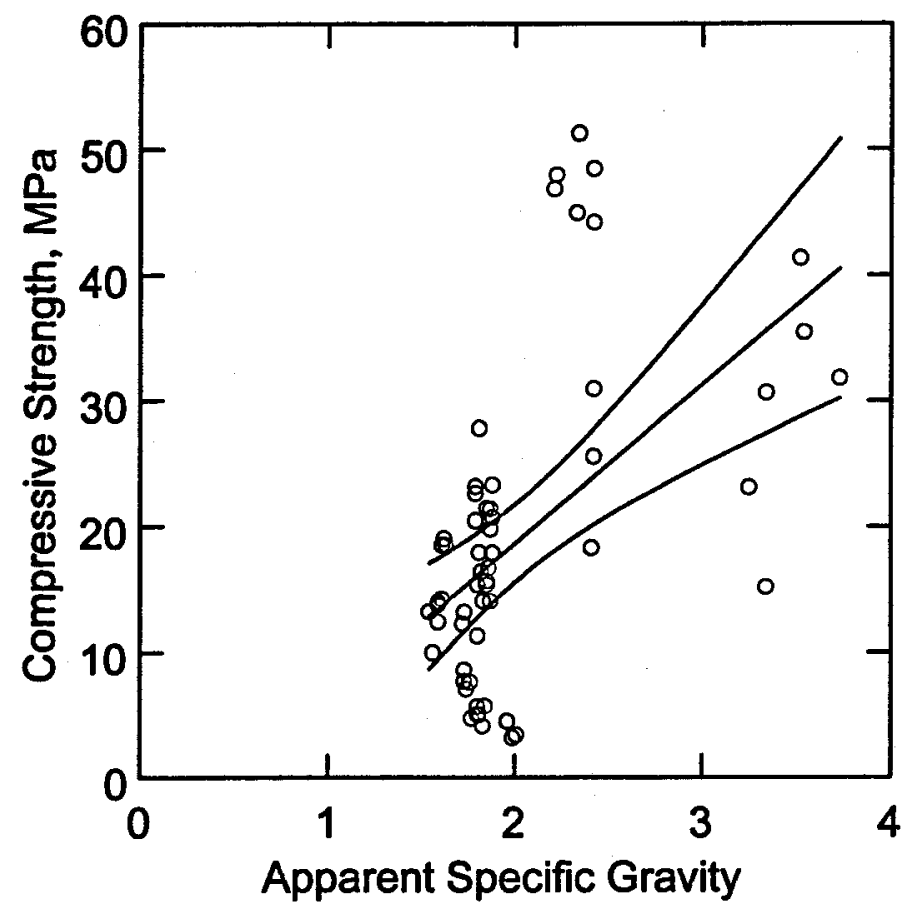

(a) Compressive Strength Vs. Apparent Specific Gravity 


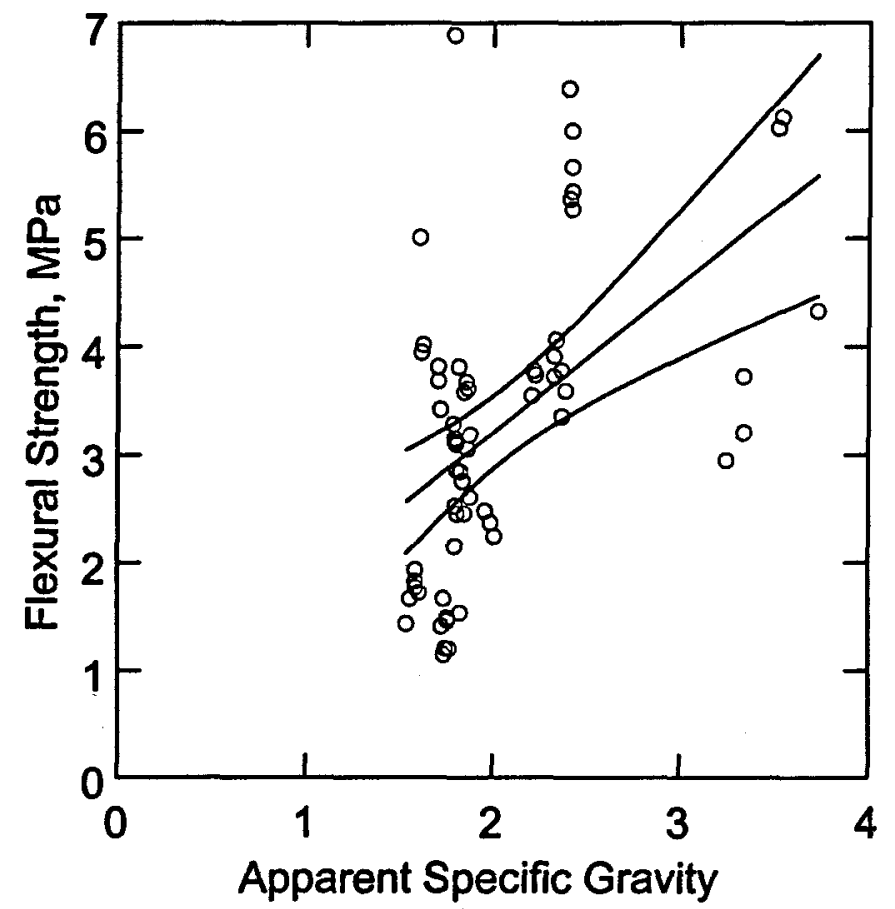

(b) Flexural Strength Vs. Apparent Specific Gravity

Figure 14. Strength Vs. Apparent Specific Gravity (with regression line and $90 \%$ confidence interval) Considering All Concrete Mixtures.

Figure 15 provides a comprehensive comparison of concrete materials with recycled plastics versus that with virgin lightweight coarse aggregate. This figure strongly suggests that recycled plastics are competitive against virgin lightweight aggregates (expanded clay in this case) in producing light-weight concrete materials with qualities suiting load-bearing structural applications. Recycled plastics produce concretes which, at comparable apparent specific gravity, compete well with virgin lightweight aggregate concrete in terms of flexural strength and, to some extent, compressive strength, and are superior to virgin lightweight aggregate concrete in terms of impact resistance. 


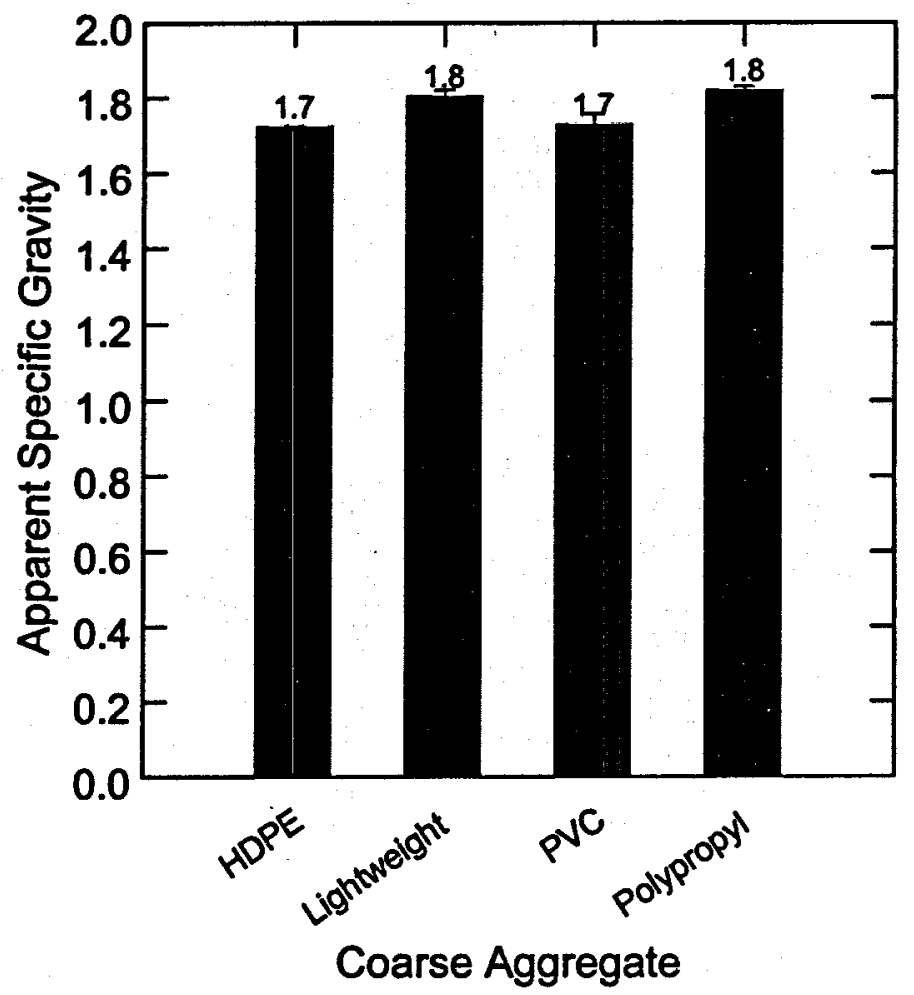

(a) Apparent Specific Gravity 


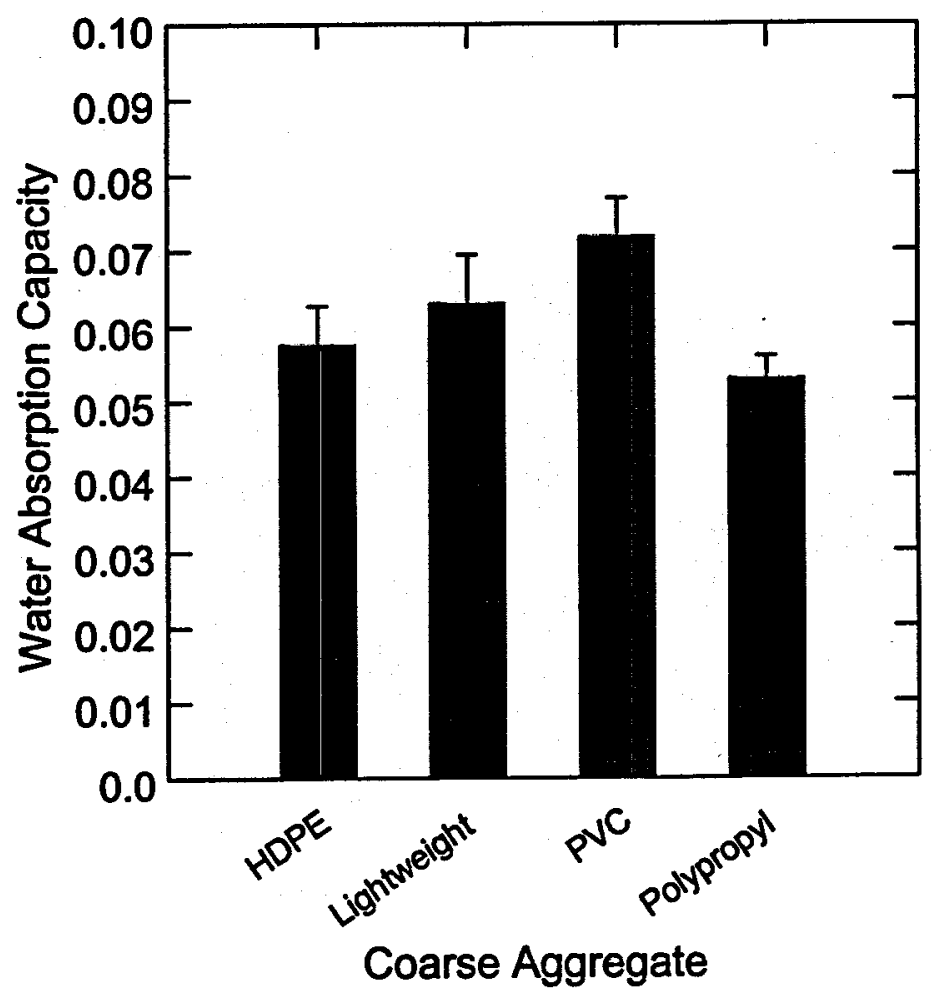

(b) Water Absorption Capacity 


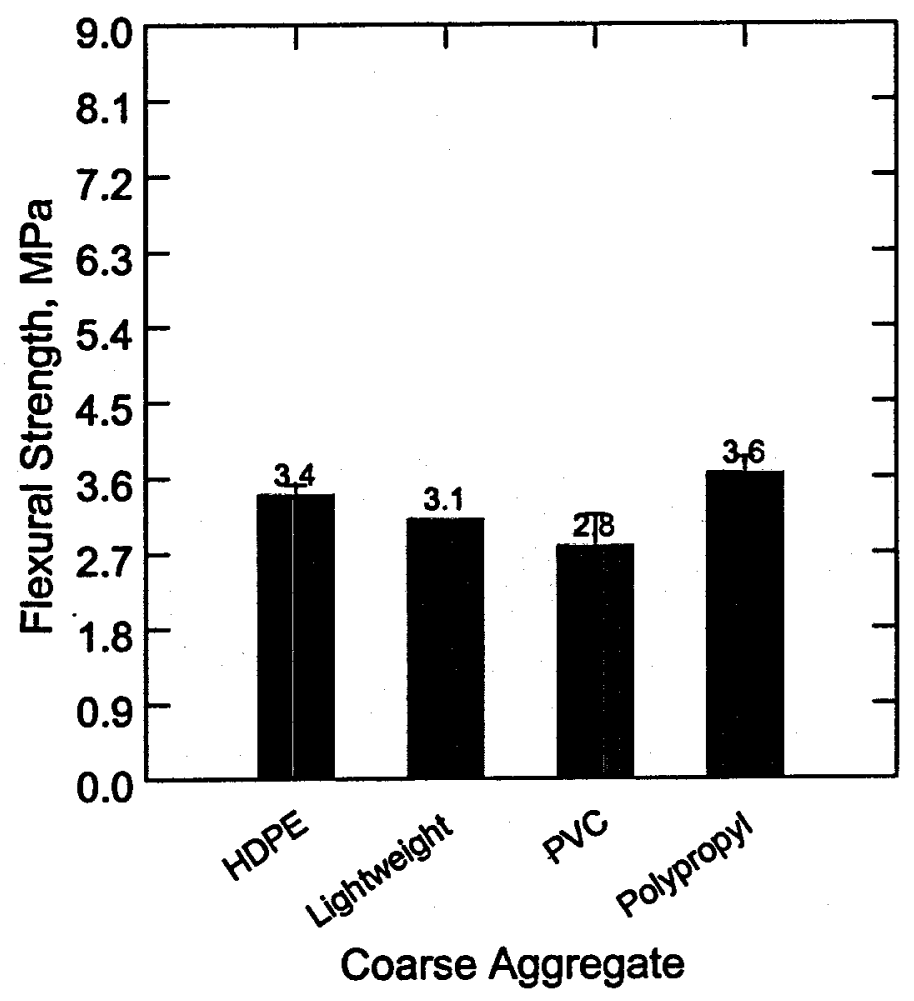

(c) Flexural Strength 


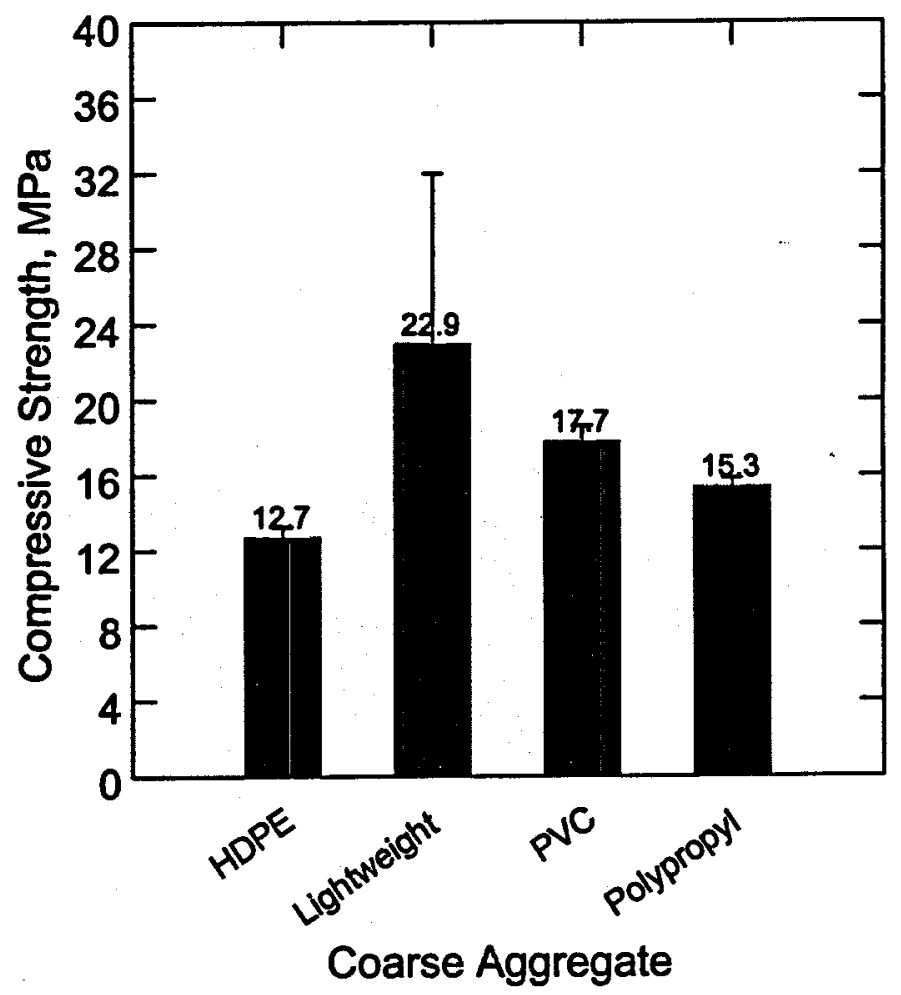

(d) Compressive Strength

30 


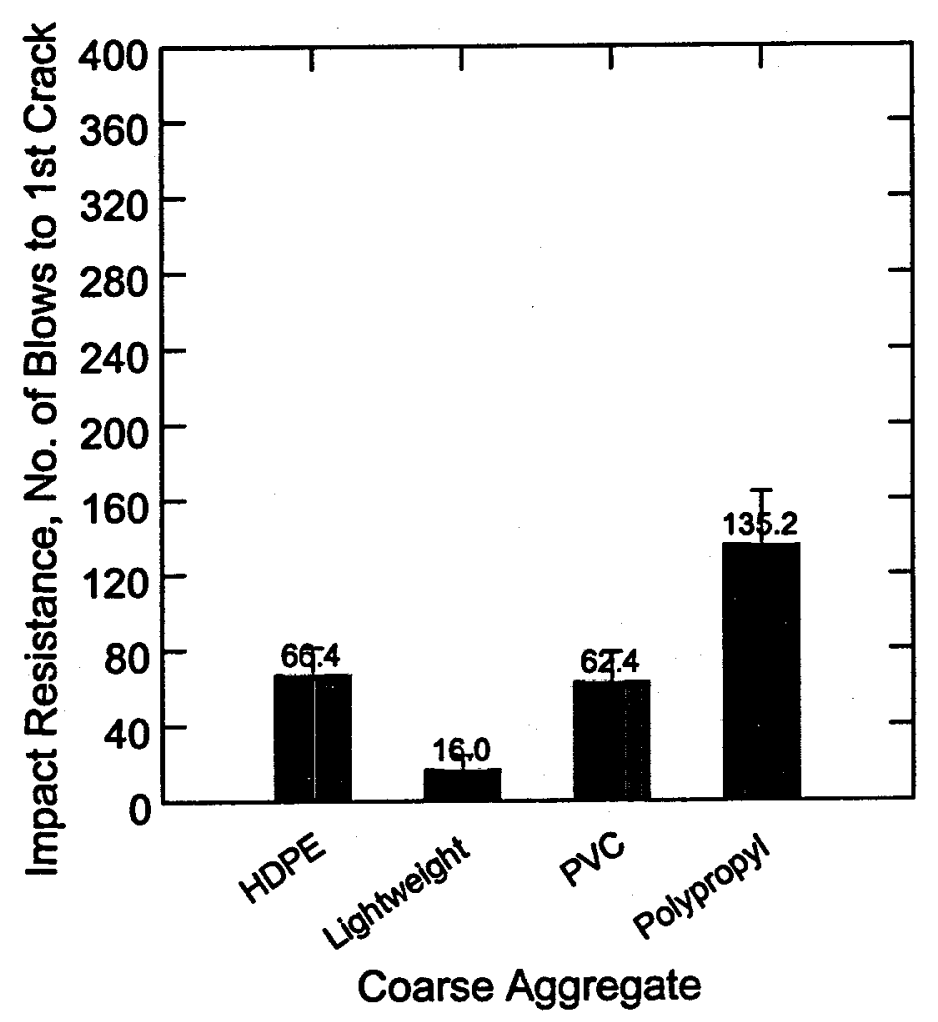

(e) Impact Resistance to First Crack 


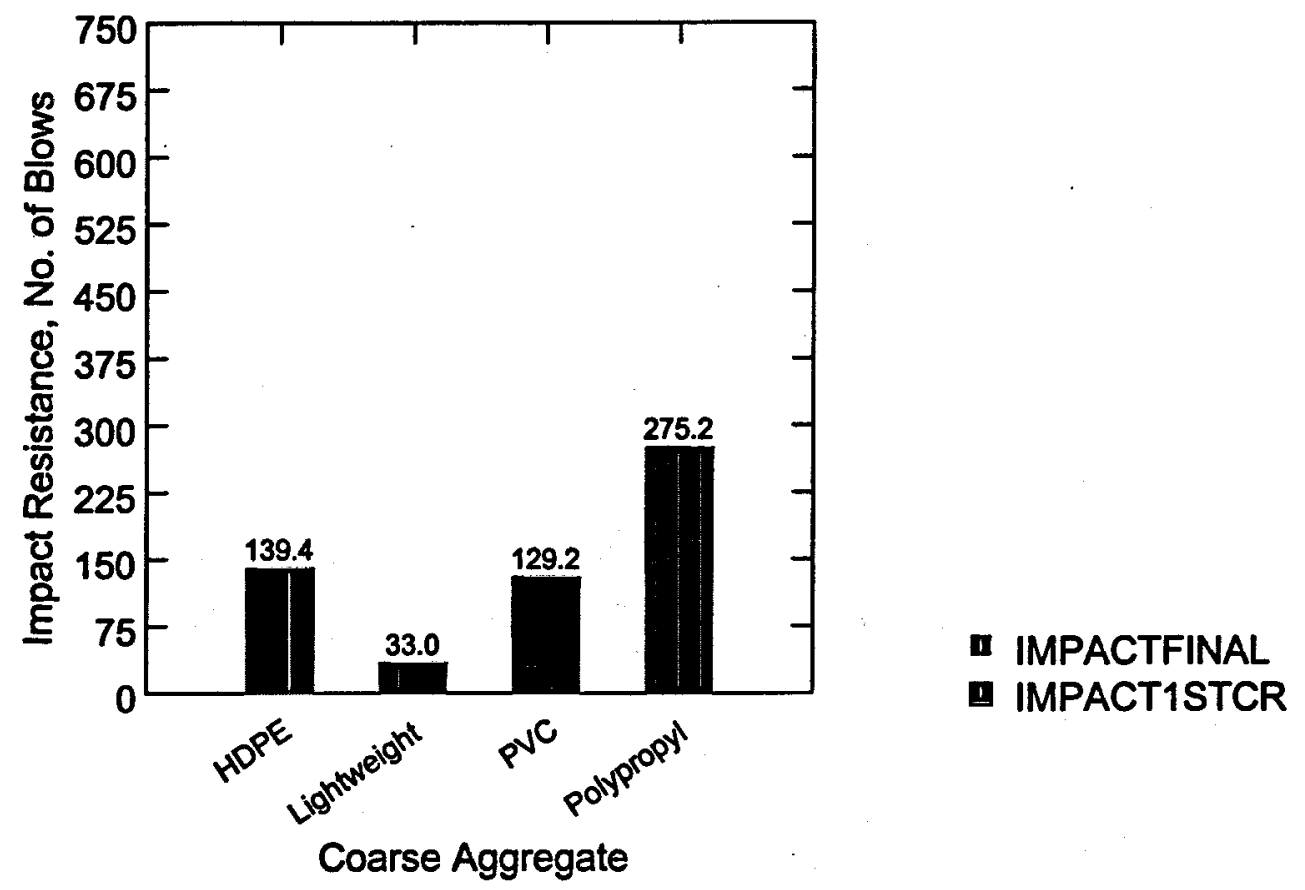

(e) Range Between Impact Resistance to First crack and to Failure

Figure 15. Performance of Concrete with Recycled Plastics Vs. Virgin Lightweight Coarse Aggregates.

When using tire and wood with virgin lightweight aggregates the resulting concrete materials are not generally competitive against virgin lightweight aggregate concrete (Figure 16); recycled wood and tire coarse aggregates, however, provide improvements over virgin lightweight aggregates in terms of post-cracking impact resistance (Figure $16 \mathrm{e})$, and wood coarse aggregates also provide a reasonable level of flexural strength. 


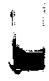

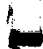

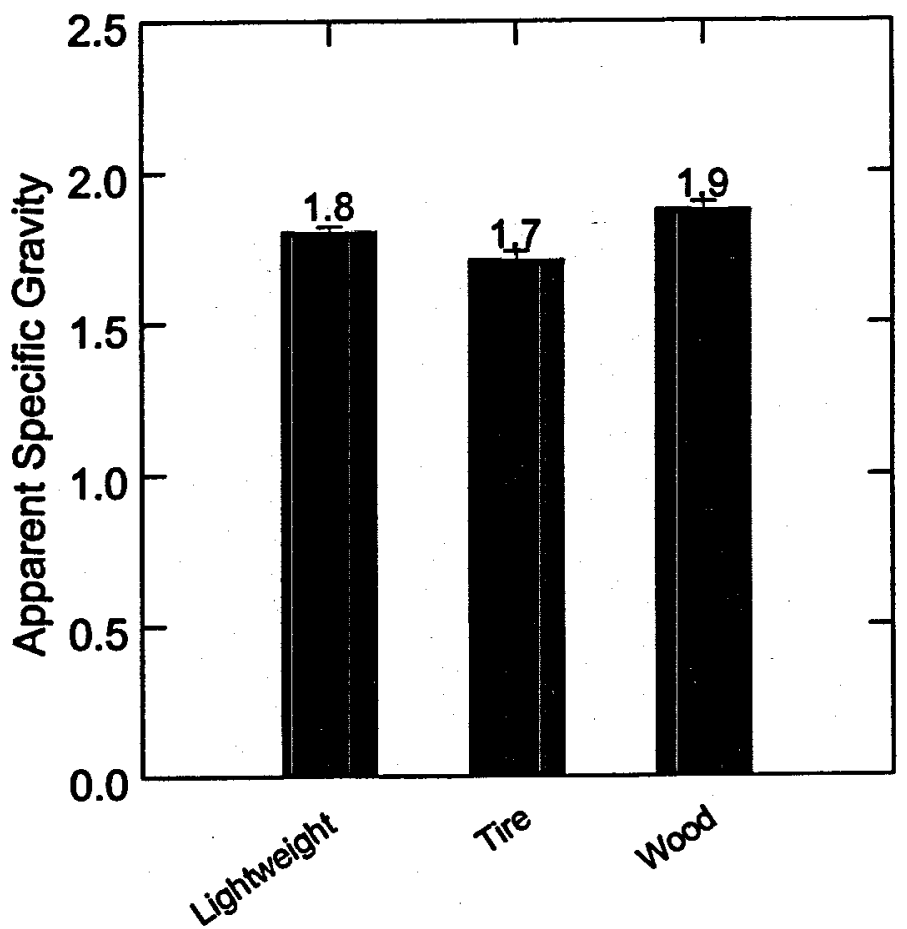

Coarse Aggregate

(a) Apparent Specific Gravity 


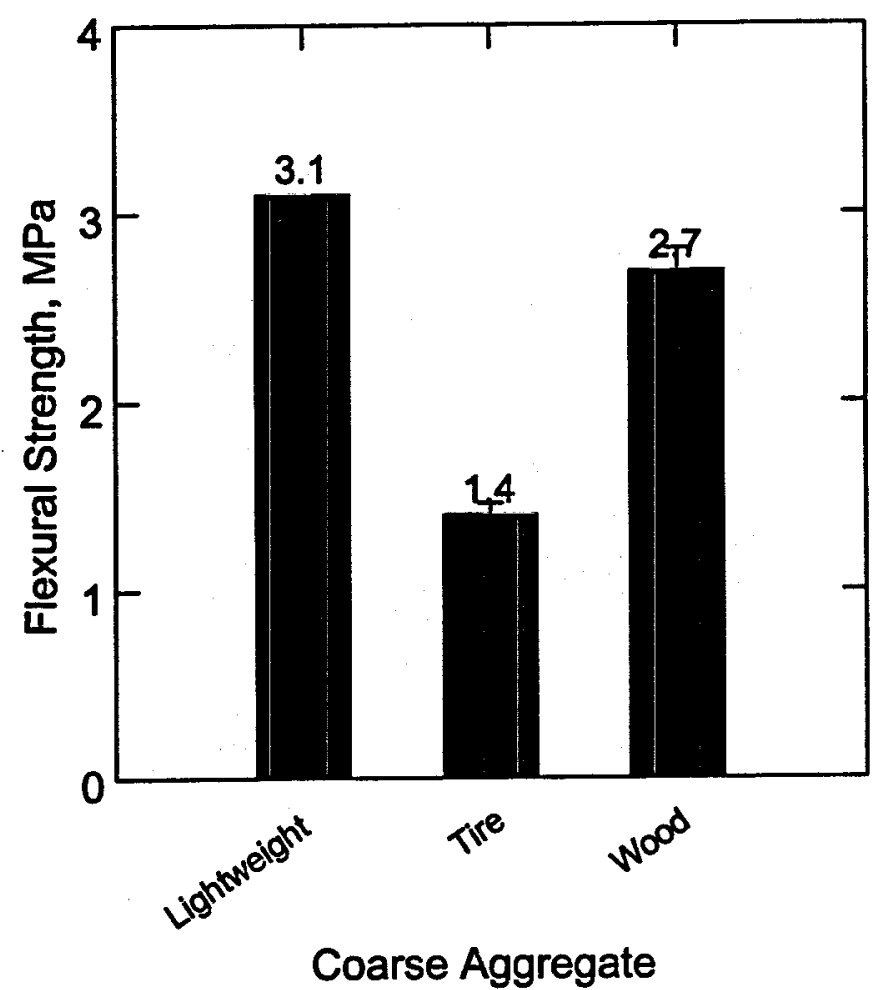

(b) Flexural Strength

34 


$$
1 .
$$




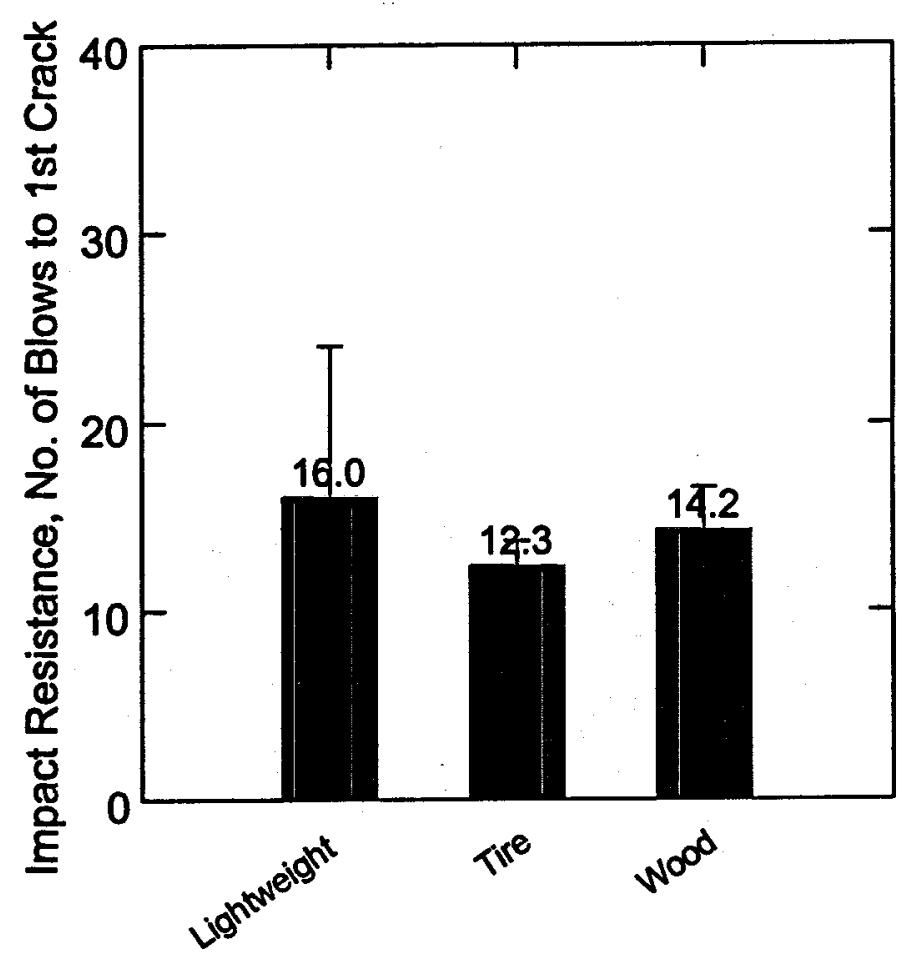

Coarse Aggregate

(d) Impact Resistance to First Crack 


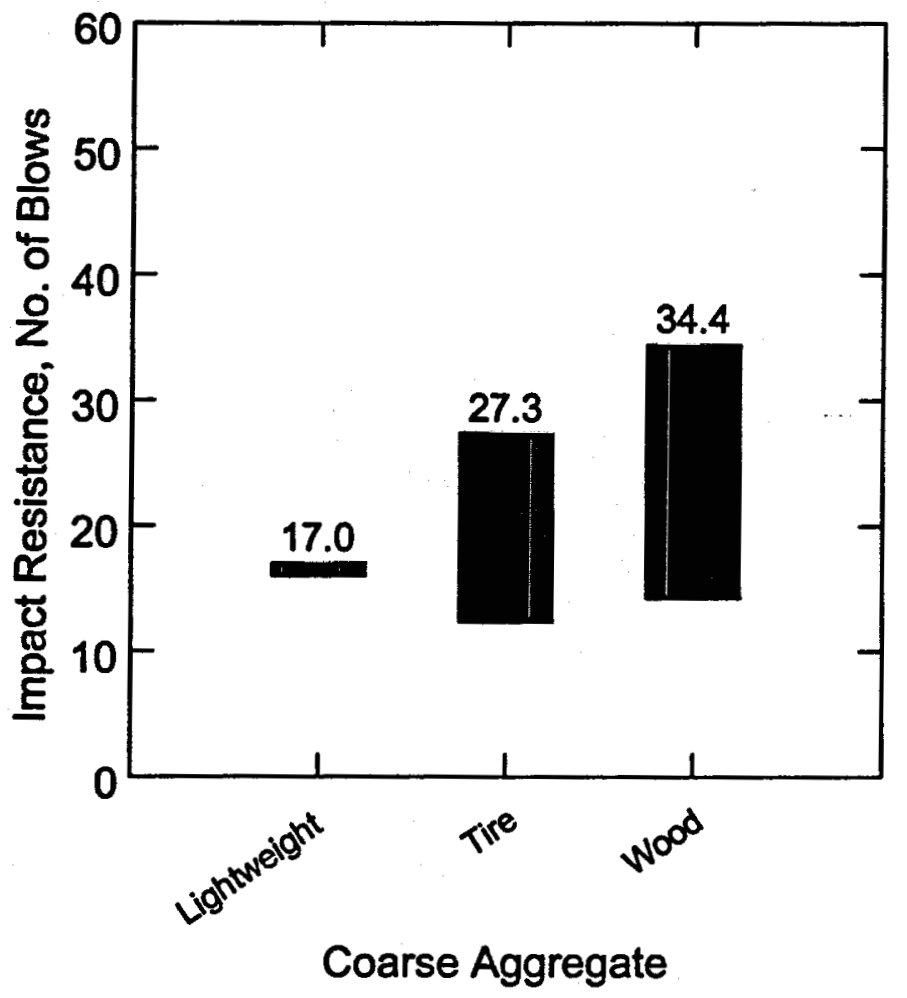

(e) Range of Impact Resistance Between First Crack and Failure

Figure 16. Performance of Concrete with Recycled Wood and Tire Vs. Virgin Lightweight Coarse Aggregates.

As noted earlier, instrumented flexure tests were performed in order to assess the flexural energy -absorption capacity (area underneath the flexural load-deflection curve) of highrecycled-content concrete materials. Figure 17 presents the flexural energy absorption test results for different concrete materials with recycled and virgin coarse aggregates. There are gains in flexural energy absorption capacity with the introduction of recycled plastics, tire and wood. The higher flexural energy absorption capacity of high-recycledcontent concrete implies that in vast applications where concrete is used to enclose (e.g., walls) or to surface (e.g., floor slabs-on-grade) there would be less need for secondary (shrinkage) steel reinforcement for the purpose of crack control in concrete. 


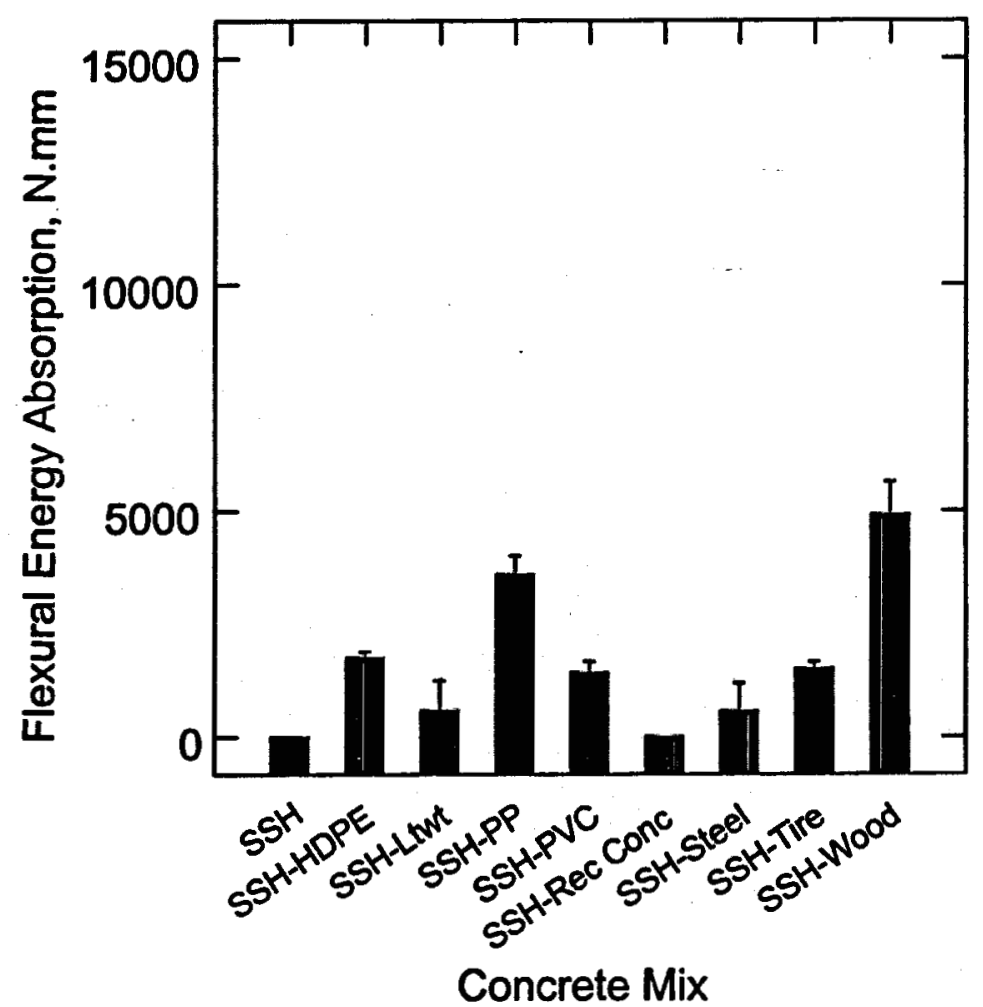

Figure 17. Flexural Energy Absorption Test Results (means and standard errors). 


\subsection{Thermal Properties and Durability Characteristics of High-Recycled-Content Concrete}

\subsection{Thermal Characteristics}

Two thermal conductivity specimens in the form of $57 \mathrm{~mm}$ thick cylinders of $406 \mathrm{~mm}$ diameter were made with concrete mixes introduced in Table 2. These specimens were demolded after 24 hours, moist cured at $100 \%$ relative humidity and $22^{\circ} \mathrm{C}$ for 13 days and then conditioned at $22^{\circ} \mathrm{C}$ and $50 \%$ relative humidity for 56 days. The specimens were subjected to thermal conductivity tests following ASTM C 177 procedures. Cores $25 \mathrm{~mm}$ in diameter and $76 \mathrm{~mm}$ in height were extracted from ruptured flexure specimens for the performance of specific heat tests following ASTM C 351 procedures.

Figure 18 presents the specific heat values (means and standard errors) for various highrecycled-content concrete materials as well as the control concrete mix (SSH). In Figure 18 , SSH-XX refers to recycled content concrete with XX recycled materials. For example, SSH-PP refers to concrete with recycled polypropylene and SSH-wood to concrete with recycled Wood. All recycled materials were introduced in Progress Report No. 1. Figure 18 indicates that the specific heat (per unit weight) of concrete (SSH refers to normal concrete) can be doubled with the introduction of recycled plastics, wood and tire.

The specific heat values of Figure 18 are presented in J per $\mathrm{kg}$ per deg. C. In order to develop a sense for specific heat per unit volume, one needs the density (apparent specific gravity of various concrete mixtures. As shown in Figure 19, while there is some drop in density with the introduction of recycled plastics, tire and wood, such drops are relatively small and do not overshadow the gains in specific heat. Hence, even when representing specific heat per unit volume of concrete, still major gains result from the use of recycled plastics, wood and tire.

An analysis of the available thermal conductivity test results is presented in Figure 20. The lower thermal conductivity of concrete with recycled plastics, wood and tire favors their benefits to energy-efficiency of buildings. Still, even high-recycled-content concretes of low thermal conductivity cannot replace relatively high levels of exterior insulation which would be critical if the mass and specific heat of concrete is to be used for energy saving. 


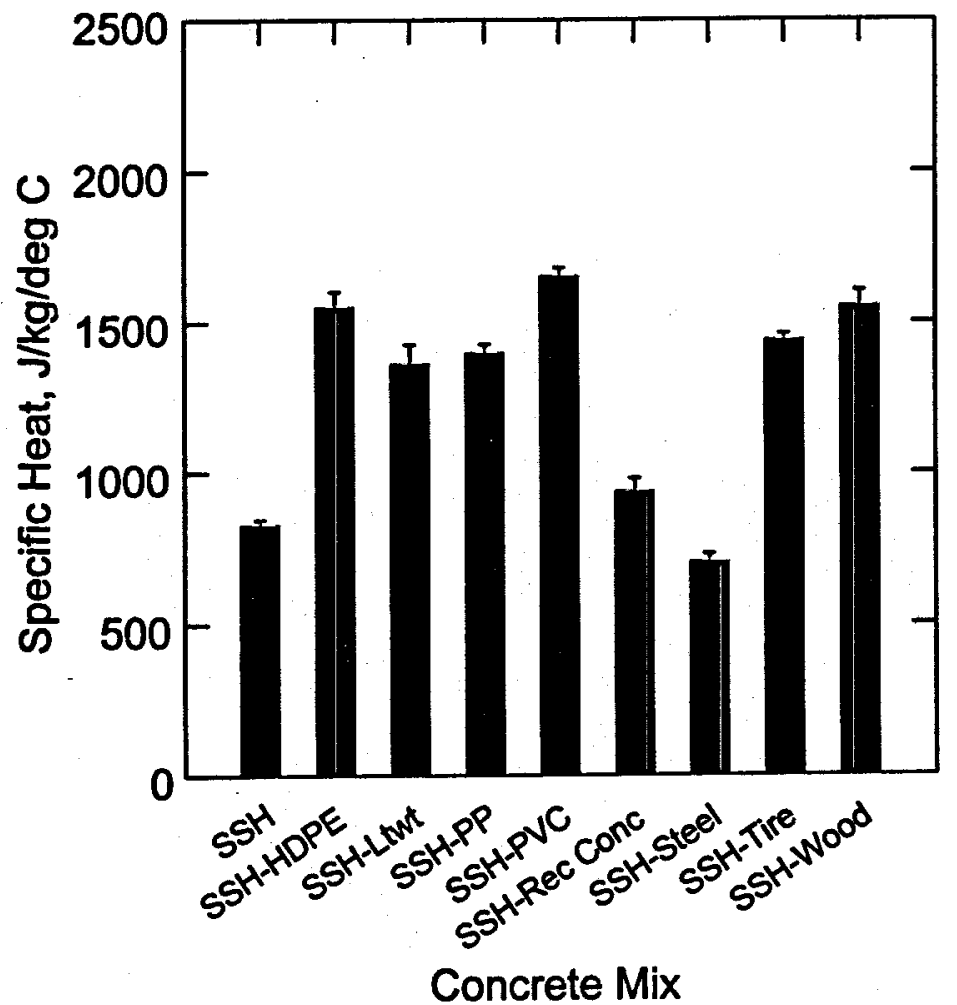

Figure 18. Specific Heat Test Results (mean values and standard errors). 


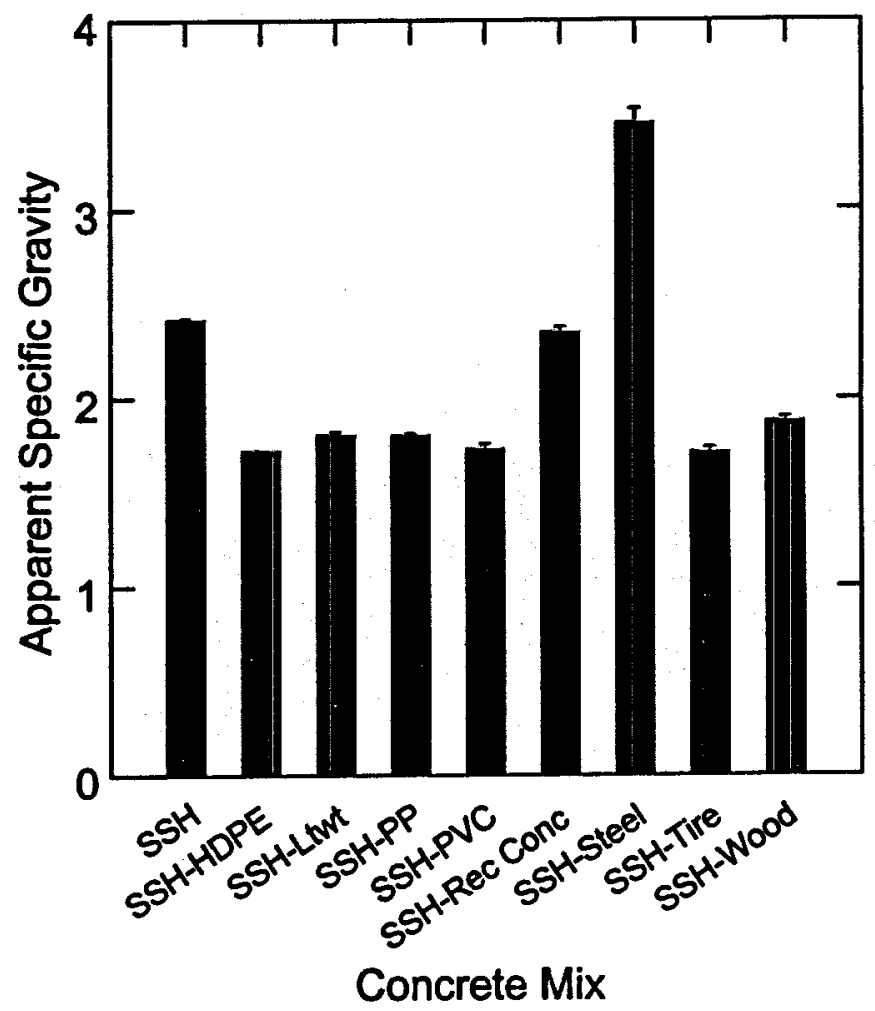

Figure 19. Apparent Specific Gravity Test Results (mean values and standard errors). 


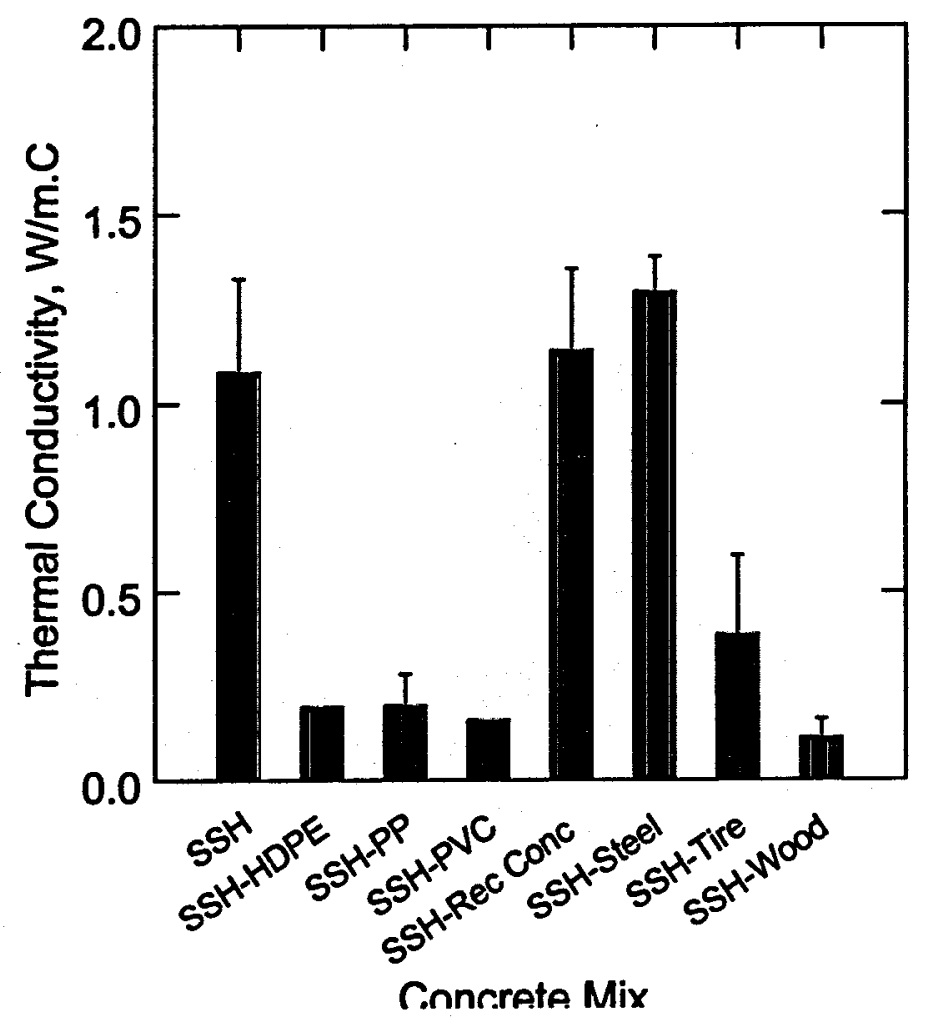

Figure 20. Thermal Conductivity Test Results (means and standard errors).

\subsection{Durability and Related Properties of High-Recycled-Content Concrete}

Flexure specimens of various concrete mixtures were subjected to the following accelerated aging effects:

- Repeated wetting-drying cycles: ASTM C 1185 - 50 cycles;

- Extreme temperature cycles: 15 cycles of exposure to $65^{\circ} \mathrm{C}$ for 3 hours followed by gradual cool-down to $22^{\circ} \mathrm{C}$ over 9 hours;

- High temperatures approaching fire effects: 6 hours at $250^{\circ} \mathrm{C}$ followed by gradual cool-down to $22^{\circ} \mathrm{C}$ over 18 hours an 48 hours of conditioning at $50 \%$ relative humidity and $22^{\circ} \mathrm{C}$. 
In addition to above accelerated aging tests, we also performed the following experiments which reflect on long-term durability and crack resistance of high-recycled-content concrete materials:

- Initial surface sorption (BS 1881: Part 5)

- Restrained drying shrinkage (ACI Committee 544)

- Abrasion resistance (ASTM C 944)

As shown in Figure 21, high-recycled-content concrete materials developed in this project perform satisfactorily under these accelerated aging effects and retain a high fraction of their flexural strength. The same conclusion generally applies to the flexural energy absorption test results presented in Figure 22, except that high-recycled woodcontent concrete suffers some losses of flexural energy absorption under accelerated aging effects.

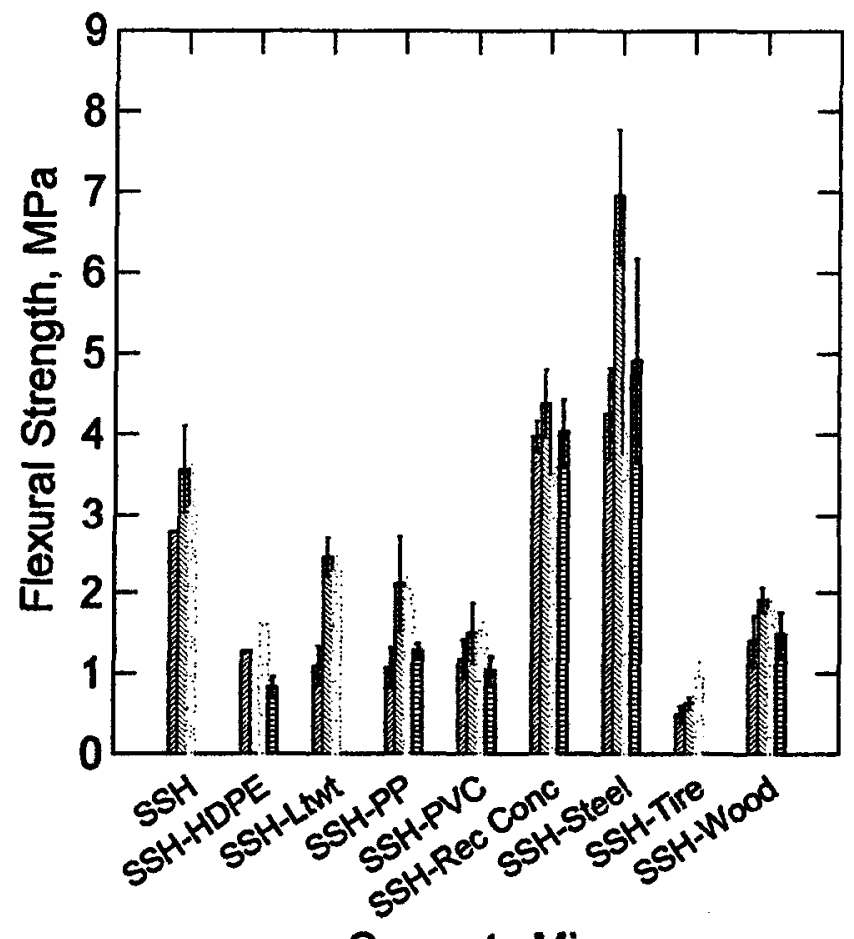

Accelerated Aging

目 Wet-Dry

Unaged

Temp Cycle

High-Temp

Concrete Mix

Figure 21. Effects of Different Accelerated Aging Conditions on Flexural Strength. 


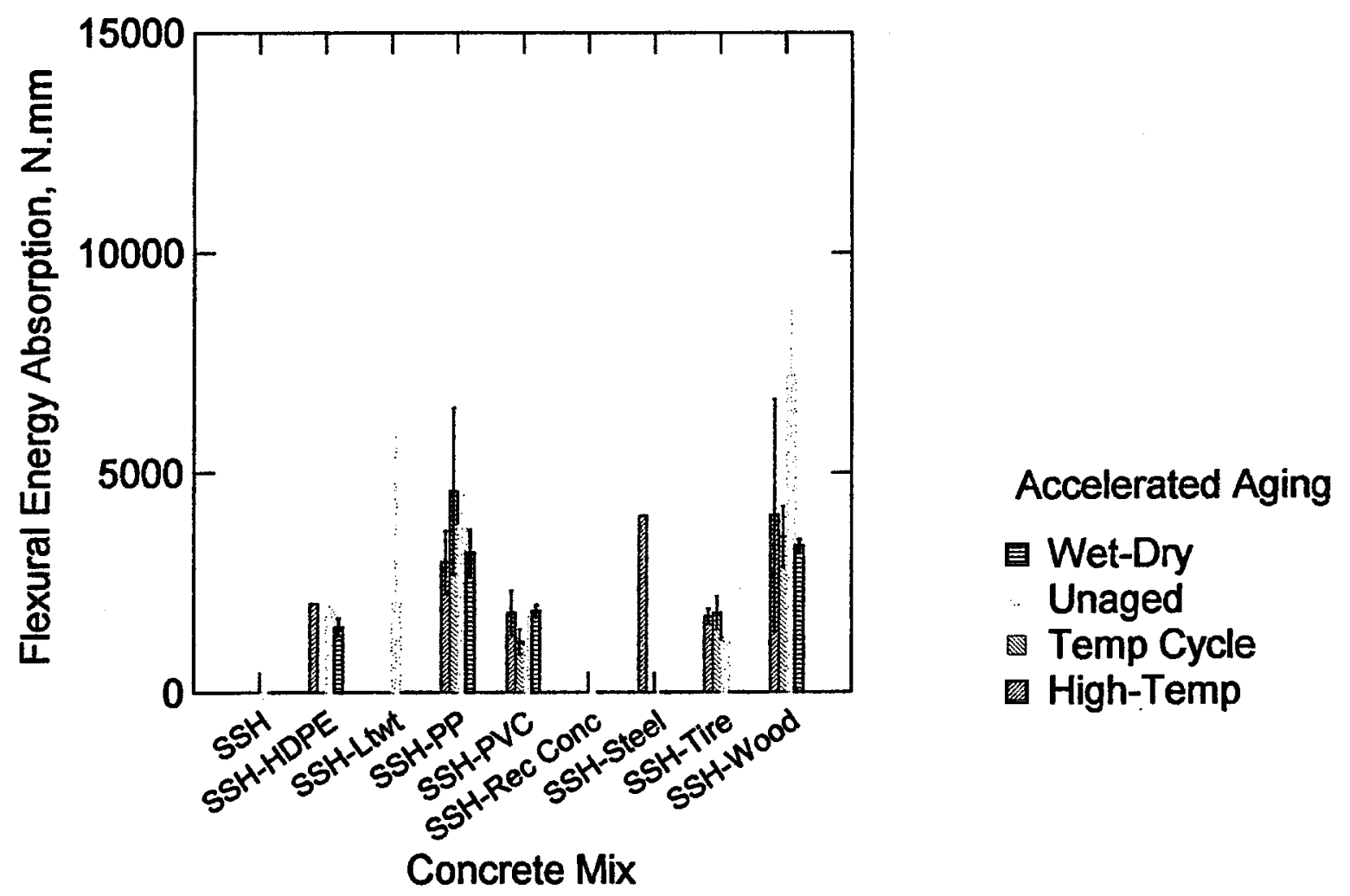

Figure 22. Accelerated Aging Effects on Flexural Energy Absorption.

As shown in Figure 23, the abrasion weight loss of high-recycled-content concretes is generally less than that of normal concrete (SSH); only high-recycled tire-content concrete exhibits a greater abrasion weight loss of normal concrete. 


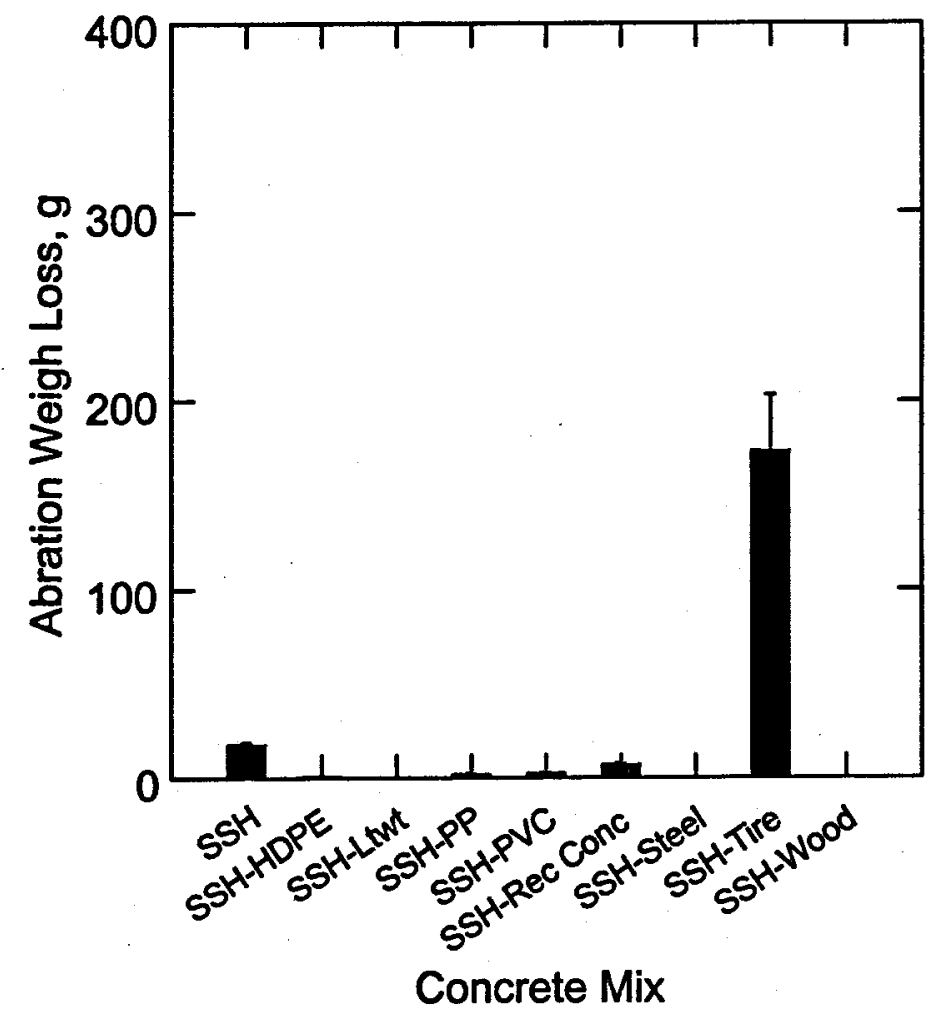

Figure 23. Abrasion Weight Loss Test Results.

Only recycled wood and tire concretes provide higher capillary sorption than normal concrete (Figure 24). There is not a significant effect of recycled materials on capillary sorption. 


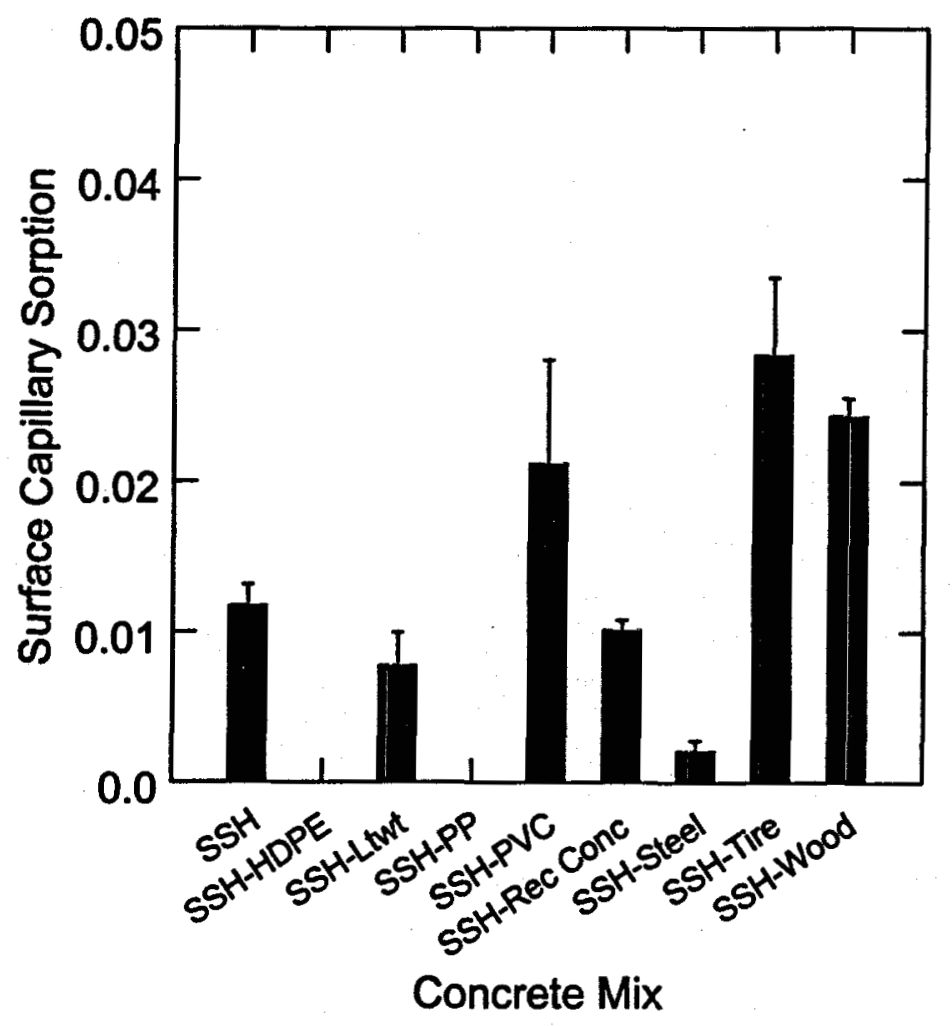

Figure 24. Surface Capillary Sorption Test Results.

The long-term restrained drying shrinkage cracking test results (Figure 25) suggest that high-recycled plastic-content concrete mixtures (SSH-HDPE, SSH-PP, SSH-PVC) present desirable shrinkage crack control attributes when compared with normal concrete (SSH); this is also true to some extent for recycled steel and wood. This finding has major practical implications in diverse fields of concrete application where enclosing and surfacing are the key functions of concrete placements. Slabs and walls are examples of such major applications of concrete. Mixtures with virgin lightweight aggregate (SSHLtwt), recycled tire particles (SSH-Tire) and recycled concrete (SSH-Rec Conc) produced higher restrained shrinkage crack widths when compared with normal concrete (SSH). The mix designated SSH-HMP in Figure 25 was the one used in field verification of the technology, and will be introduced later. 


\section{SSH SSH-HDPE SSH-HMP SSH-Ltwt}
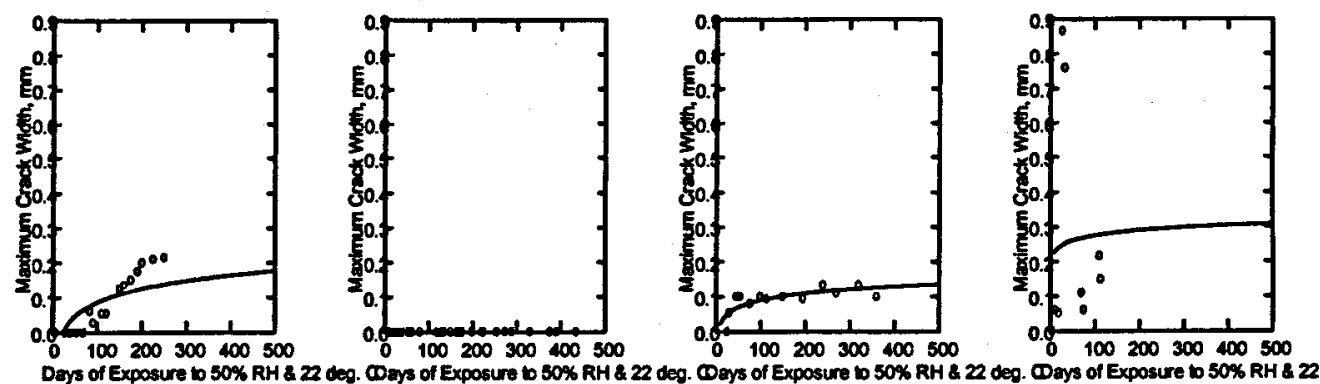

SSH-PP

SSH-PVC SSH-Rec Conc SSH-Steel
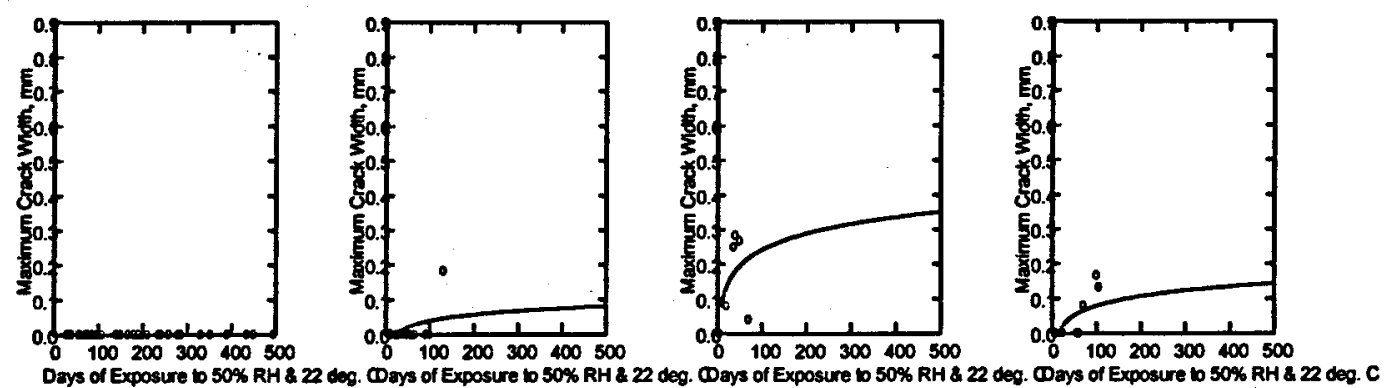

SSH-Tire

SSH-Wood

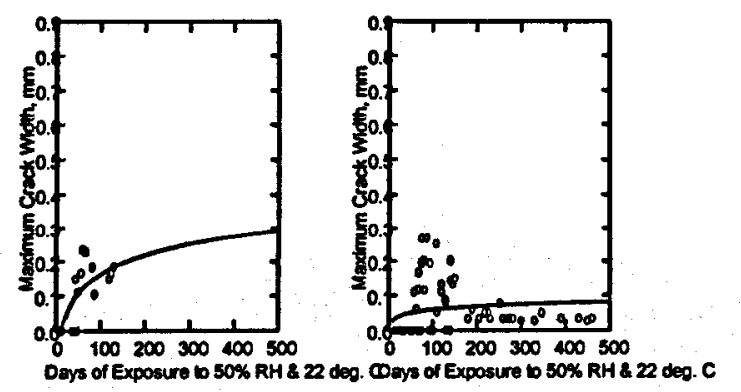

Figure 25. Restrained Shrinkage Crack Width Measurements. 


\subsection{Development and Characterization of High-Recycled-Content Concrete Masonry Products}

\subsection{Introduction}

Concrete masonry production differs from normal (cast-in-place) concrete production in terms of mix proportions (concrete masonry uses less cement and water contents and smaller coarse aggregates), processing (concrete masonry is subjected to a combination of pressure and vibration to develop sufficient integrity for immediate demolding), and common curing practices (steam curing is predominant in concrete masonry production). The purpose of this stage of our investigation was to assess the merits of replacing the coarse aggregates in concrete masonry with different recycled materials.

\subsection{Mix Proportioning, Processing Conditions, and Experimental Program}

The mix proportions of conventional (cast-in-place) concrete differ from those of concrete masonry. Table 3 compares the control concrete masonry and conventional concrete mix proportions used in this investigation. Concrete masonry has a relatively high aggregate content and relatively low cement and water contents. Compared to the conventional concrete mix, the concrete masonry mix is relatively dry and cannot be poured using conventional concrete construction procedures. Concrete masonry can thus be produced under factory conditions; the mix is molded and then compacted under the effects of pressure and vibration. In our production process (Figure 26) we vibrated concrete masonry products under a pressure of $0.0208 \mathrm{MPa}$ for a period of 60 seconds.

Table 3. Mix Proportions of Conventional Concrete and masonry (weight ratios).

\begin{tabular}{ccccc}
\hline & Fine/Coarse Agg. & Cement/Agg. & Water/Agg. & Admixture \\
\hline Concrete & 0.84 & 0.28 & 0.12 & Air Entr. Admix. \\
Masonry & 2.0 & 0.15 & 0.074 & None \\
\hline
\end{tabular}

Control and high-recycled-content concrete mix compositions are presented in Table 4. High-recycled-content concrete mixtures were proportions by replacing the coarse aggregate (birdeye stone) in control masonry mixtures with an equivalent bulk volume of recycled products. The same recycled products used in conventional concrete mixtures (introduced in our earlier reports) were used in concrete masonry mixtures. 
Table 4. Control and High-Recycled-Content Concrete Masonry Mix Proportions (weight ratios).

\begin{tabular}{cccc}
\hline Coarse Aggregate & $\begin{array}{c}\text { Coarse/Fine } \\
\text { Agg. }\end{array}$ & $\begin{array}{c}\text { Cement/Fine } \\
\text { Agg. }\end{array}$ & Water/Cement \\
\hline Birdeye Stone (Control) & 0.500 & 0.222 & 0.500 \\
PVC & 0.228 & 0.222 & 0.500 \\
Polypropylene (PP) & 0.153 & 0.222 & 0.500 \\
High-Density Polyethylene (HDPE) & 0.181 & 0.222 & 0.50 \\
Tire & 0.203 & 0.222 & 0.500 \\
Wood & 0.0822 & 0.222 & 0.685 \\
Lightweight Aggregate & 0.256 & 0.222 & 0.5 \\
Recycled Concrete & 0.527 & 0.222 & 0.500 \\
Steel & 1.14 & 0.222 & 0.500 \\
\hline
\end{tabular}

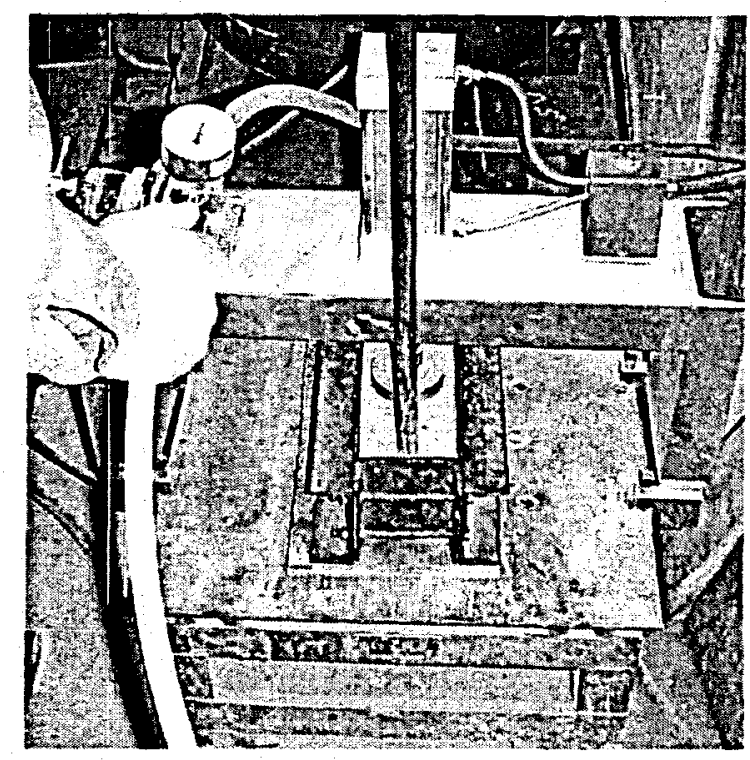

Figure 26. Consolidation of Concrete Masonry Units Under the Combined Effects of Vibration and Pressure

After consolidation (Figure 26), concrete masonry products were subjected to steam curing (Figure 27a) in a process which comprised 3 hours of pre-setting in ambient conditions followed by 14 hours of steam curing (see Figure $27 \mathrm{~b}$ for temperature timehistory). The steam-cured products were then moist-cured for 14 days and conditioned at $22^{\circ} \mathrm{C}$ and $50 \%$ relative humidity for another 14 days. 


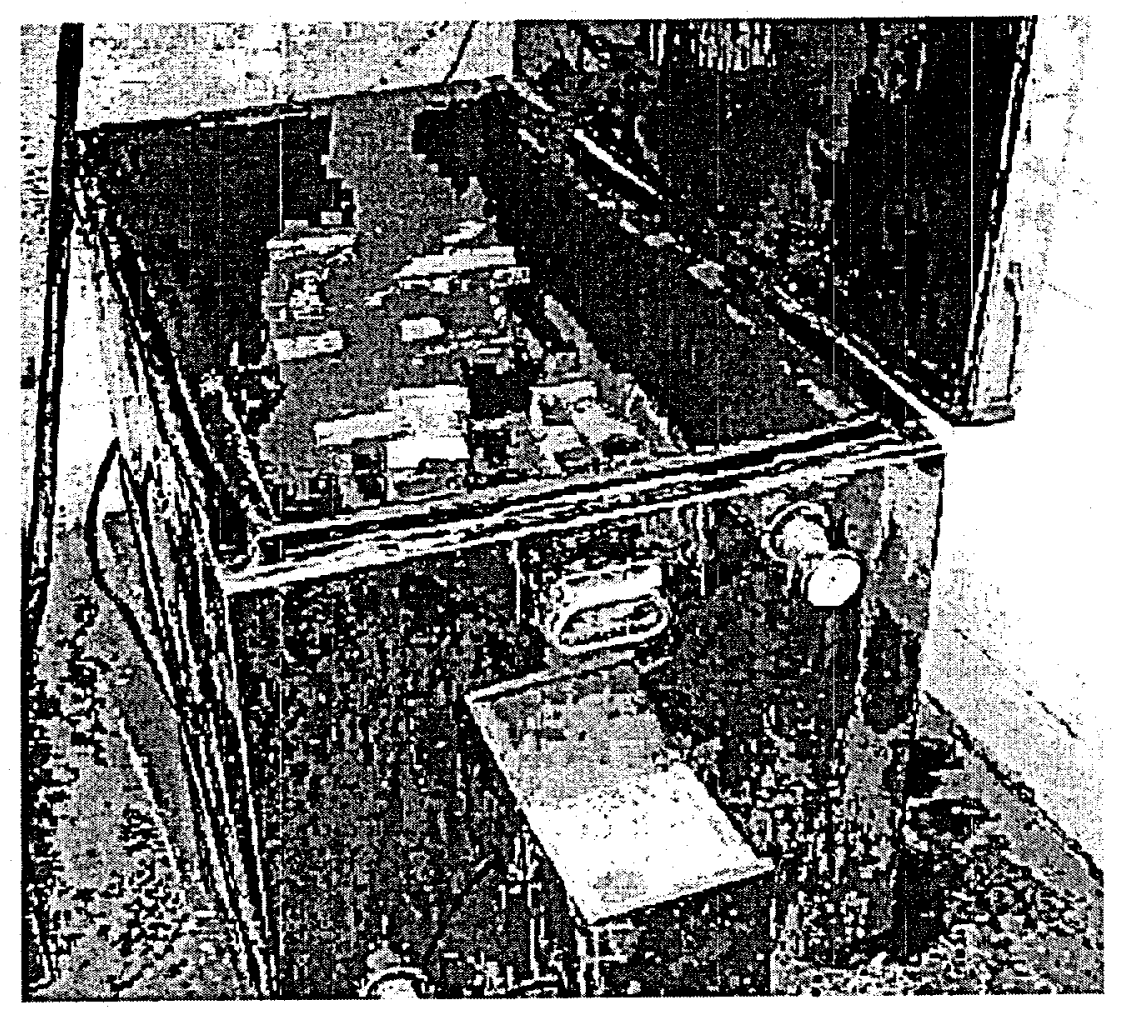

(a) Steam Curing Chamber.

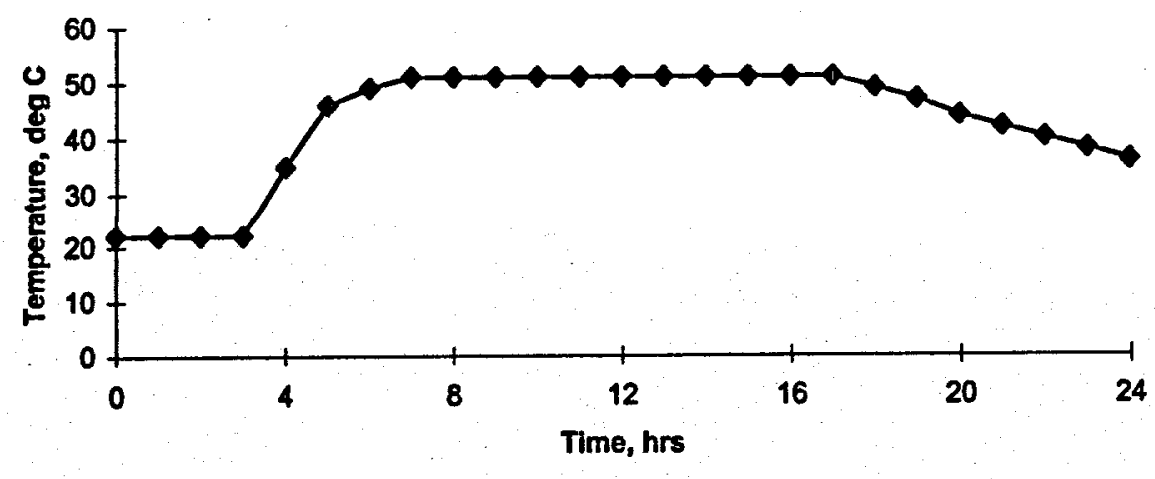

(b) Temperature Time-History of Steam Curing

Figure 27. Steam Curing of Concrete Masonry Units.

Masonry units were subjected to flexure test immediately after steam curing (prior to any further moist curing or conditions), and were also subjected to the following tests in unaged condition immediately after the steam curing and conditioning steps described above: 
(a) Flexure (ASTM C 78) - Figure 28a

(b) Water absorption and apparent specific gravity (ASTM C 642) - Figure 28b

(c) Drying shrinkage (ASTM C 341) - Figure 28c

(d) Initial surface sorption (BS 1881: Part 5) - Figure 28d

(e) Specific heat (ASTM C 351) - Figure 28e

(f) Thermal conductivity (ASTM C 177) - Figure $28 \mathrm{f}$

Masonry units were also subjected to the following accelerated aging effects, after which they were tested in flexure:

(a) Freeze-thaw cycles (ASTM C 666) - Figure 29a

(b) Wetting and drying cycles (ASTM C 1185) - Figure 29b

(c) Hot water immersion (ASTM C 1185) - Figure 29c

(d) High-temperature exposure (6 hours at $250^{\circ} \mathrm{C}$ follwed by gradual cool down over a period of 18 hours and 48 hours of conditioning at $50 \% \mathrm{RH}$ and $22^{\circ} \mathrm{C}$ - Figure $29 \mathrm{~d}$

(e) Temperautre cycling ( 15 cycles of exposure to $65^{\circ} \mathrm{C}$ for 3 hours followed by gradual cool down to $22^{\circ} \mathrm{C}$ over a period of 9 hours) - Figure $29 \mathrm{~d}$

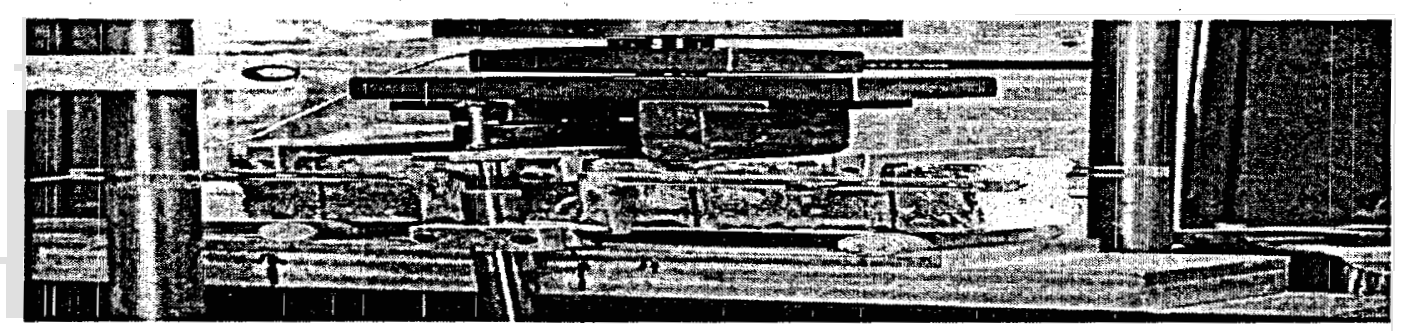

(a) Flexure

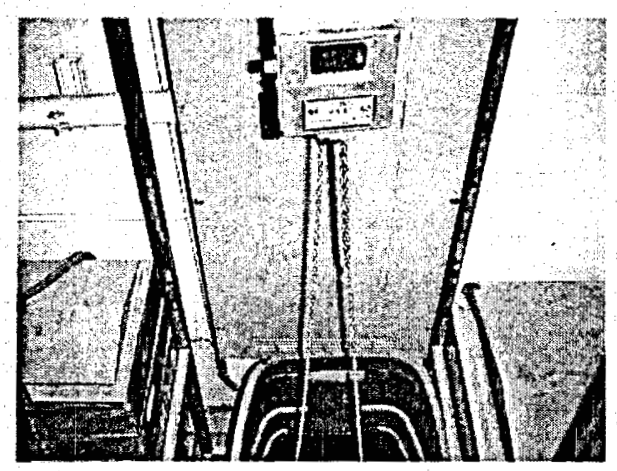

(b) Water Absorption and Apparent Specific Gravity 


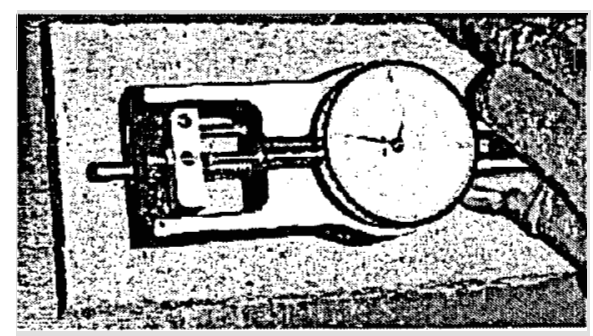

(c) Drying Shrinkage

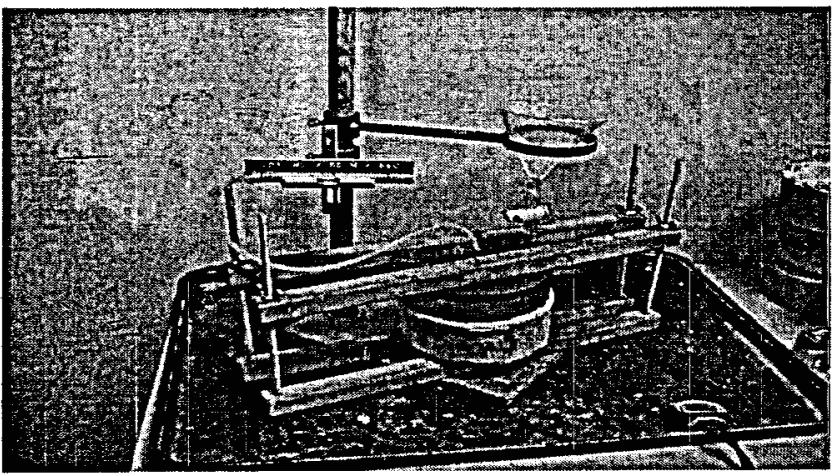

(d) Initial Surface Absorption

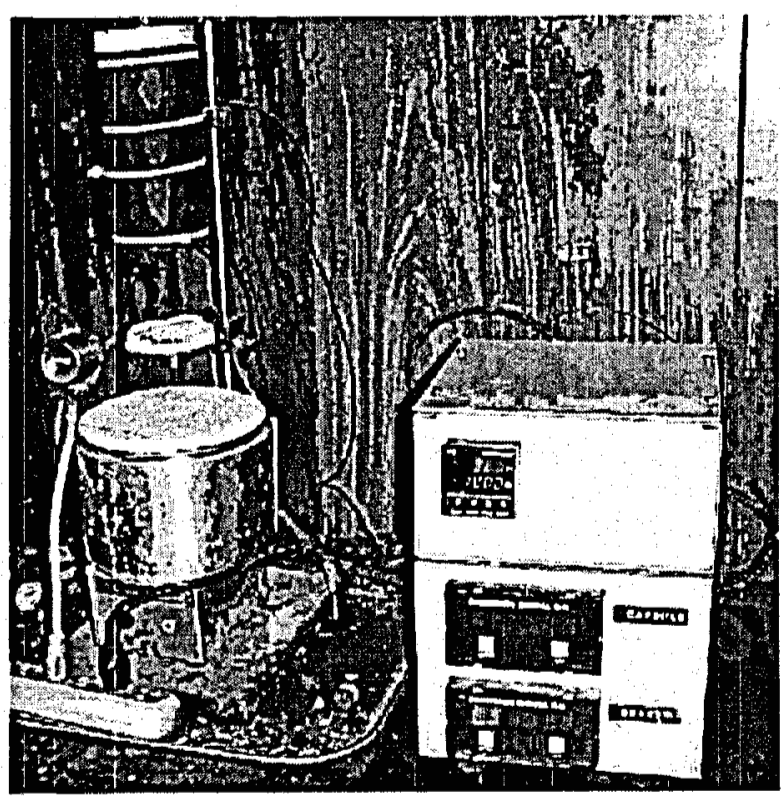

(e) Specific Heat 


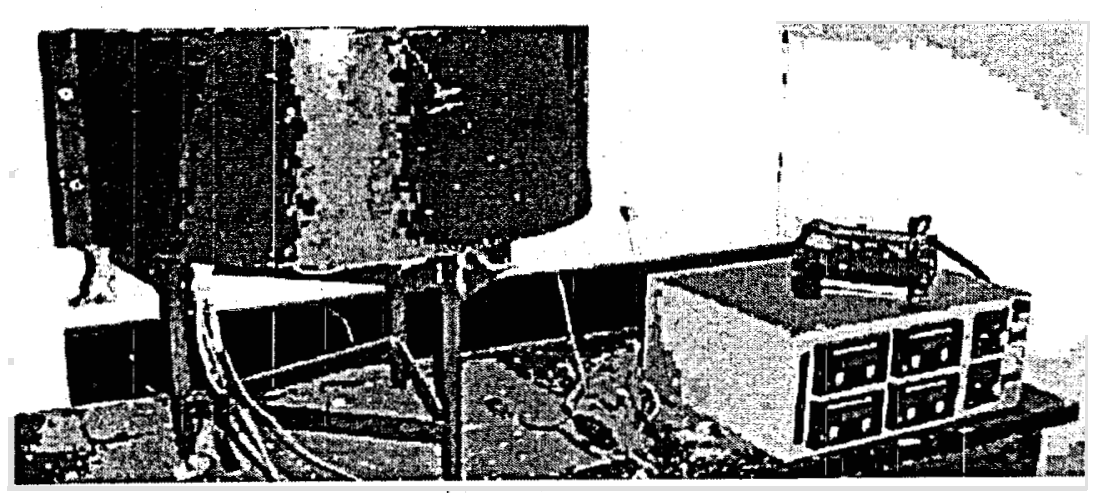

(f) Thermal Conductivity

Figure 28. Test Set-Ups.

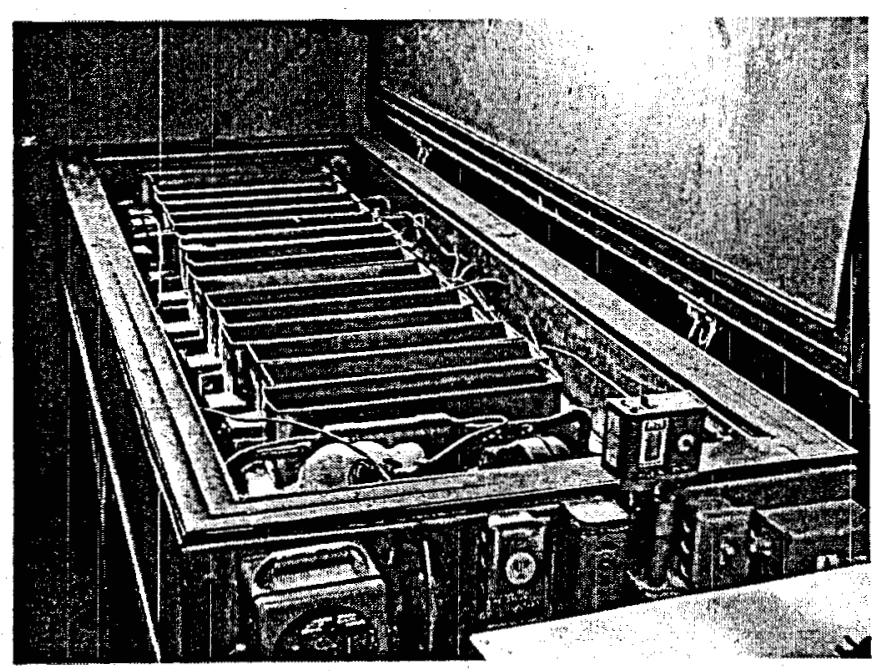

(a) Freeze-Thaw 


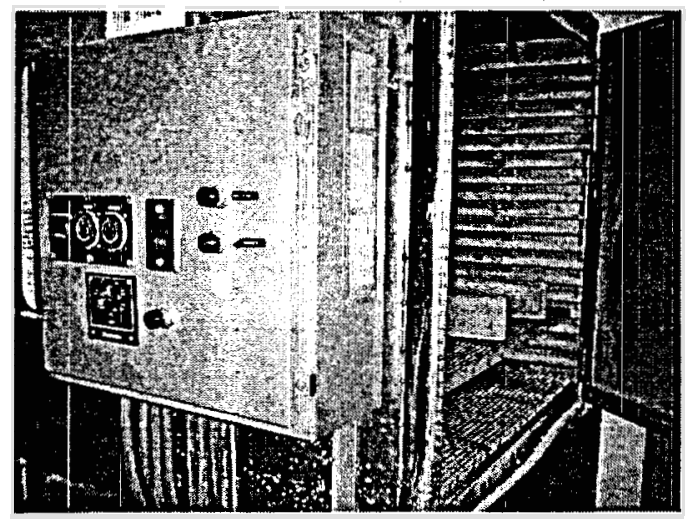

(b) Wetting-Drying

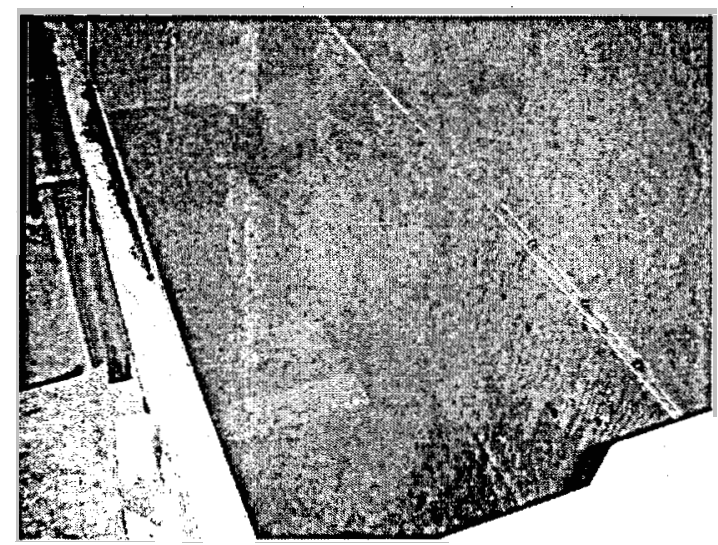

(c) Hot Water Immersion

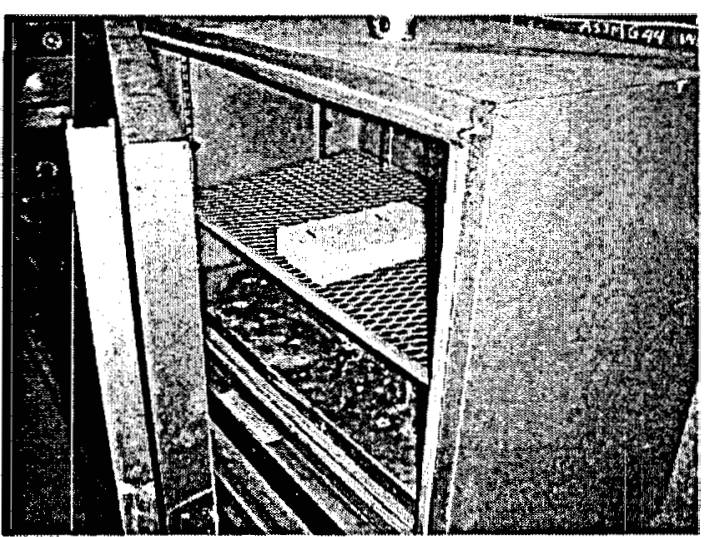

(d) High-Temperature Exposure (and Temperature Cycling)

Figure 29. Accelerated Aging Set-Ups. 


\subsection{Experimental Results}

Fractured flexural specimens of different high-recycled concrete masonry systems are depicted in figure 30. Flexural load-deflection behavior of recycled wood, plastic and tire concrete were distinguished by highly desirable post-peak ductility and toughness characteristics.

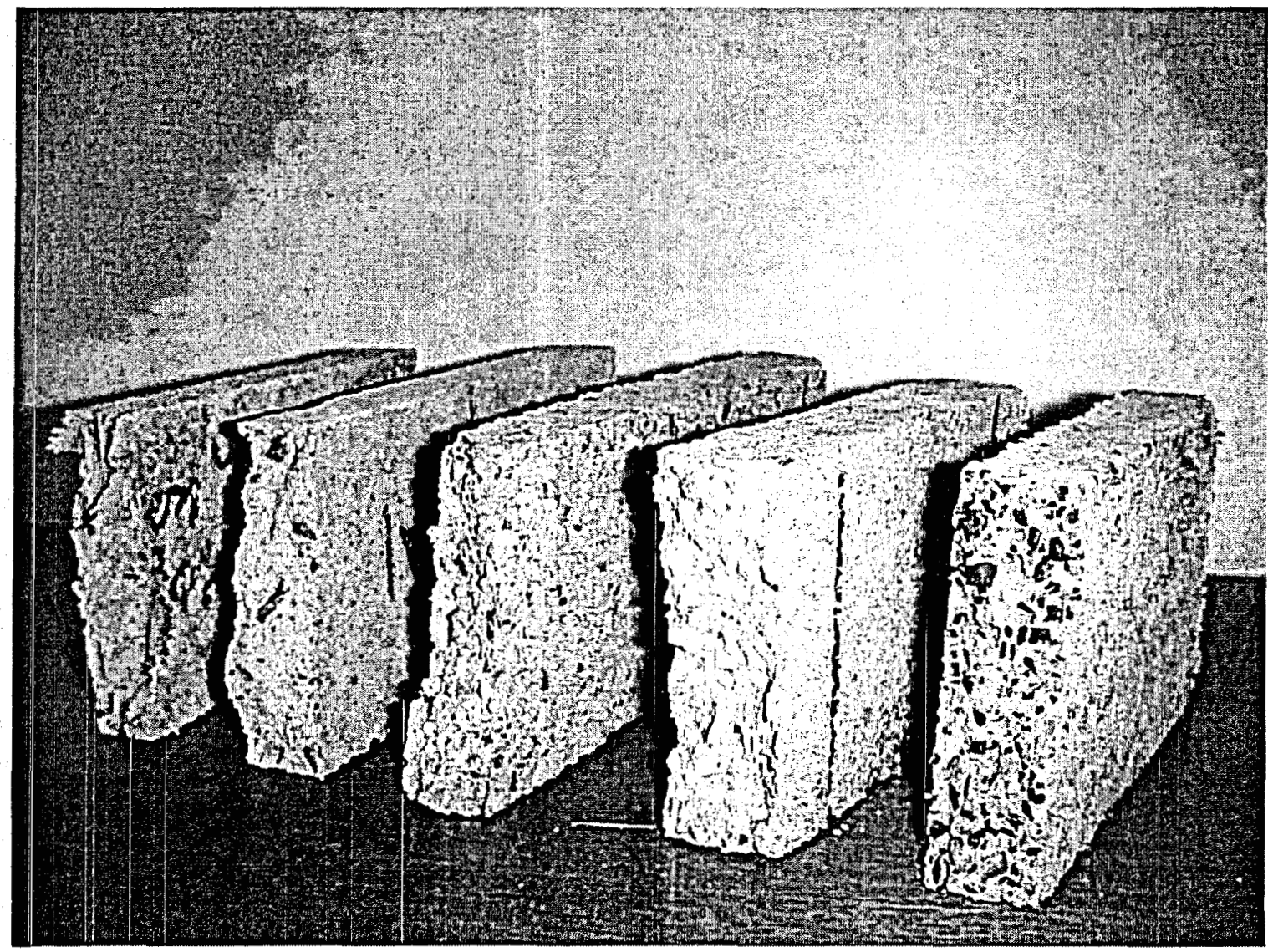

Figure 30. Fractured Flexural Specimens of Different High-Recycled-Content Concrete Masonry Materials.

Figure 31 presents flexural strength and energy absorption capacity (total area underneath the flexural load-deflection curve) of control (normal) and different high-recycledcontent concrete materials immediately after steam curing (prior to any complementary moist curing followed by conditioning at $50 \%$ relative humidity). The error bars mark the standard error of measurements. Masonry systems with birdeye and lightweight aggregates are the control normal-weight and lightweight systems, respectively, used in this project. High-recycled-content masonry systems are observed to provide competitive levels of strength and superior levels of energy absorption (toughness) when compared 
with control concrete masonry systems. Figure 32, which presents flexural properties of different concrete masonry materials after complementary moist curing followed by conditioning at $50 \%$ relative humidity, yields similar results as far as comparative performance of the control and high-recycled-content concrete masonry systems is concerned. Complementary moist curing of various systems after the initial steam curing is observed to almost double the flexural strength and energy absorption capacity of (noting that masonry systems were tested saturated immediately after moist curing, but in equilibrium with $50 \%$ relative humidity environment after complementary moist curing). This is clearly shown in Figure 33 which compares flexural properties immediately after steam curing versus those obtained after complementary moist curing and conditioning at $50 \%$ relative humidity.

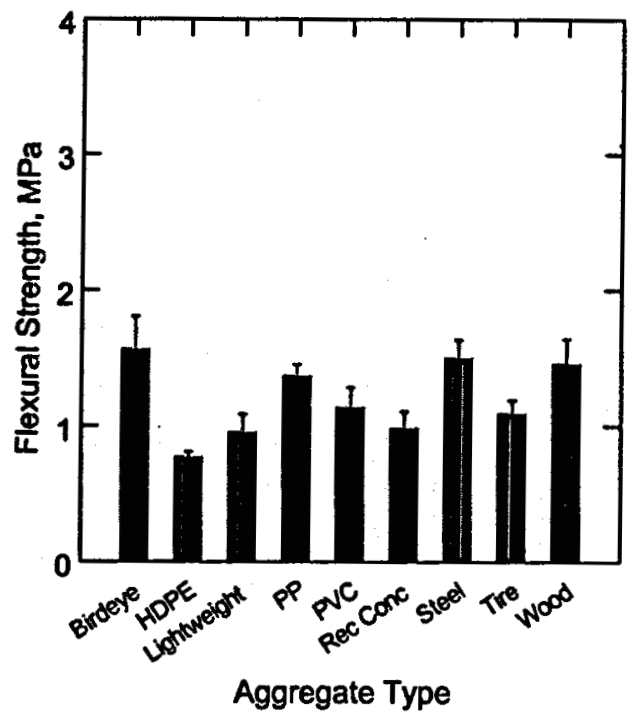

(a) Flexural Strength 


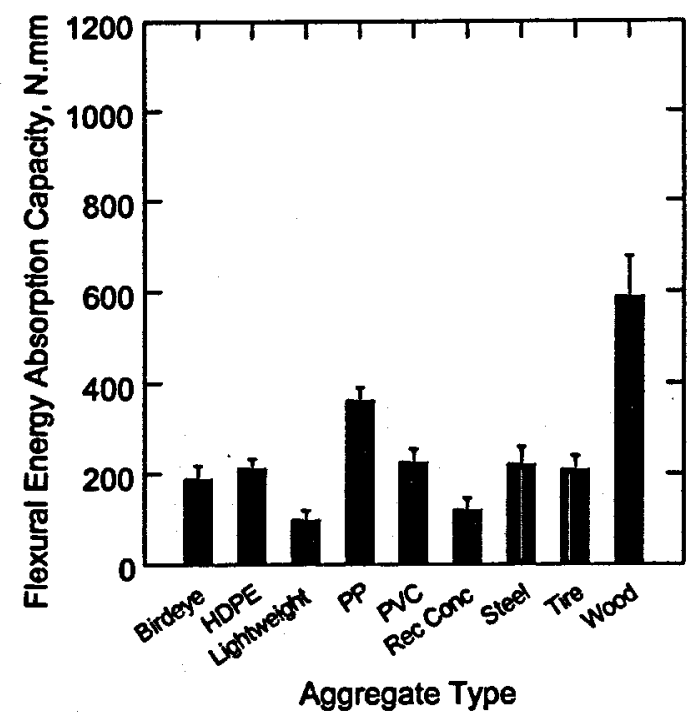

(b) Flexural Energy Absorption Capacity

Figure 31. Flexural Properties of Control (Birdeye and Lightweight) and Different HighRecycled-Content Concrete Masonry Materials Immediately After Steam Curing.

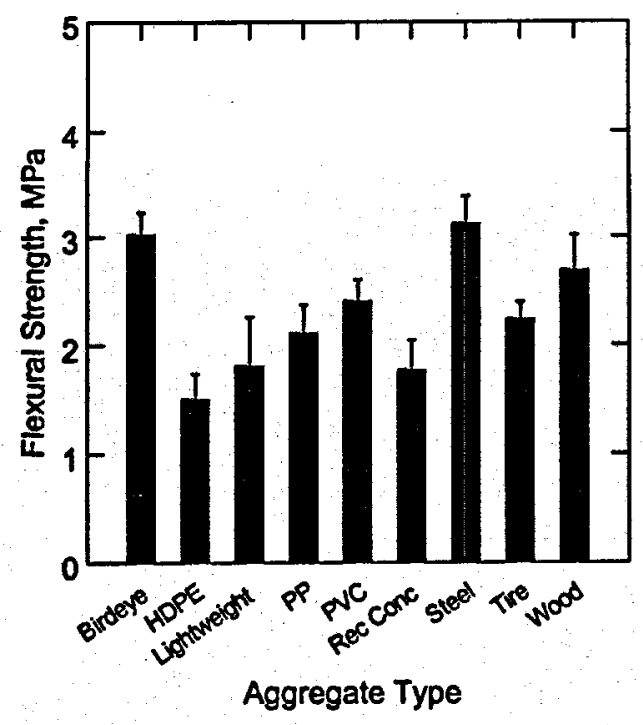

(a) Flexural Strength 


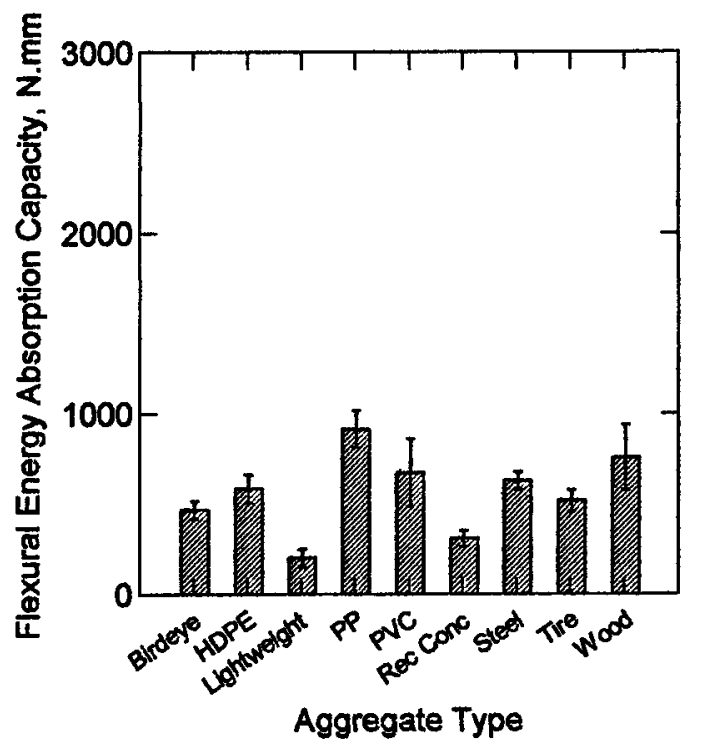

(b) Flexural Energy Absorption Capacity

Figure 32. Flexural Properties of Control (Birdeye and Lightweight)

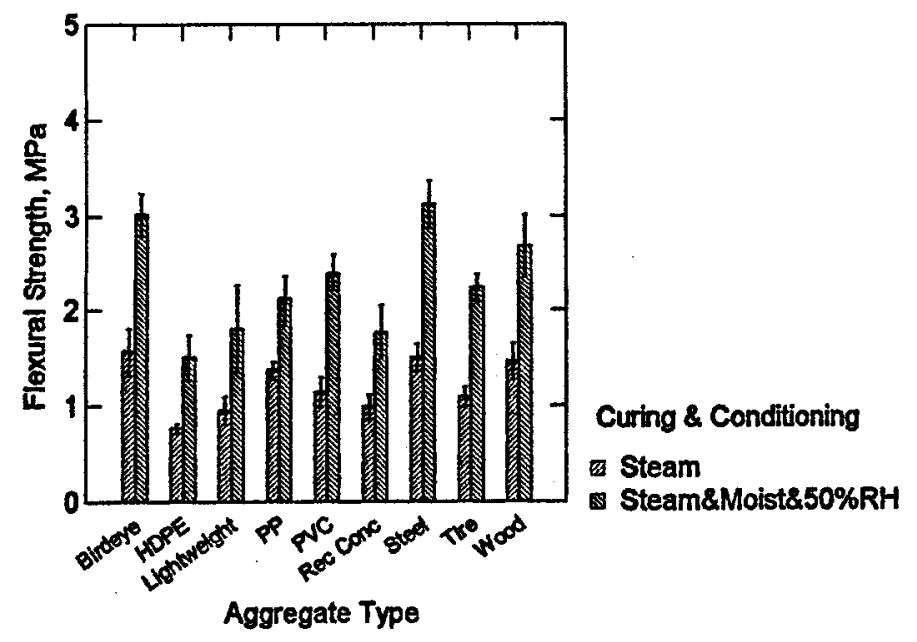

(a) Flexural Strength 


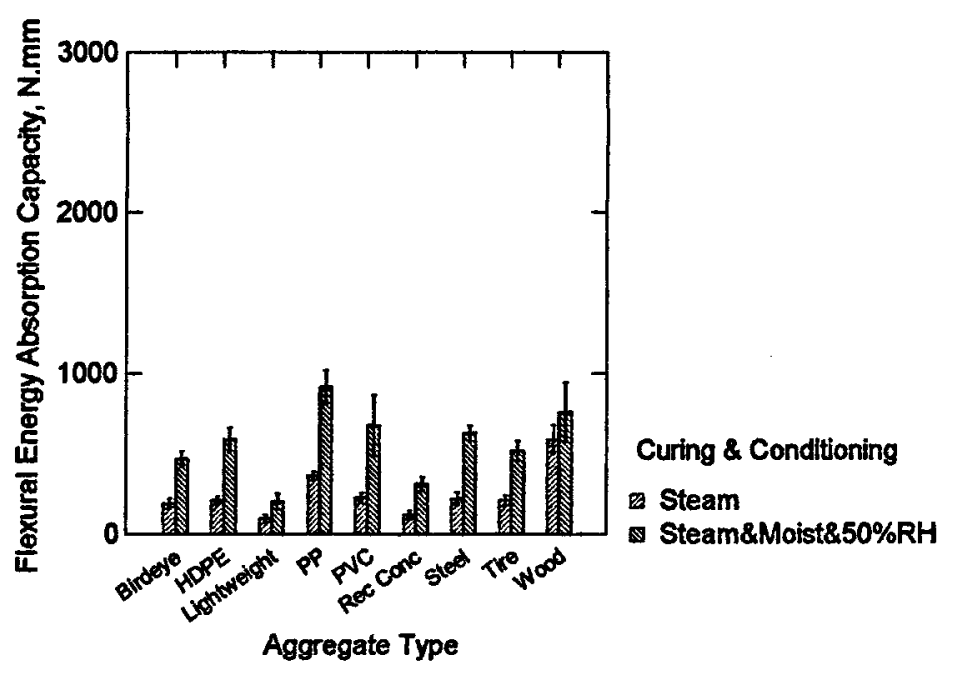

(b) Flexural Energy Absorption Capacity.

Figure 33. Flexural Properties Immediately After Moist Curing Versus Those After Complementary Moist Curing and Conditioning at 50\% Relative Humidity.

Figure 34 compares the apparent specific gravity and water absorption capacity of some high-recycled-content concrete masonry materials with those of control (birdeye and lightweight) concrete masonry systems. Lightweight recycled particles (e.g., plastics and tire), as expected, yield lightweight concrete masonry systems which favorably impact the construction process and are expected to offer better thermal characteristics. 


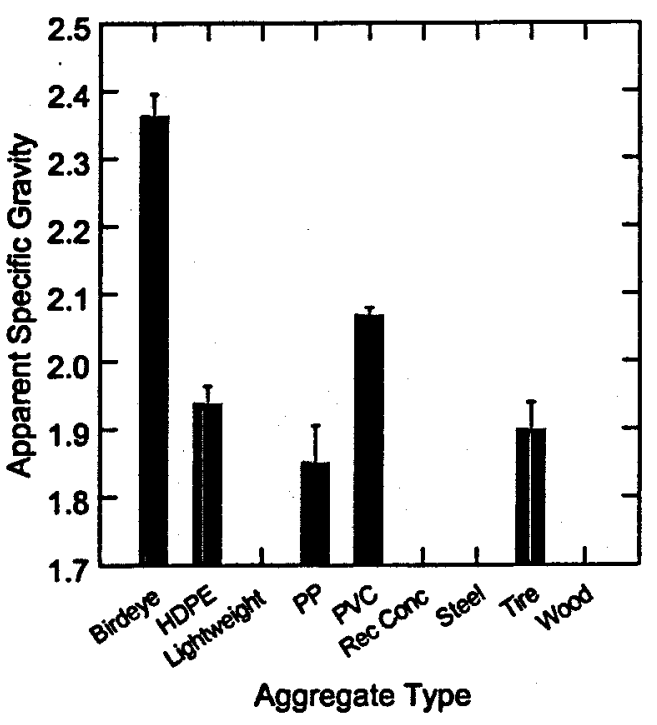

(a) Apparent Specific Gravity

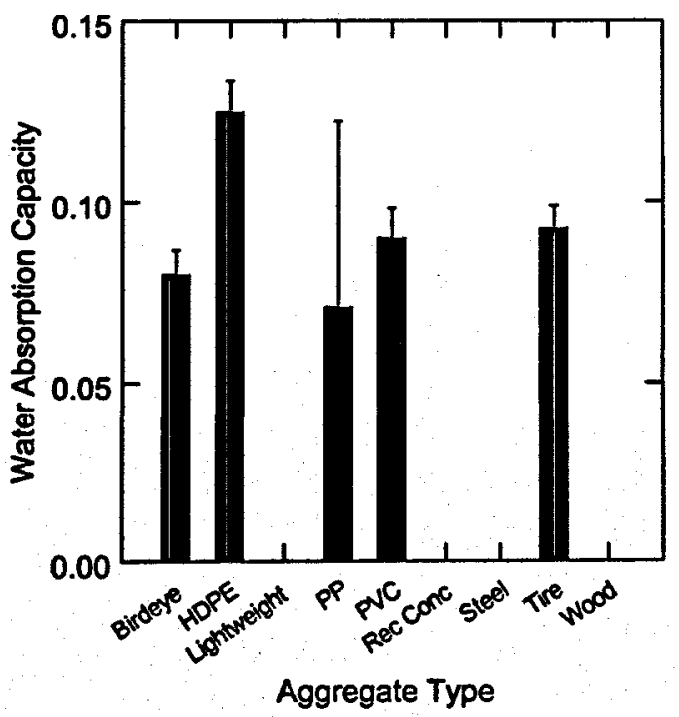

(b) Water Absorption Capacity

Figure 34. Apparent Specific Gravity and Water Absorption Capacity of Control (Birdeye and Lightweight) and High-Recycled-Content Concrete Masonry Materials. 
Some key physical attributes of control certain high-recycled-content concrete masonry systems are presented in Figure 35. These physical attributes are quite competitive against conventional concrete and masonry systems commonly used in building construction.

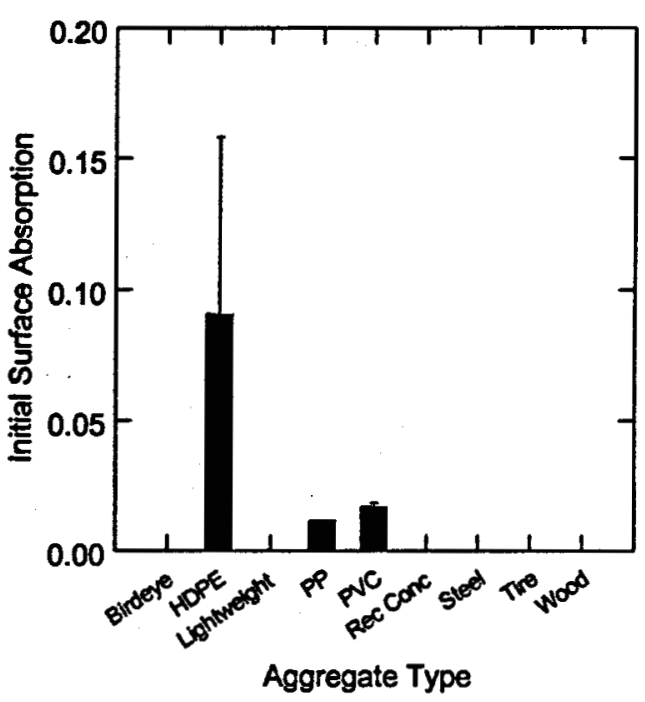

(a) Initial Surface Absorption ( $\mathrm{ml} / \mathrm{m}^{2} . \mathrm{s}$ )

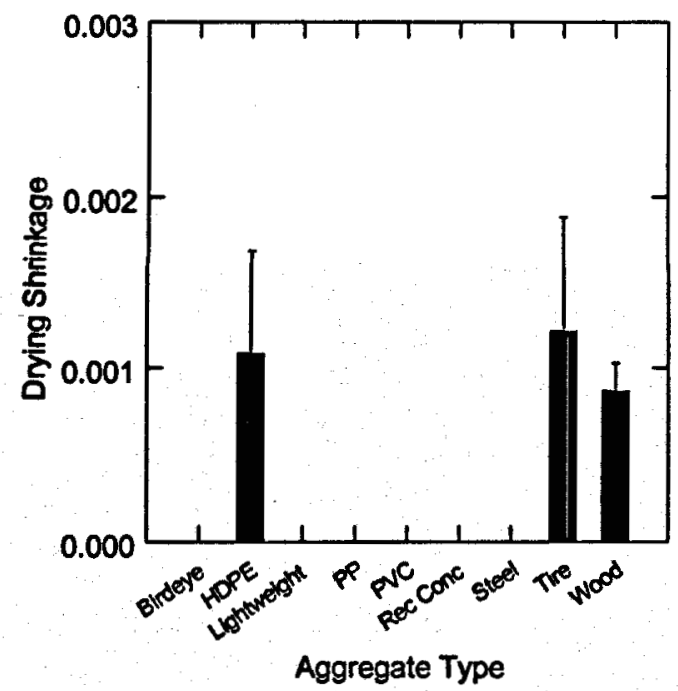

(b) Drying Shrinkage

Figure 35. Some Key Physical Attributes of Control and High-Recycled-Content Concrete Masonry Materials. 
Effects of diverse accelerated aging conditions on the flexural strength and energy absorption capacity of control (birdeye and lightweight) and high-recycled-content concrete masonry materials are presented in Figure 36. The results, which are relevant to exterior application of concrete masonry, imply that all high-recycled-content concrete masonry systems except for those made with recycled wood and tire are suitable for exterior applications in diverse climatic conditions.

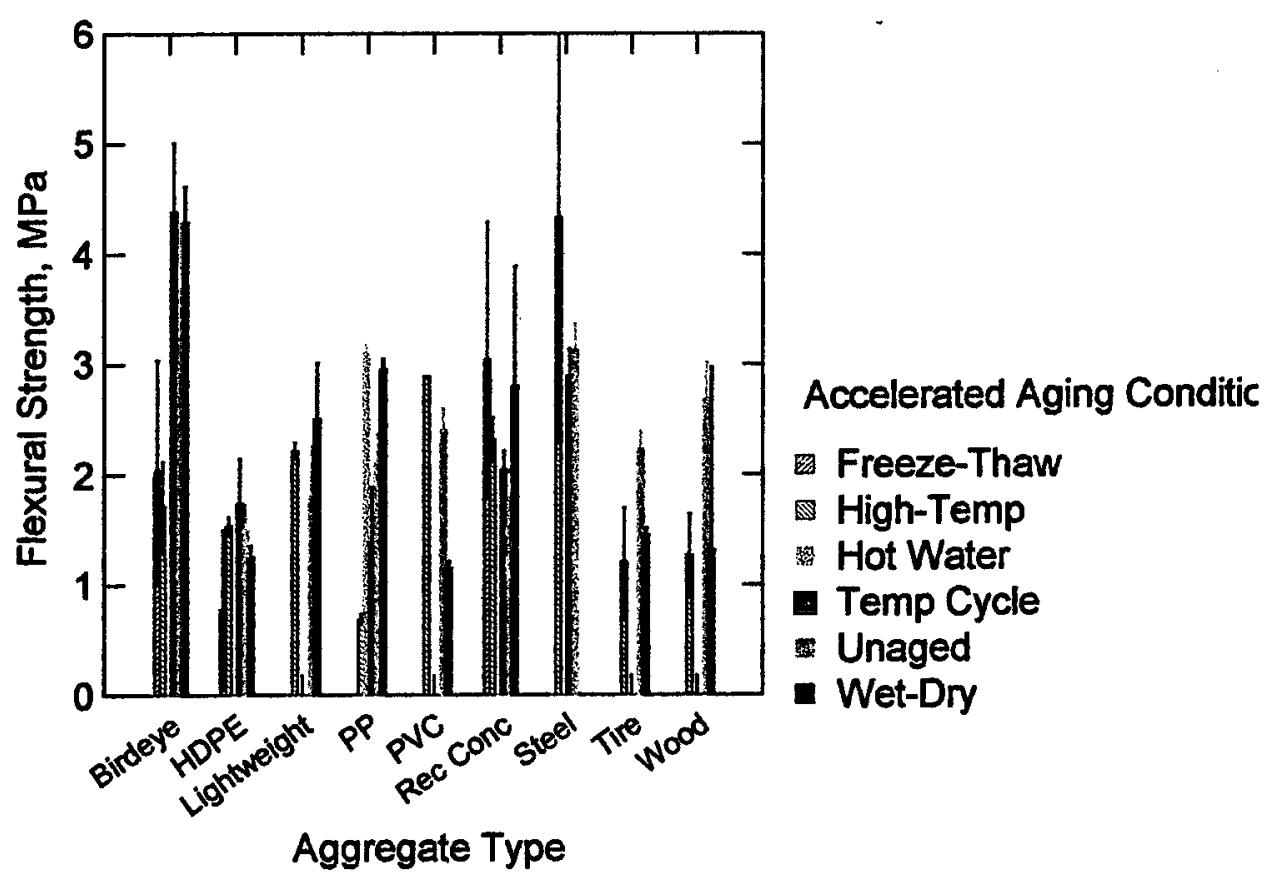

(a) Flexural Strength 


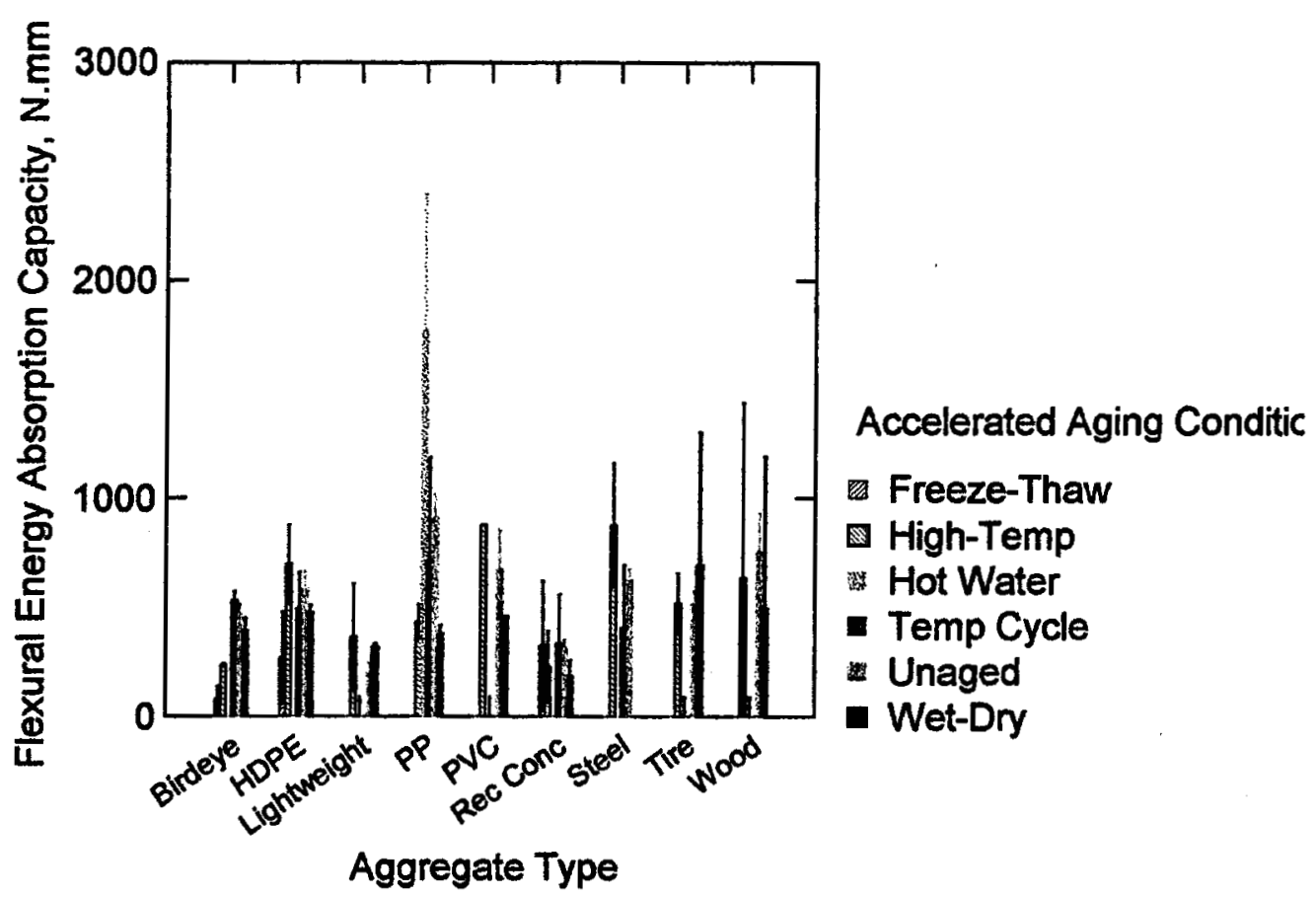

(b) Flexural Energy Absorption Capacity

Figure 36. Effects of Diverse Accelerated Aging Conditions on Flexural Performance of Control (Birdeye and Lightweight) and High-Recycled-Content Concrete Masonry Materials.

As shown in Figure 37a, high-recycled-content concrete masonry materials all provide relatively high levels of specific heat when compared with the control (MAS) material made with normal aggregate (birdeye stone). This confirms our success in developing high-recycled-content masonry materials with significant thermal energy absorption capacity. The thermal conductivity test results (Figure $37 \mathrm{~b}$ ) suggest that recycled plastics, wood and tire possess the potential to enhance thermal insulation attributes of concrete masonry. 


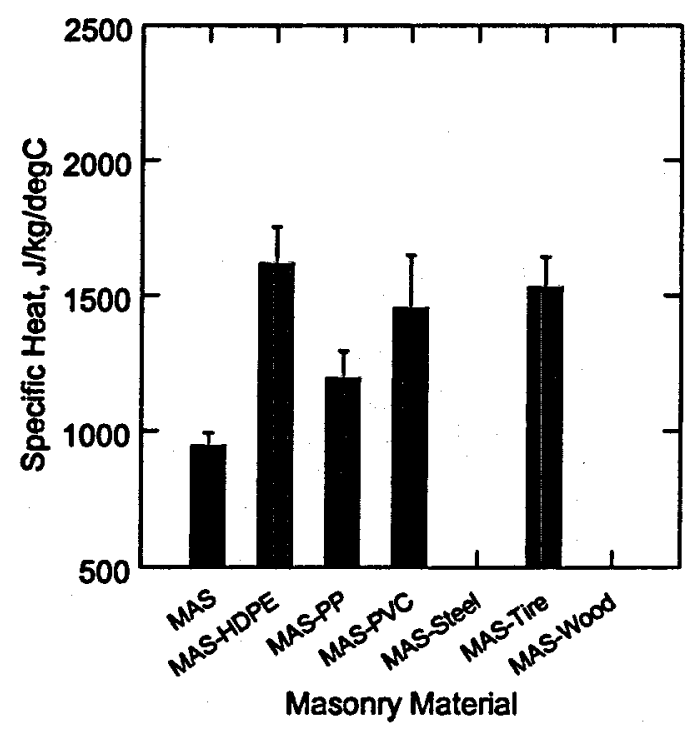

(a) Specific Heat

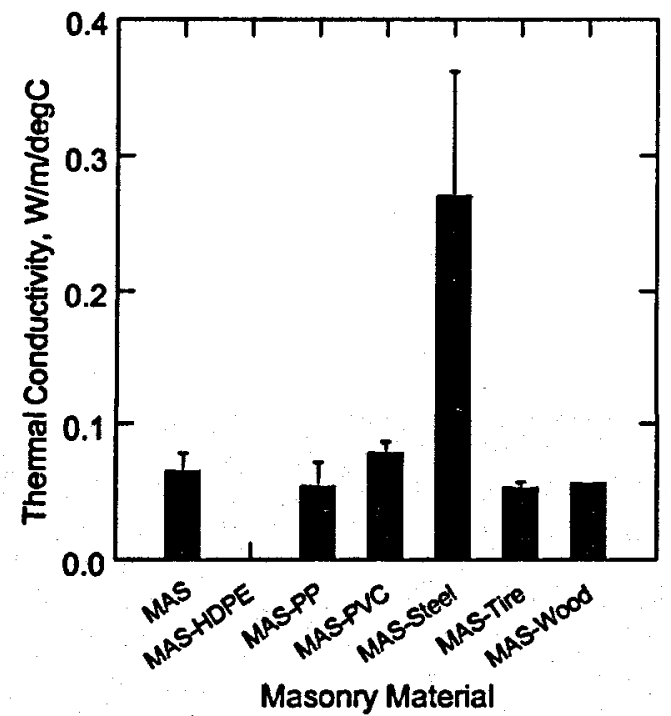

(b) Thermal Conductivity

Figure 37. Specific Heat and Thermal Conductivity of Control (MAS) and HighRecycled-Content Concrete Masonry Units. 


\subsection{Field Evaluation of Energy-Efficient Building Construction with High-Recycled-Content Concrete}

\subsection{Description of the Field Project}

Two similar reinforced concrete buildings, one with normal concrete and the other with high content of recycled (mixed) plastics were designed, constructed and monitored for energy-efficiency and comfort.

The plan view and elevations applicable to both buildings are shown in Figure 38 . The buildings have a lower level (basement) in addition to the main floor, and they are built for commercial use. The experimental data produced in the laboratory phase of our research on mechanical and thermal characteristics of high-recycled-content concrete were used to design the building system for structural loads and energy efficiency. These buildings were subjected to comprehensive analyses, and were thoroughly instrumented for short-term and long-term monitoring of their energy performance and comfort condition.
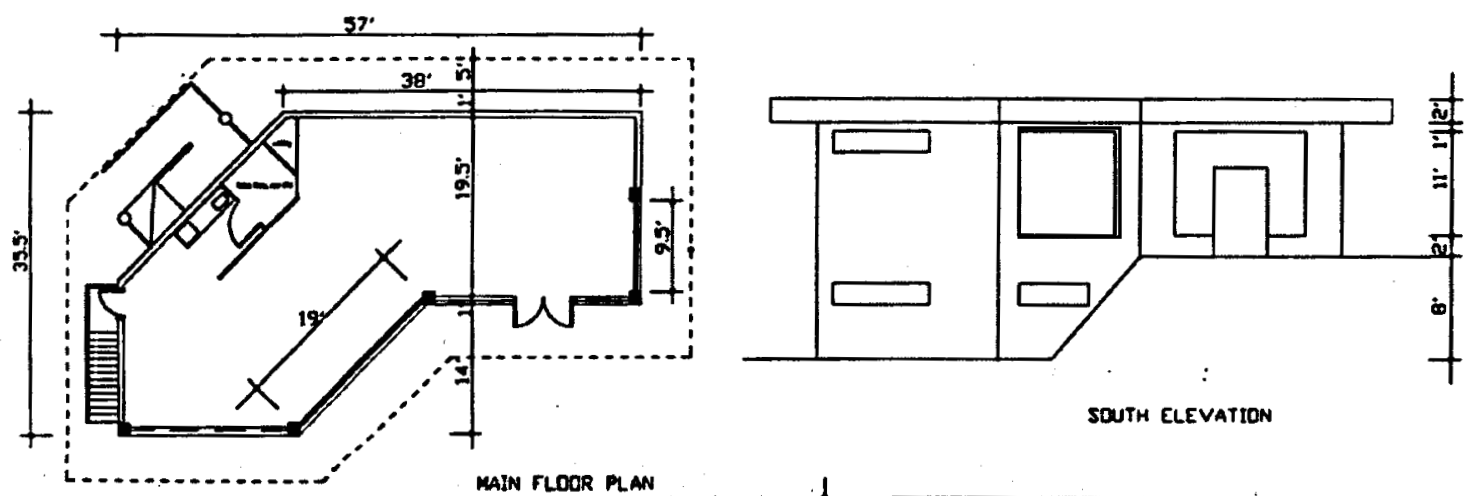

MAIN FLOOR MLAN

SOUTH ELEVATION
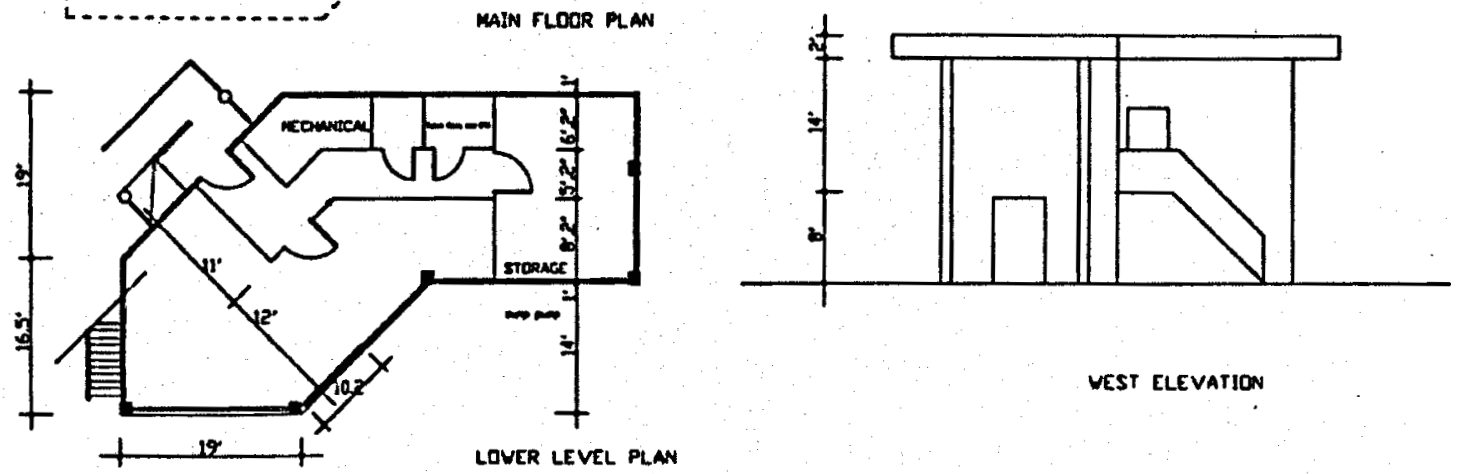

VEST ELEVATION

Figure 38. Plan View and Elevations. 


\subsection{Energy Analysis of Buildings}

Building simulations for energy analysis were performed using two computer programs: DOE2.1e developed by Lawrence Berkeley National Laboratory (LBNL), and SUNREL developed by National Renewable Energy Laboratory (NREL). DOE2.1e is designed primarily for commercial buildings and can analyze daylighting as well as hourly loads and operation of HVAC equipment. SUNREL is designed for residential buildings that are envelope- or load- dominated. SUNREL was the primary simulation tool used for this analysis due to the relatively small size of the buildings and the large percentage of solar loads.

Parametric studies were performed on various building components in order to determine the optimum parameter settings. These parametric studies keep all building parameters constant while varying one to determine its effect on the overall performance of the building. As shown in Table 5, high-recycled-content concrete materials differ from normal concrete (using crushed stone as coarse aggregate) in terms of specific heat, density and thermal conductivity.

Figure 39 shows the effect of specific heat of the construction material (concrete) on building energy performance. The simulations were run by varying the specific heat and maintaining a constant thermal conductivity. The high specific heat of high-recycledcontent concrete is observed to reduce the annual energy load by about $50 \%$ when compared with common building systems (e.g., light wood frame construction) which offer minimal heat storage capacity. Inability of light wood frame buildings to store heat leads to overheating from solar and internal gains that result in an increased cooling load; the heating load also increases because stored heat cannot be released into the building during evening hours.

Figure 40 examines the effect of concrete thermal conductivity on overall building energy load. This graph was produced by varying thermal conductivity with three different fixed values of specific heat. A lower thermal conductivity of concrete results in a lower energy load. As the thermal conductivity of concrete increases, its effect as a heat barrier tends to be overshadowed by the insulation, thus the energy load levels off.

With the measured values of specific heat and thermal conductivity for normal and highrecycled-content concrete (Table 5), one arrives at the annual energy loads of Figure 41 for the building system shown in Figure 38. High-recycled-content concrete incorporating shredded mixed plastic, which is subject of our field investigation, is observed to reduce energy loads below those of normal concrete. 
Table 5. Measured Thermal Properties of Different Concrete Materials.

\begin{tabular}{cccc}
\hline Concrete Coarse Aggregate & $\begin{array}{c}\text { Specific } \\
\text { Heat, } \\
\text { Btu/b. }{ }^{\circ} \mathrm{F}\end{array}$ & $\begin{array}{c}\text { Density, } \\
\mathrm{lb} / \mathrm{ft}^{\mathrm{t}^{3}}\end{array}$ & $\begin{array}{c}\text { Thermal Conductivity, } \\
\mathrm{Btu} . \mathrm{in} / \mathrm{h} . \mathrm{ft}^{2}{ }^{.} \mathrm{F}\end{array}$ \\
\hline Crushed Limestone (normal) & 0.159 & 152 & 7.26 \\
Crushed Recycled Concrete & 0.223 & 147 & 7.73 \\
Shredded HDPE & 0.370 & 108 & 1.39 \\
Shredded PP & 0.335 & 113 & 1.47 \\
Shredded PVC & 0.398 & 108 & 1.24 \\
Shredded Mixed Plastics & 0.325 & 118 & 1.74 \\
Recycled Steel & 0.167 & 218 & 8.73 \\
Granulated Tire & 0.344 & 106 & 2.71 \\
Milled Wood & 0.374 & 117 & 0.775 \\
\hline
\end{tabular}
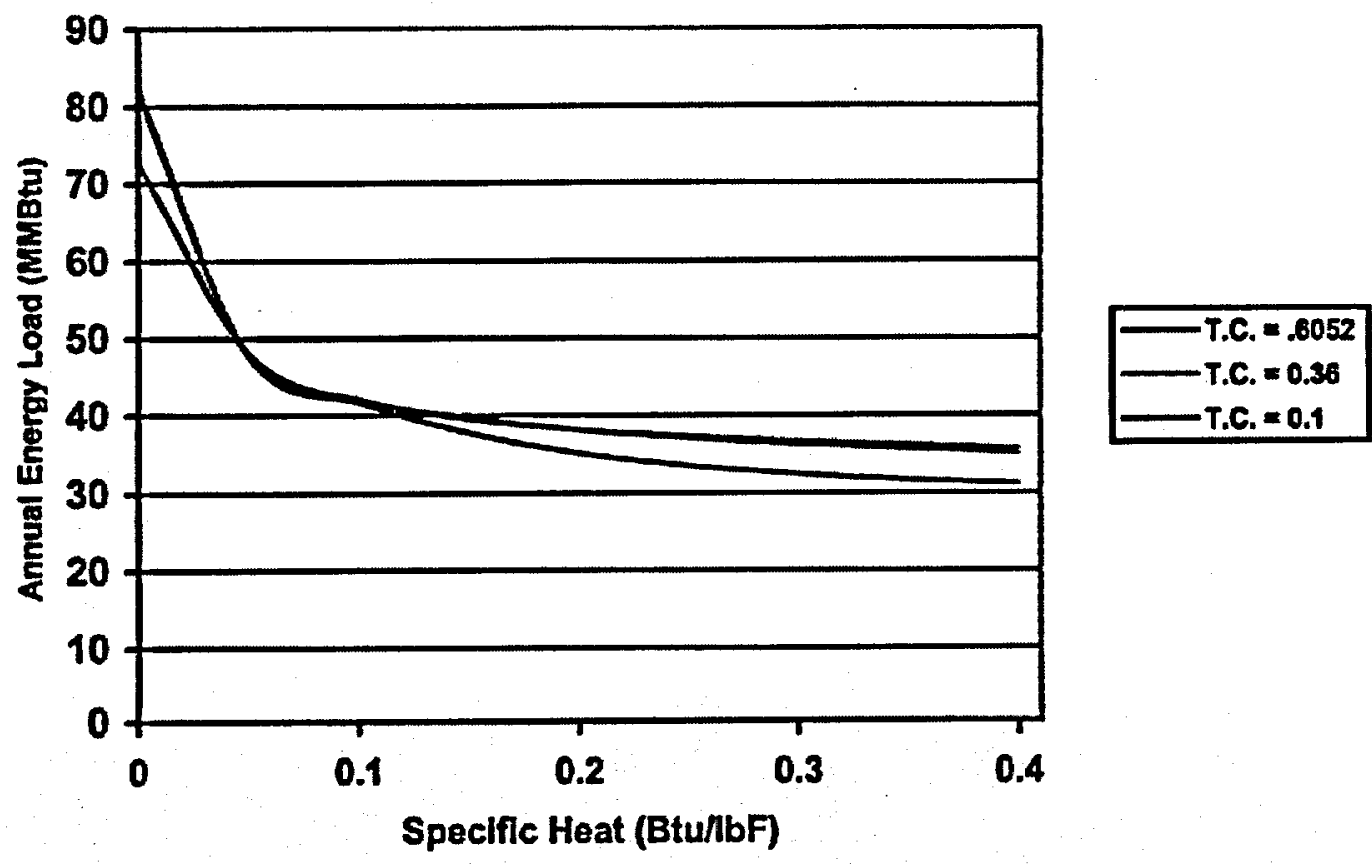

Figure 39. Effect of Specific Heat on Energy Load. 


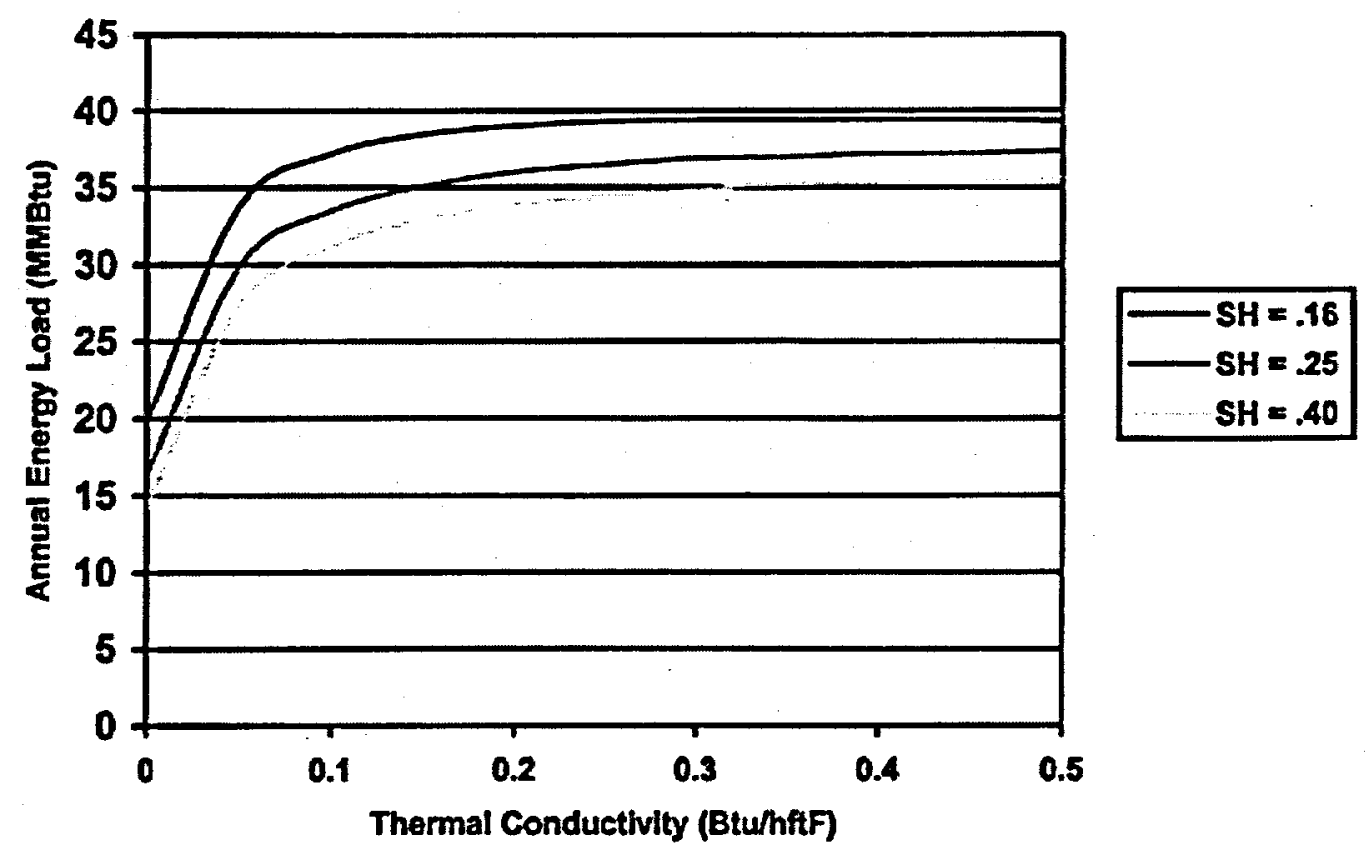

Figure 40. Effect of Thermal Conductivity on Energy Load.

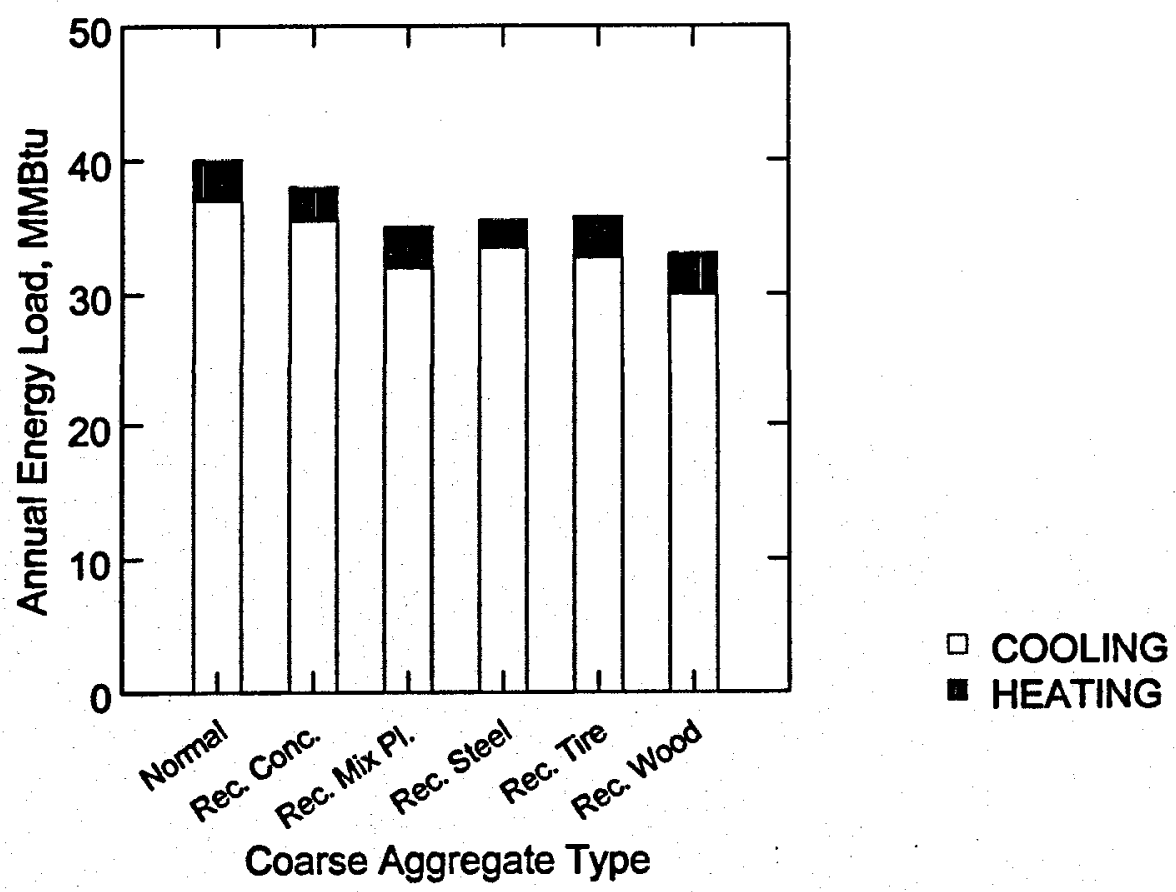

Figure 41. Annual Energy Loads with Normal Concrete Vs. Different High-RecycledContent Concrete Materials. 
Parametric analyses similar to those presented above yielded the optimum building parameters presented in Table 6 . The building was constructed with recycled mixed plastic concrete using the parameters of Table 6 .

Table 6. Optimum Building Parameters with Recycled Plastic Concrete.

\begin{tabular}{ll}
\hline \multicolumn{1}{c}{ Building Parameter } & \multicolumn{1}{c}{ Optimum Condition } \\
\hline South Window Area (first floor) & $363 \mathrm{ft}^{2}$ - solar gain; $30 \mathrm{ft}^{2}$ daylighting \\
Glazing Properties & Shading Coeff. $>0.7 ; \mathrm{U}<0.35$ \\
Overhang Length & $5 \mathrm{ft}$ \\
Exterior Wall Insulation & $\mathrm{R}-25$ \\
Roof Insulation & $\mathrm{R}-35$ \\
Slab Insulation & $\mathrm{R}-20$ \\
Below Grade Wall Insulation & $\mathrm{R}-15$ \\
Economizer & Yes \\
\hline
\end{tabular}

\subsection{Construction and Instrumentation of Buildings}

The building construction project uses granulated mixed plastic waste (Figure 42), which has limited markets and is largely disposed of in landfills. Based on a trial-andadjustment approach at different stages of the field project, we developed the refined high-recycled plastic-content concrete mix proportions shown in Table 7 in order to meet various requirements of building construction, including strength, pumpability and finishability.

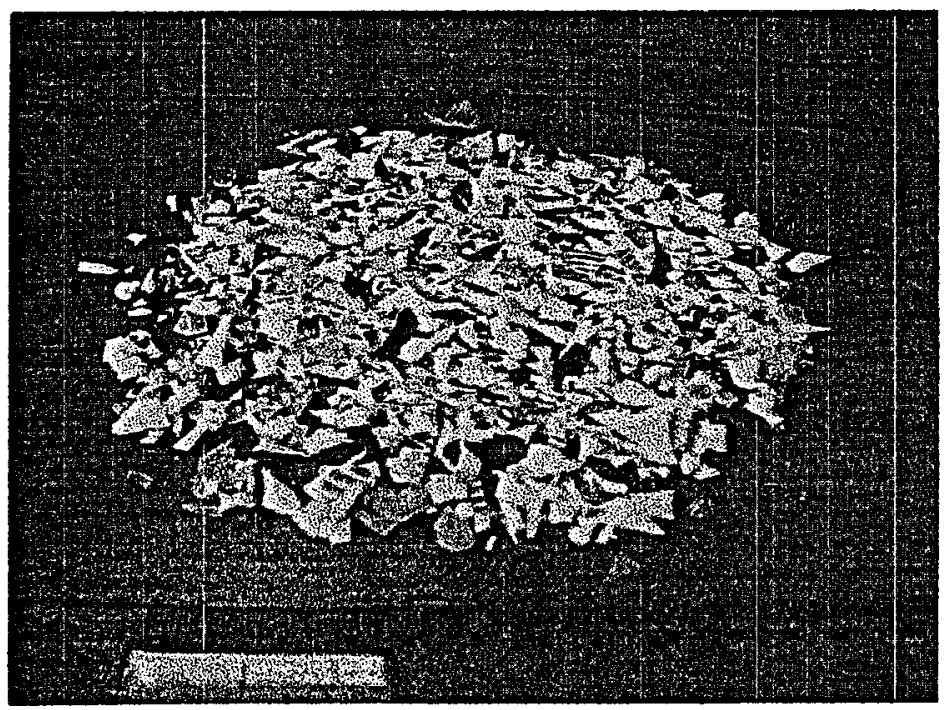

Figure 42. Granulated Mixed Plastic Waste. 
Table 7. Final Mix Proportions of High-Recycled Mixed Plastic-Content Concrete.

\begin{tabular}{lc}
\hline \multicolumn{1}{c}{ Mix Ingredient } & Dosage \\
\hline Cement & $680 \mathrm{lb} / \mathrm{yd}^{3}$ \\
Water & $265 \mathrm{lb} / \mathrm{yd}^{3}$ \\
Sand & $1342 \mathrm{lb} / \mathrm{yd}^{3}$ \\
Crushed Limestone (Grade 31A) & $684 \mathrm{lb} / \mathrm{yd}^{3}$ \\
Shredded Mixed Plastic & $185 \mathrm{lb} / \mathrm{yd}^{3}$ \\
Air-Entraining Agent & $0.3 \mathrm{Oz}$ per $100 \mathrm{lb}$ of cement \\
Water-Reducer (Rheobuild ${ }^{\mathrm{TM}}$ ) & $10 \mathrm{Oz} \mathrm{per} 100 \mathrm{lb}$ of cement \\
Processed Cellulose Fiber (Fabroset & $1.5 \mathrm{lb} / \mathrm{yd}^{3}$ \\
\hline
\end{tabular}

In order to ensure uniform dispersion of recycled plastics in concrete, they were added first to empty ready-mixed concrete truck (Figure 43); other concrete ingredient were then loaded and mixed (Figure 44) following common practice. The resulting highrecycled-content concrete proved to be highly compatible with conventional concrete construction procedures, including pumping (Figure 45), consolidation (Figure 46), and finishing (Figures 47 and 48). Finished surfaces of high-recycled mixed plastic-concrete were aesthetically acceptable (Figure 49).

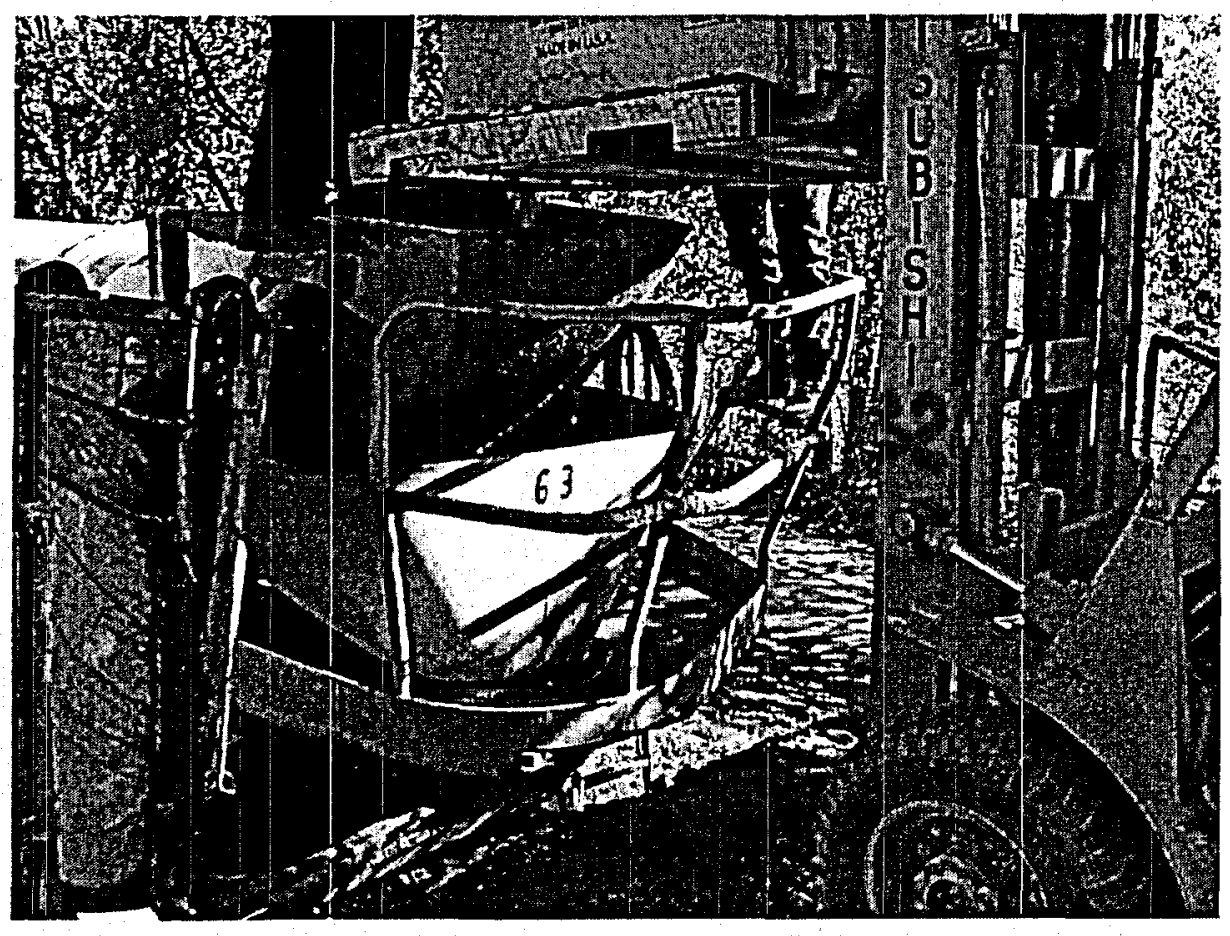

Figure 43. Addition of Granulated Mixed Plastics to Empty Concrete Truck. 


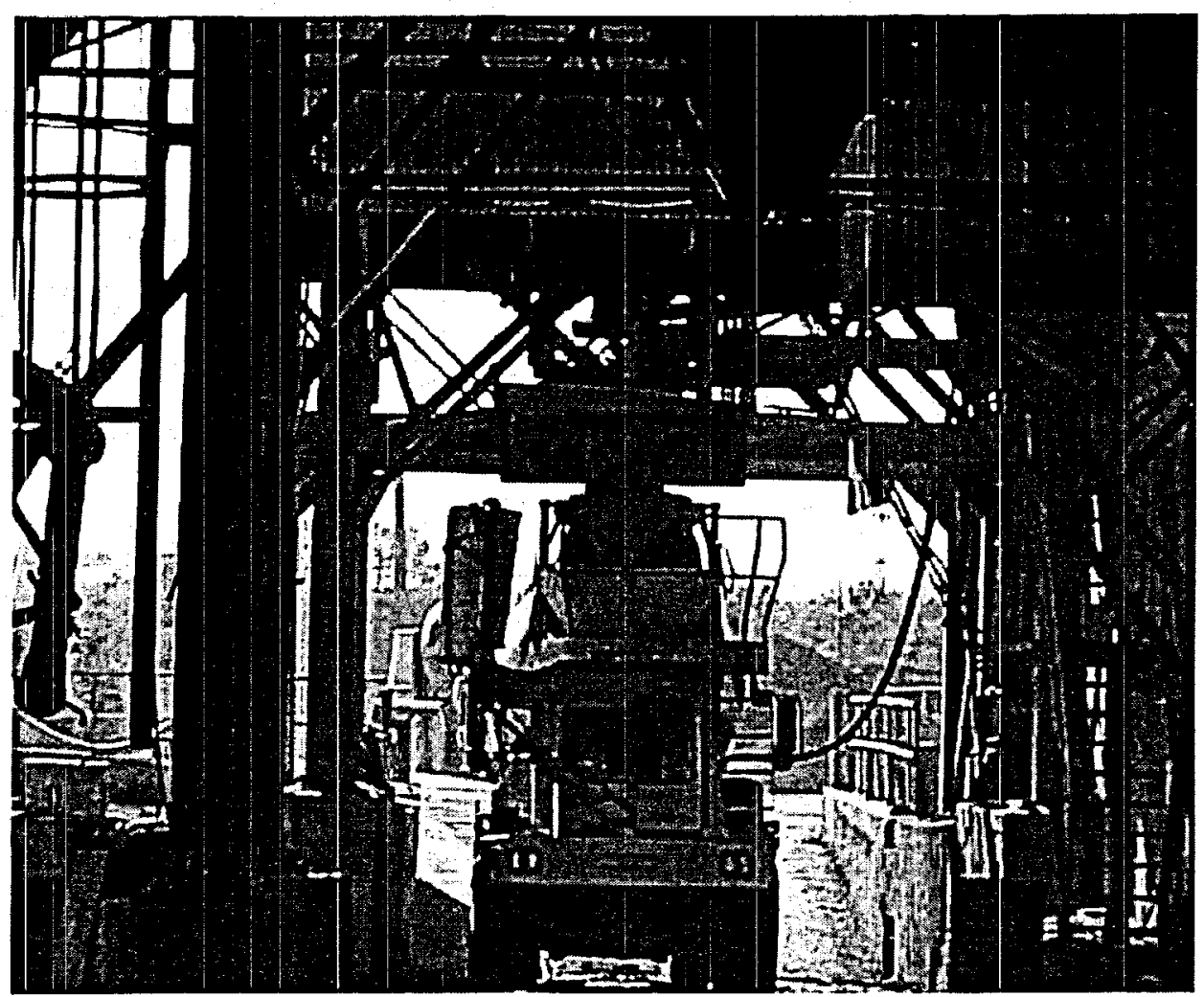

Figure 44. Conventional Batching of Other Concrete Mix Ingredients.

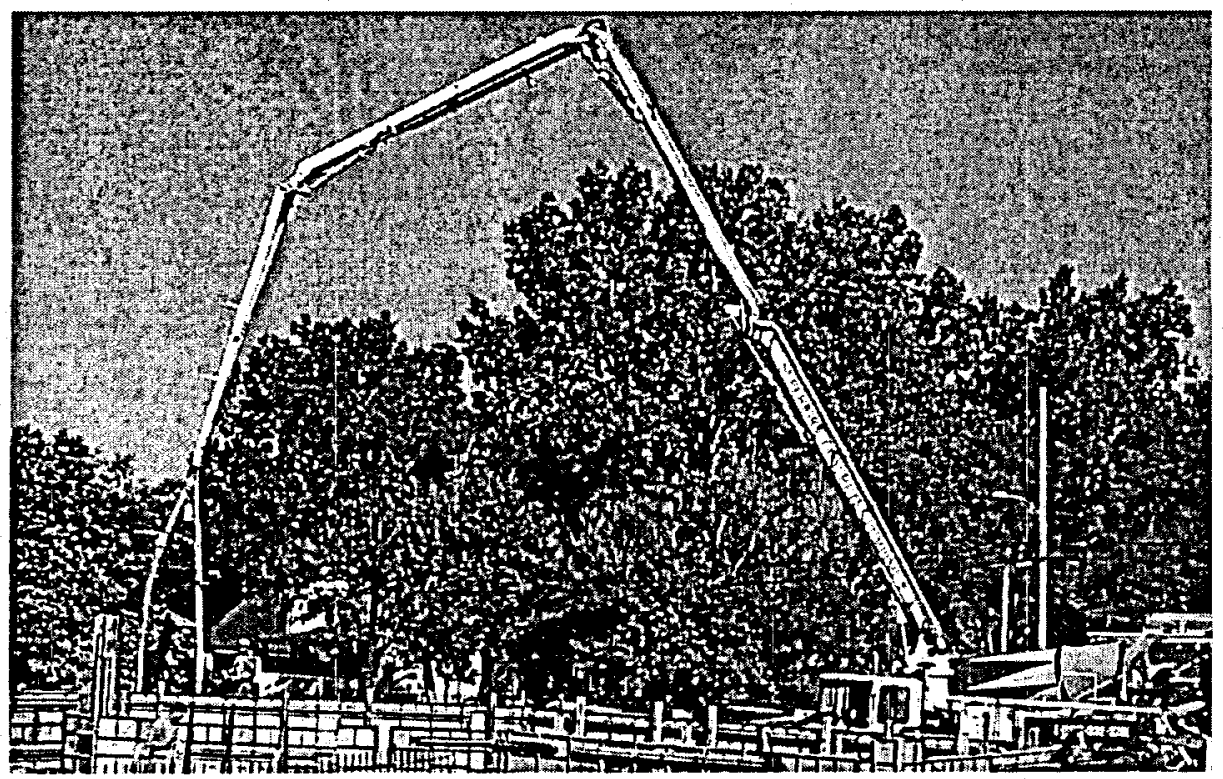

(a) Overall View of the Pump 


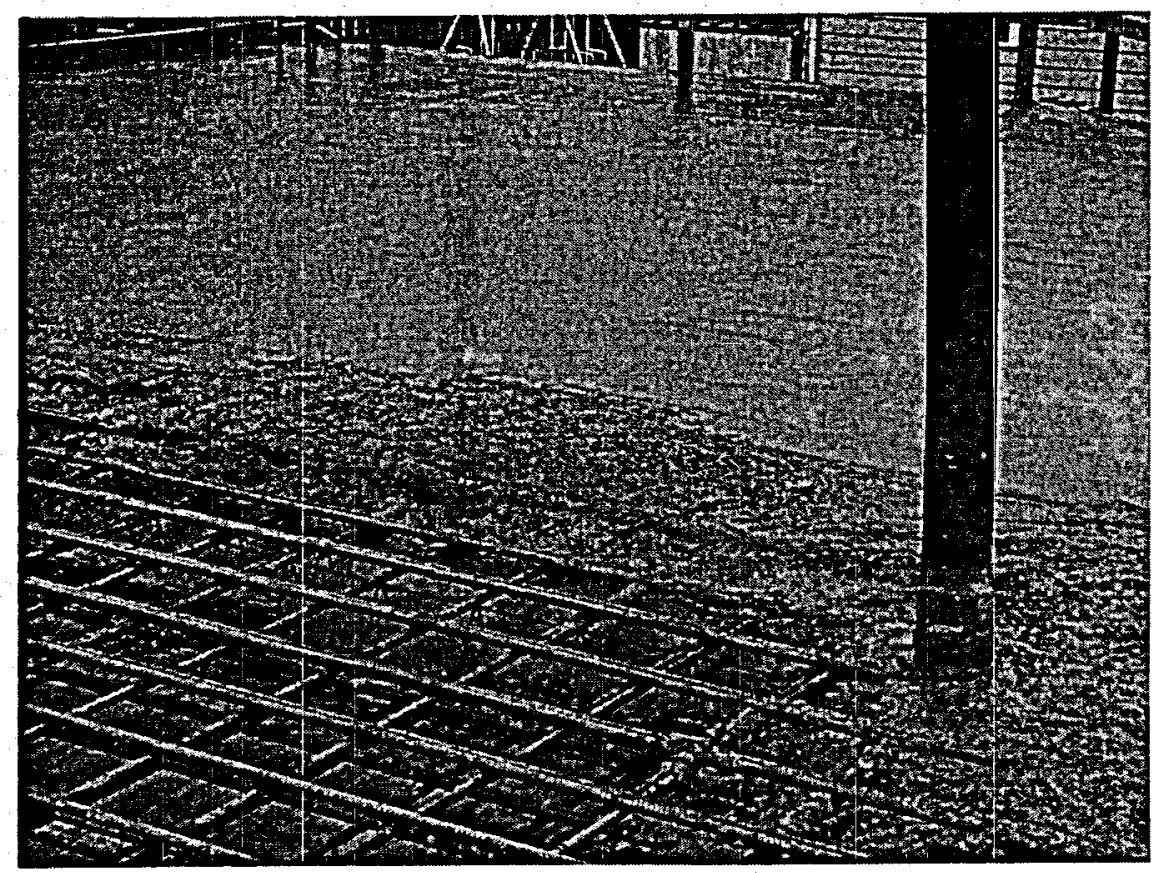

(b) Exit of Recycled-Content Concrete From Pump

Figure 45. Pumping of High-Recycled Mixed Plastic-Content Concrete.

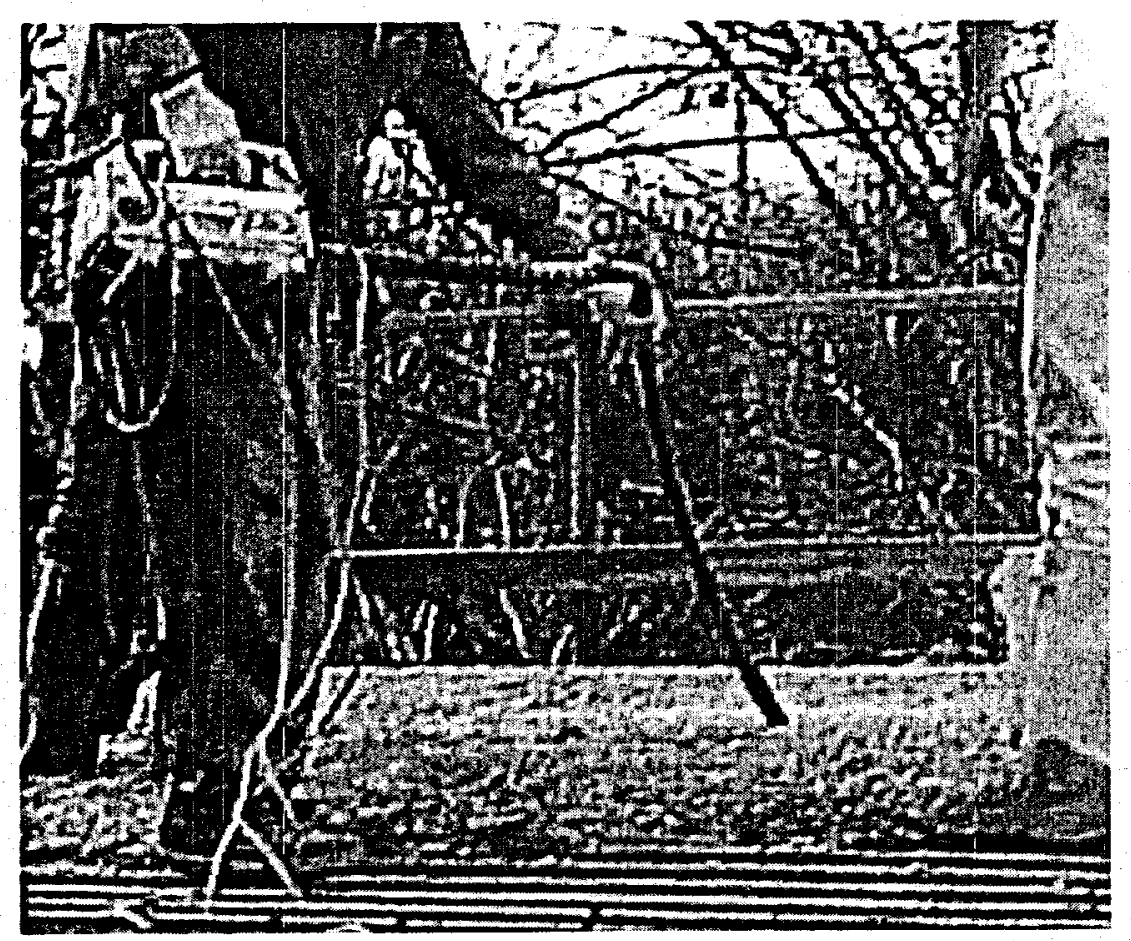

Figure 46. Consolidation of High-Recycled Mixed Plastic-Concrete by Internal Vibration. 


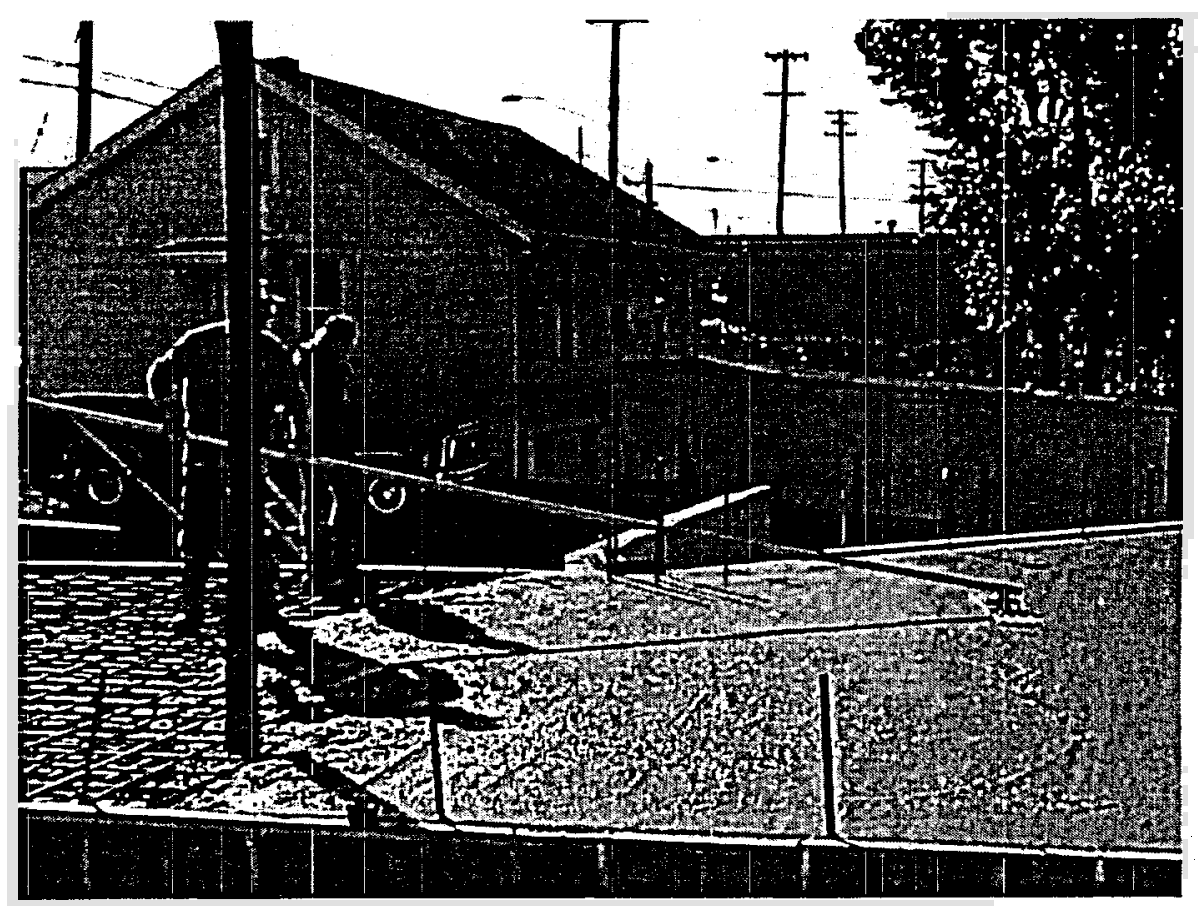

Figure 47. Floating of High-Recycled Mixed Plastic-Content Concrete.

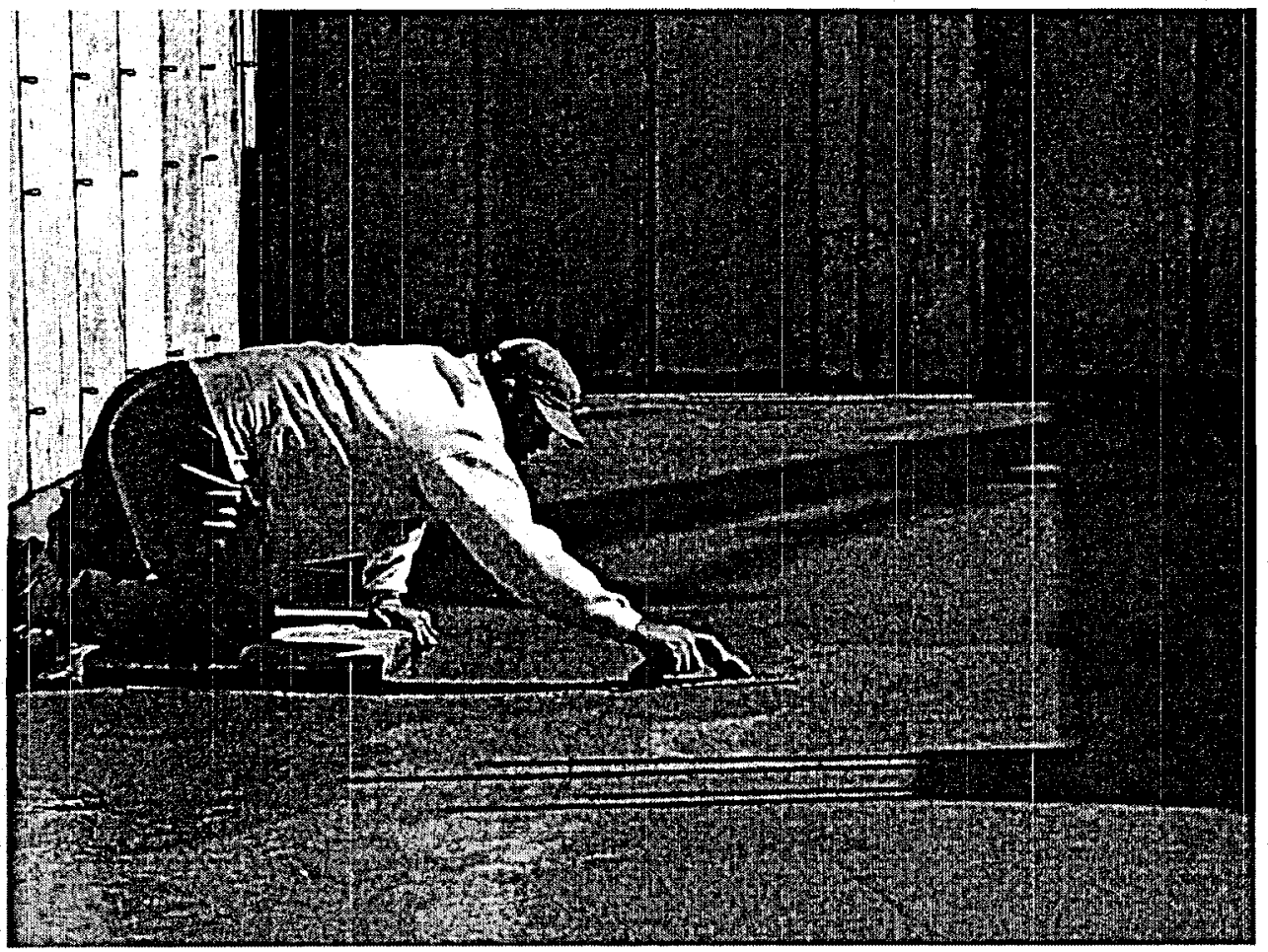

Figure 48. Finishing of High-Recycled Mixed Plastic-Content Concrete. 


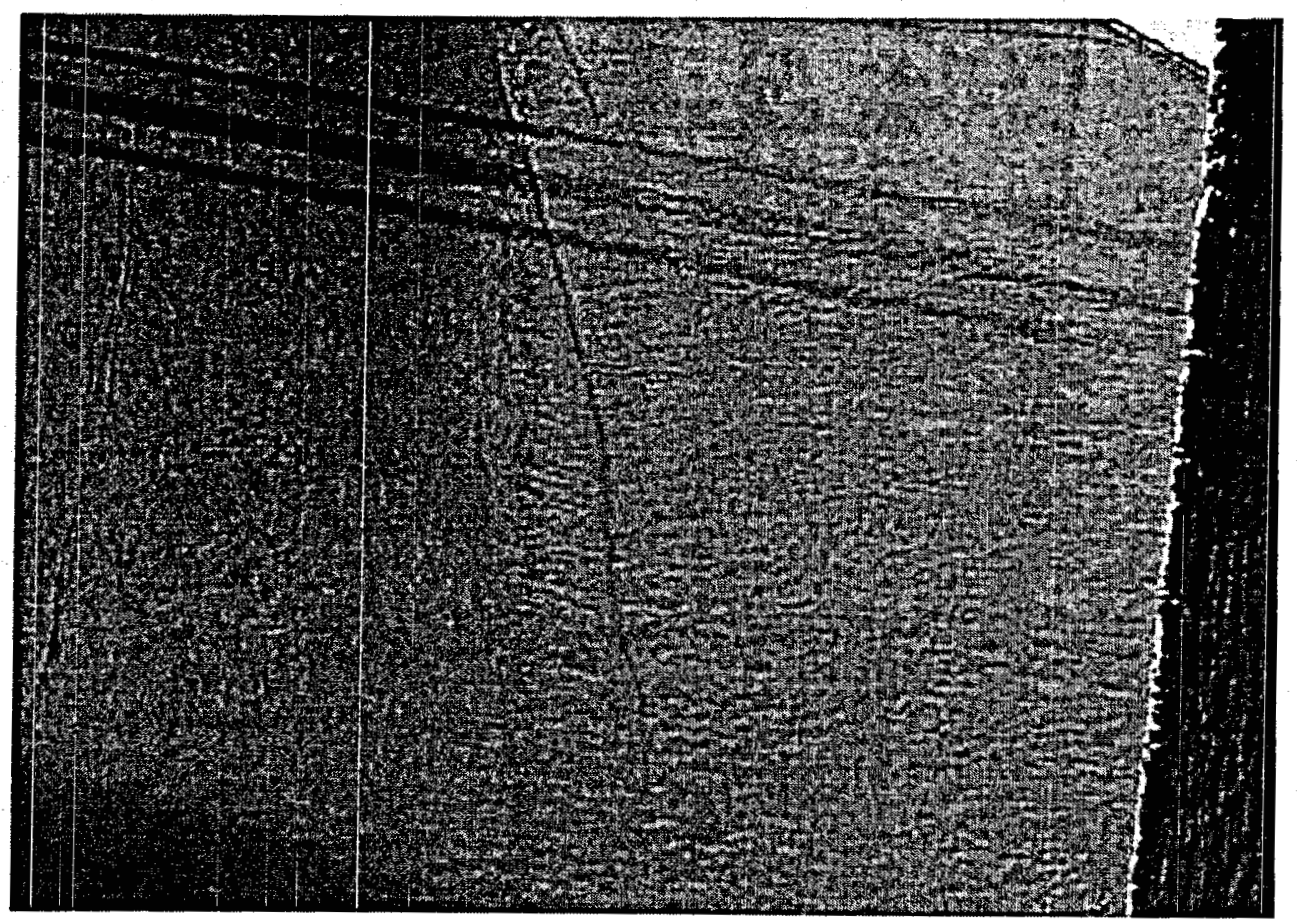

Figure 49. Finished Surface of High-Recycled Mixed Plastic-Concrete.

The two buildings constructed with normal and high-recycled-content concrete were subjected to comprehensive short-term and long-term monitoring in order to demonstrate the advantages of high-recycled-content concrete in terms of energy-efficiency and comfort level of buildings. This monitoring involved, among other things, assessment of heating and cooling energy loads, lighting and temperature conditions within the building, and temperature gradient within recycled-content concrete. For this purpose, thermocouples were installed within concrete and on concrete surfaces at some strategic locations (see Figure 50). Examples of thermocouple installations on recycled-content concrete floors and walls are shown in Figures 51 and 52, respectively. 


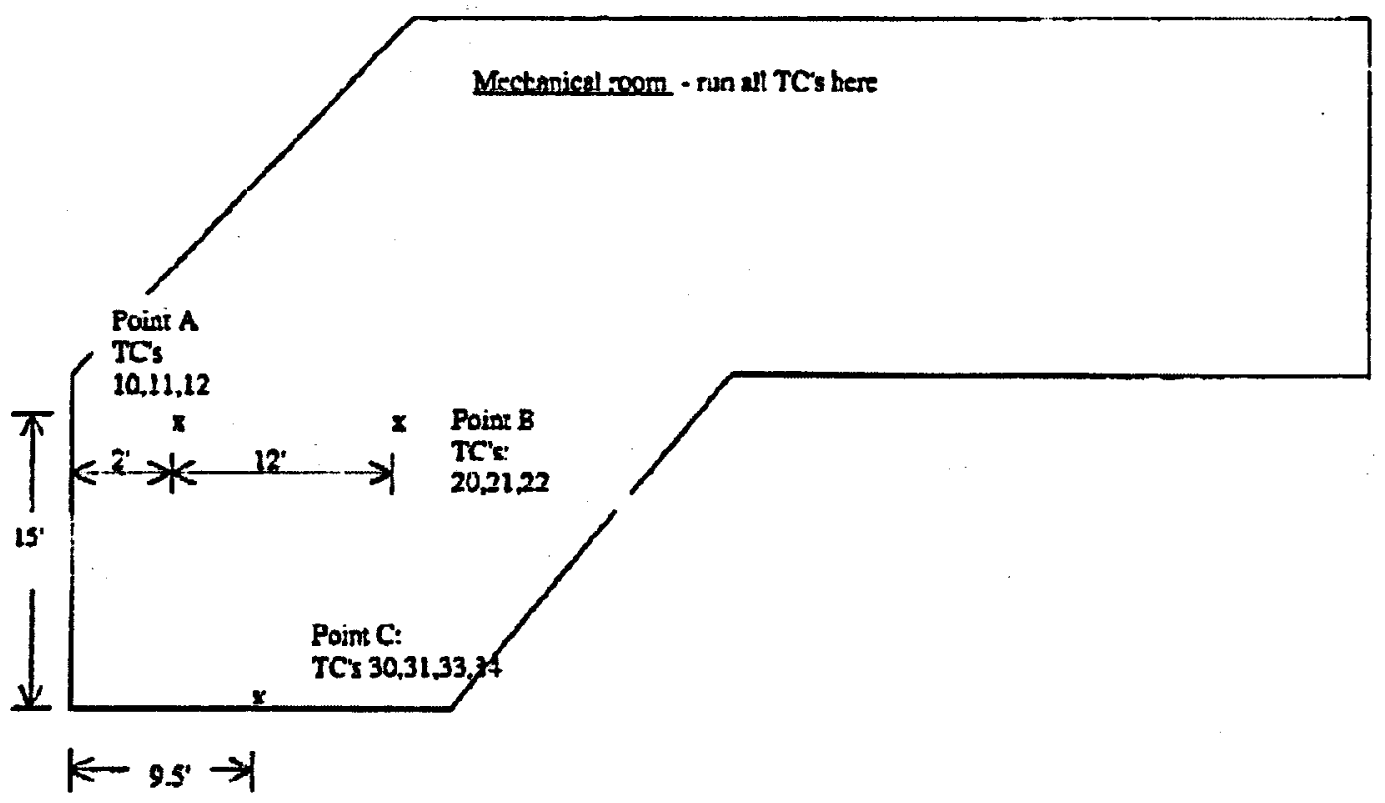

(a) Overall View

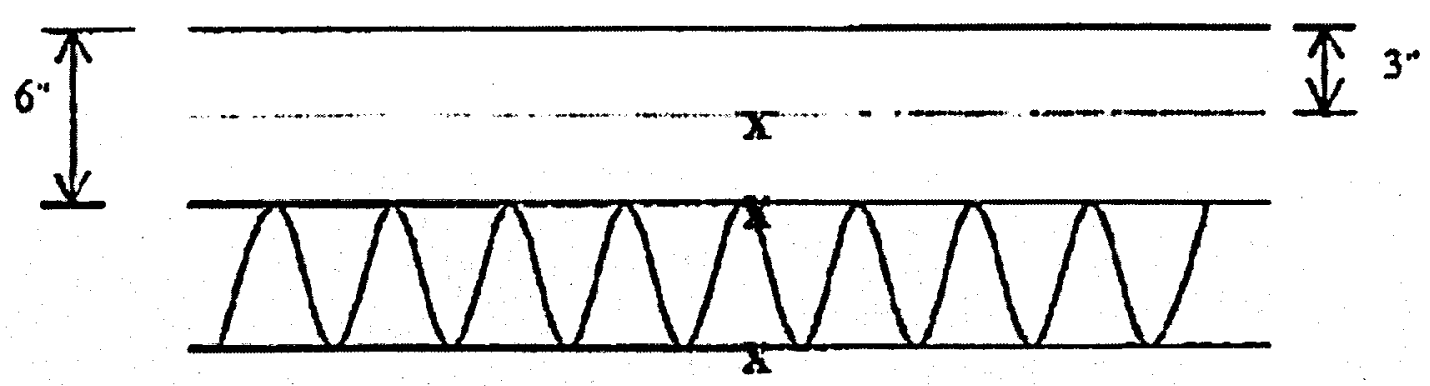

(b) Installation of Floor Termocouples 


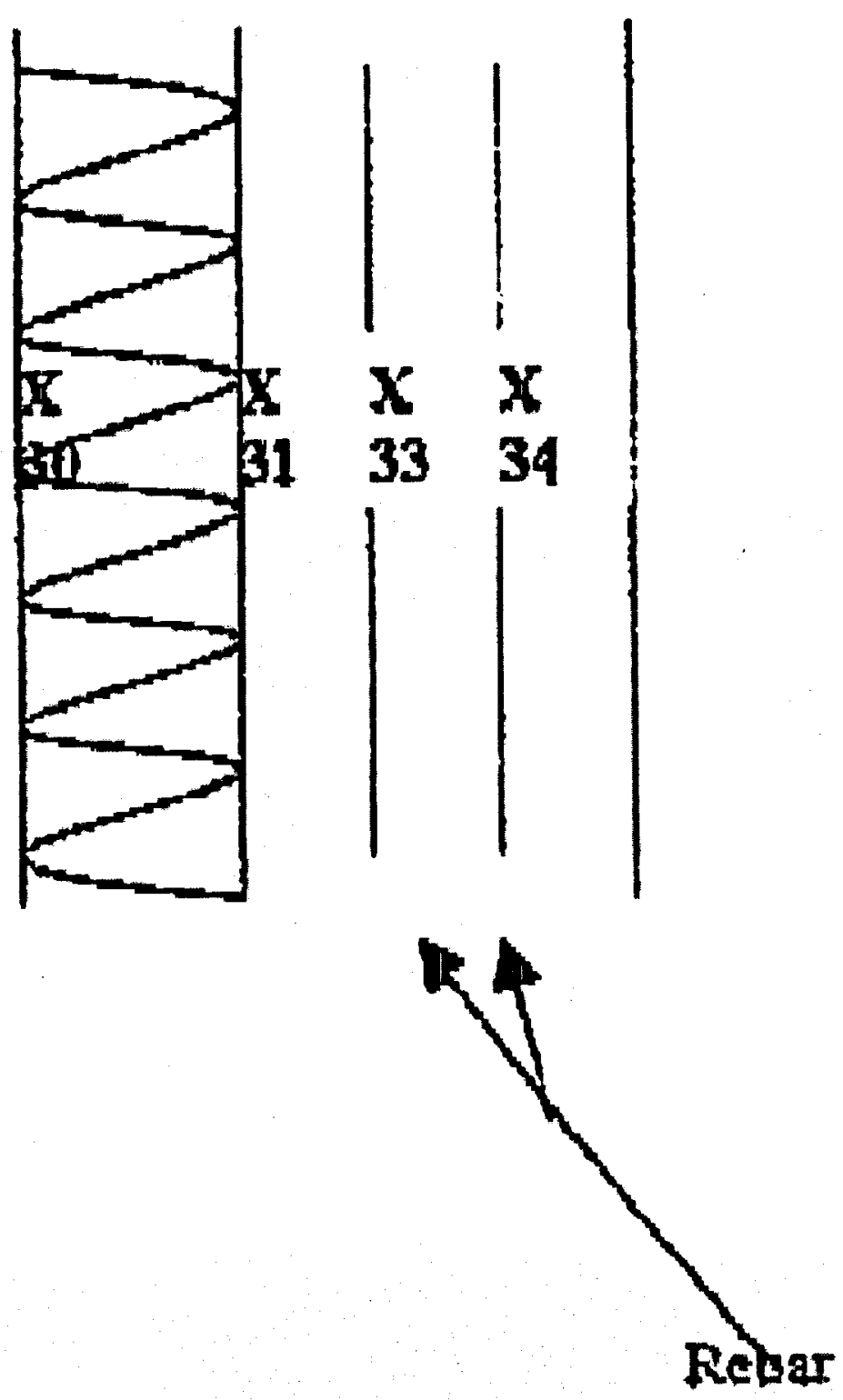

(c) Installation of Wall Thermocouples

Figure 50. Strategic Positioning of Thermocouples Within Recycled-Content Concrete Floors and Walls. 


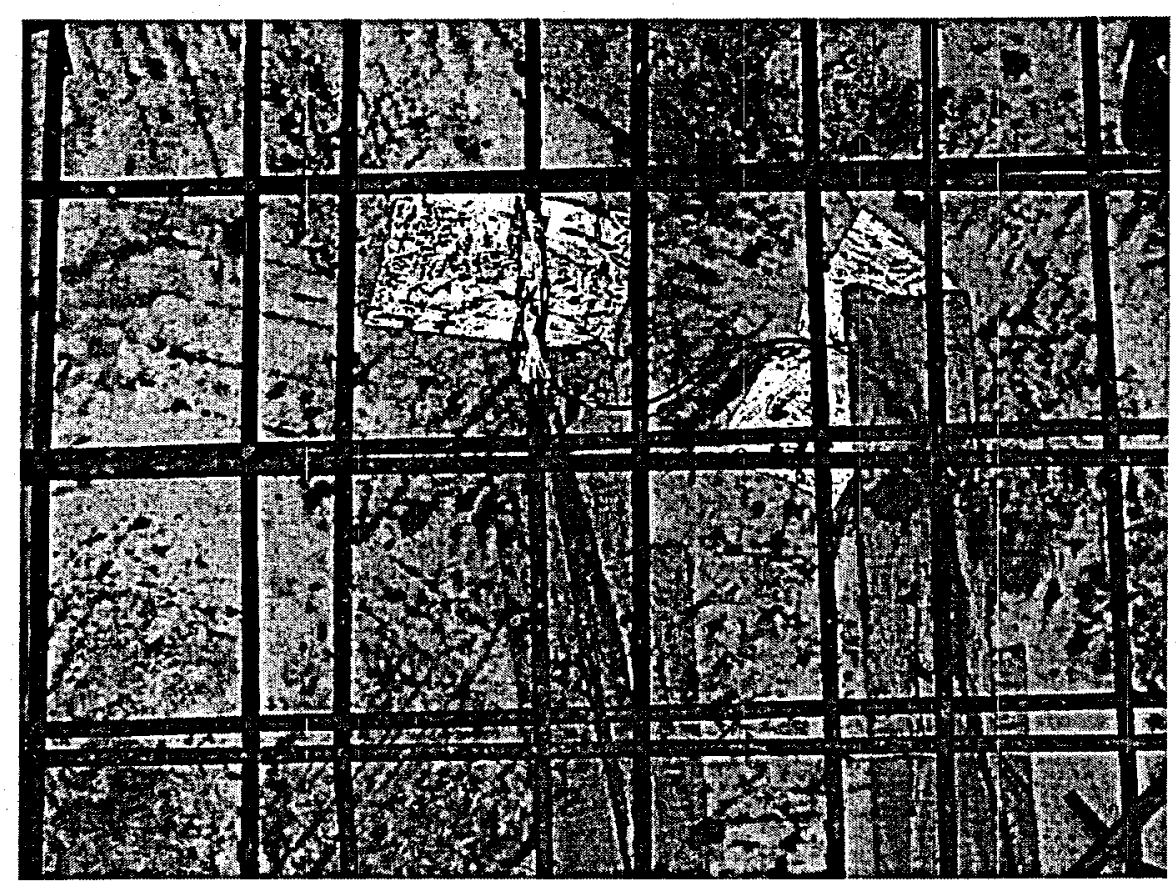

Figure 51. Example of Floor Thermocouples.

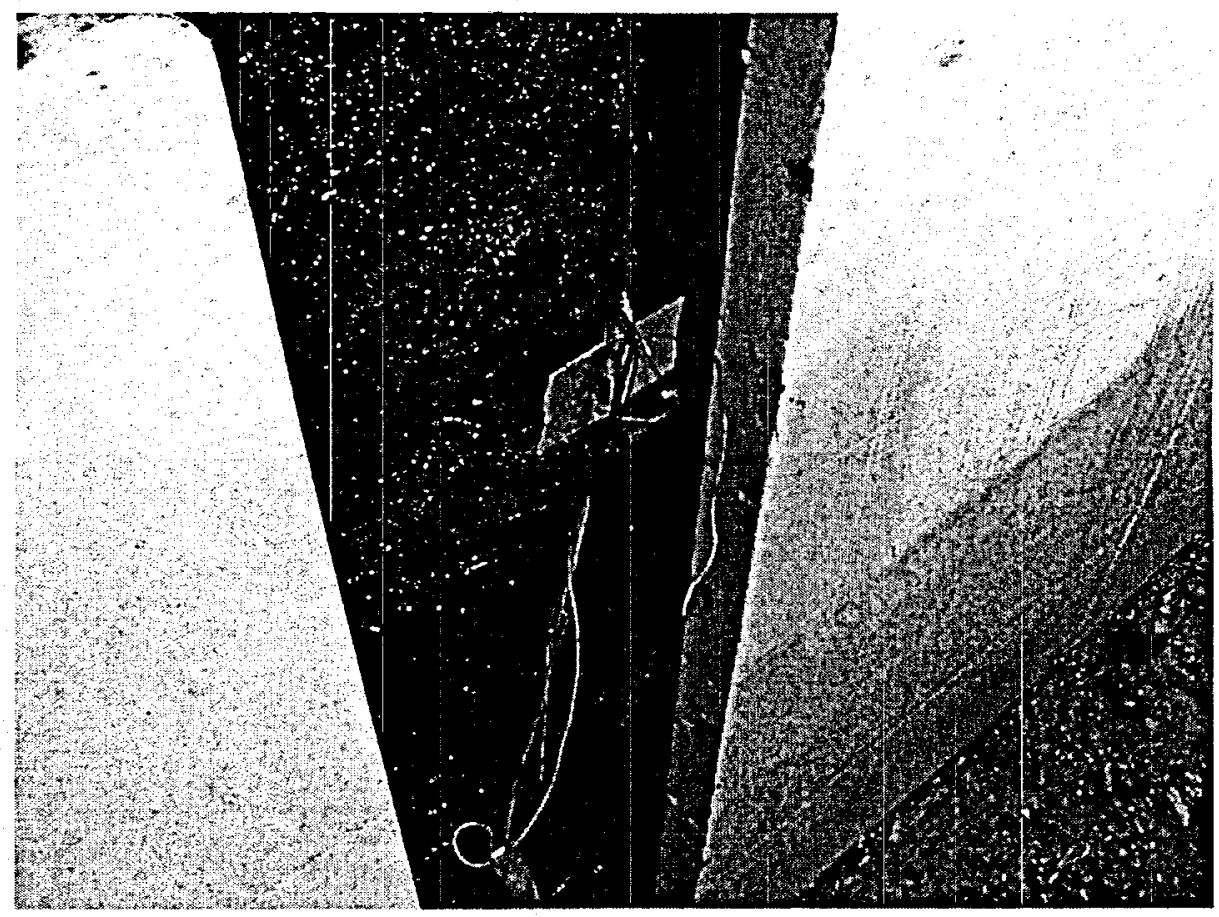

Figure 52. Example of Wall Thermocouples. 
A Campbell Scientific CR 10X data logger system was installed in the utility room of the recycled-plastic concrete building to measure inputs from sensors for long-term monitoring. The hourly average data stored by the data logger are listed in Table 8 . The outside dry bulb temperature and relative humidity sensors were located in a R.M. Yound radiation shield located on the north wall of the building. The Licor Pyranometers measuring horizontal and vertical south irradiance are located on the roof near the south edge. The vertical pyranometer is glued to the vertical south facing trim at the roof line. Four interior air temperatures are measured with type $T$ thermocouples, two on the upper floor and two on the lower floor of the recycled-plastic concrete building. On the upper floor, one thermometer is located next to the thermostat about $1.5 \mathrm{~m}$ above the floor, and the other is located about $0.75 \mathrm{~m}$ below the ceiling. Both thermocouples are mounted in thermostat enclosures attached to the interior partition wall. Four separate electric power measurements are made for the upper and for the lower floor circuit breaker panels. The total electric power for the panel is measured along with separate measurements for air conditioning, lighting, and air handler power. These measurements are made with WattNode watthour meters located inside the panel boxes.

Table 8. Data Items Monitored by the Long-Term Data Logger.

\begin{tabular}{cl}
\hline Data Item \# & \multicolumn{1}{c}{ Description } \\
\hline 1 & Site Code \\
2 & Year \\
3 & Day \\
4 & Hour \\
5 & Battery Voltage, VDC \\
6 & TC Reference Temperature, ${ }^{\circ} \mathrm{C}$ \\
7 & T10 Floor Insulation Bottom Surface \\
8 & T11 Floor Insulation Top Surface \\
9 & T12 Floor Slab Center \\
10 & T20 Floor Insulation Bottom Surface \\
11 & T21 Floor Insulation Top Surface \\
12 & T22 Floor Slab Center \\
13 & T30 Wall Insulation Outer Surface \\
14 & T31 Wall Concrete Outer Surface \\
15 & T33 Wall Concrete \\
16 & T34 Wall Concrete \\
17 & TinUp1 Upper Floor Air Temperature, ${ }^{\circ} \mathrm{C}$ \\
18 & TinUp2 Upper Floor Air Temperature, ${ }^{\circ} \mathrm{C}$ \\
19 & TinDown1 Lower Floor Air Temperature, ${ }^{\circ} \mathrm{C}$ \\
20 & TinDown2 Lower Floor Air Temperature, ${ }^{\circ} \mathrm{C}$ \\
21 & Tout TC Outside Air Temperature, ${ }^{\circ} \mathrm{C}$ \\
22 & Thoriz Horizontal Irradiance on Roof, W/m ${ }^{2}$ \\
23 & Ivert Vertical South Irradiance at Roof Line, W/m ${ }^{2}$ \\
24 & TRHout Humitter Outside Air Temperature, ${ }^{\circ} \mathrm{C}$ \\
25 & Rhout Humitter Outside Relative Humidity, \% \\
26 & ElecTot Upper Floor Total Electric Power, Watts \\
27 & ElecAC Upper Floor Air Conditioner Power, Watts \\
28 & ElecLights Upper Floor Lighting Power, Watts \\
29 & ElecAH Upper Floor Air Handler Power, Watts \\
30 & ElecTot Lower Floor Total Electric Power, Watts \\
31 & ElecAC Lower Floor Air Conditioner Power, Watts \\
32 & ElecLights Lower Floor Lighting and Plugs, Watts \\
33 & ElecAH Lower Floor Air Handler Power, Watts \\
34 & Furnace Status (not installed) \\
35 & Firmace Statis (not installed) \\
\hline &
\end{tabular}


The quality of high-recycled-content concrete used in building construction is controlled closely throughout the project. This is required in order to ensure that targeted performance levels are achieved. Test data on high-recycled mixed plastic-content concrete produced under field conditions are summarized in Table 9, and Figure 53 presents a typical flexural load-deflection curve for this concrete. The high-recycledcontent concrete produced under field conditions successfully satisfied the targeted performance requirements of the project.

Table 9. Test Data for Recycled-Content Concrete Produced Under Field Conditions.

$\begin{array}{cccc}\text { Compressive Strength, MPa } & 16.0 & 17.2 & 17.4 \\ 1^{\text {st }} \text { Crack Impact Resistance, No. of Blows } & 41 & 82 & 30 \\ \text { Failure Impact Resistance, No. of Blows } & 49 & 91 & 45 \\ \text { Apparent Specific Gravity } & 1.96 & 1.94 & 1.95 \\ \text { Water Absorption Capacity, \% } & 6.66 & 6.98 & 7.28 \\ \text { Flexural Strength, MPa } & 3.79 & 3.51 & 3.41 \\ \text { Flexural Energy Absorption, N.mm } & 8458 & 7185 & 5140\end{array}$

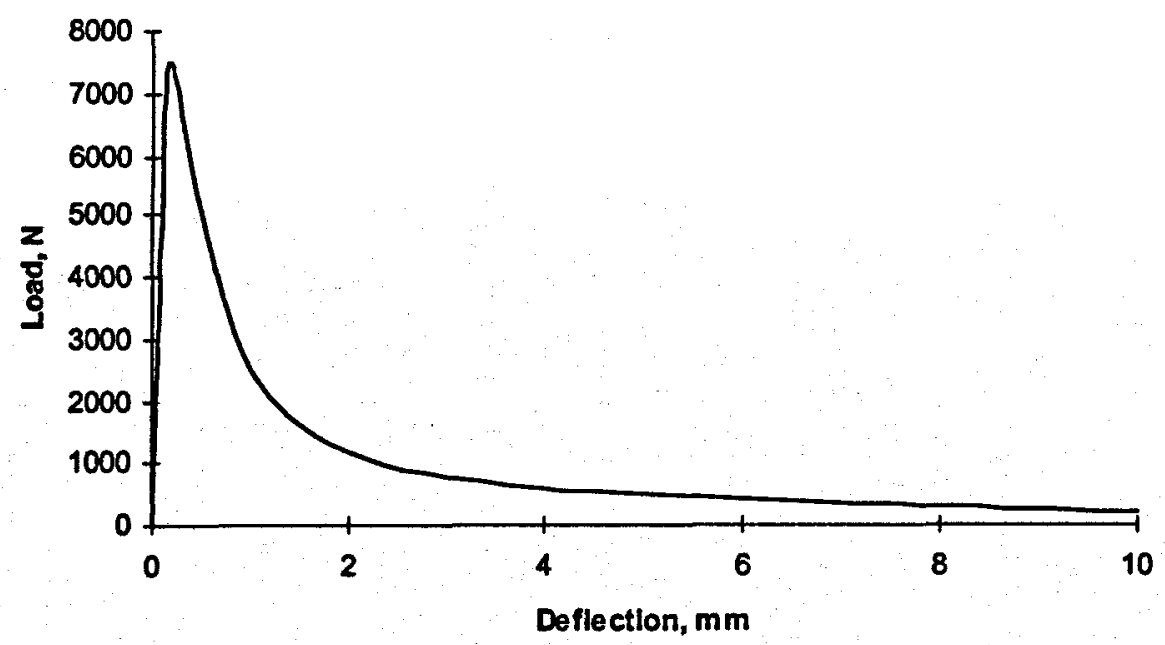

Figure 53. Typical Flexural Load-Deflection Behavior of the High-Recycled Mixed Plastic-Content Concrete Produced Under Field Conditions. 


\subsection{Field Performance Data}

The thermal performance of recycled-plastic concrete and normal concrete buildings were tested. Blower door, tracer gas, coheating, and daylighting tests were also performed.

\subsubsection{Air Tightness and Ventilation}

Blower door tests (Figure 54) were done on both recycled-plastic-concrete and normalconcrete buildings. The blower door was installed in the front door of the upper level and multi-point depressurization tests were completed. Table 10 presents the test results. The equivalent leakage area (ELA at $4 \mathrm{~Pa}$ ) is 102 in $^{2}$ for the recycled-plastic-concrete building and 71 in $^{2}$ for the normal-concrete building, indicating that the shell of each building is relatively tight compared to standard practice, and that the normal-concrete building appears to be tighter than the recycled-plastic-concrete building.

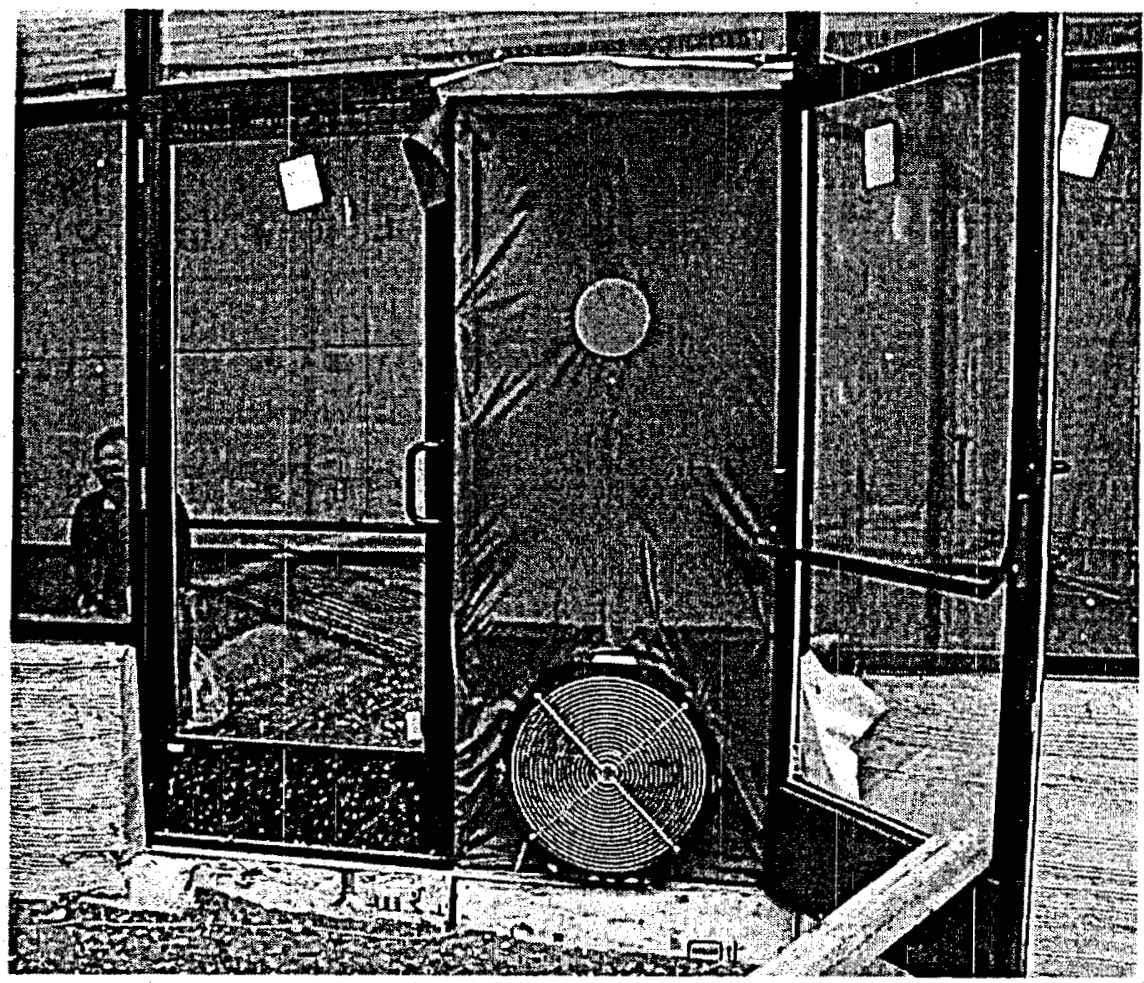

Figure 43. Blower Door Test Set-Up. 
Table 10. Blower Door Test Results.

\begin{tabular}{lcc}
\hline & Recycled-Plastic-Concrete Building & Normal-Concrete Building \\
\hline ELA @ 4 Pa, in & 104 & 71 \\
CFM@ @ Pa & 1470 & 1047 \\
c & 171.5 & 114.8 \\
n & 0.548 & 0.565 \\
\hline
\end{tabular}

There are differences between the South and North buildings that may influence the test results. These differences are as follows:

1. At the time of measurements, the exterior stucco was nearly complete on the North building and was not started on the South building. Some wall cracks were obviously sealed when the stucco was applied.

2. Since the blower door was mounted in the upper floor, the connection to the lower floor was ambiguous. The connection between floors was created in the South building. There is an access door (approximately one square foot)in the utility chase between floors in the South building only. This provides a direct air flow path between floors; a significantly volume of air was observed to flow through this door. The door was open during the test because instrument wires were temporarily installed through the door. The leakage area for the upper floor of the South building will be reduced when this access door is closed in normal operation.

3. The South building has an outside air inlet for intentional ventilation and economizer operation which is not present in the North building. The damper for this inlet was closed during the blower door test, but there still could be extra air leakage around the outside air inlet area. An additional blower door test was done with the outside air inlet blocked and taped on the outside. The difference in ELA was insignificant, indicating that this physical difference between the buildings is probably not contributing to the difference in air tightness.

Tracer gas tests were completed in both buildings starting on Thursday, April 13, 2000 at $6 \mathrm{pm}$, and ending on Wednesday April 19,2000 at 6 am. This test measures the net air exchange rate between the inside and outside air. For these tests, tracer gas was injected and sampled only in the upper floor volumes of both buildings. Therefore, air flowing from the lower floor to the upper floor would be measured as outside air. The equipment and techniques used in these tests are not able to determine multi-zone air exchange rates. That is, the air exchange rates of the upper and lower floors cannot be separately measured in one test with this technique. The tracer gas test results are presented in Figure 44. 


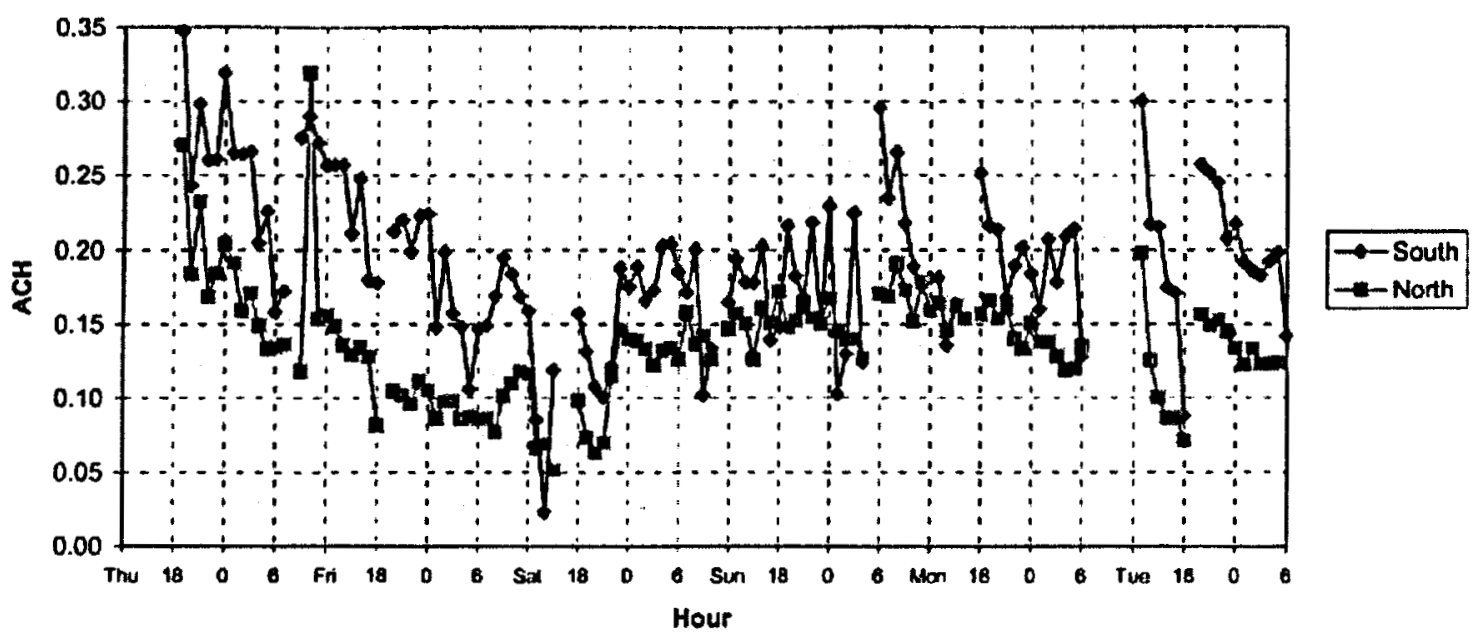

Figure 44. Tracer Gas Measurements of Air Exchange Rates (April 13-19, 2000).

\subsubsection{Coheating Test Results}

The North and South buildings were heated using temporarily-installed electric heaters (see Figure 45a) from Thursday April 13, 2000 until Tuesday April 18, 2000, with temperature monitored (see Figure 45b)at several locations throughout the buildings. The purpose of this electric "coheating" test was to enforce a constant and uniform interior temperature in both buildings while making an accurate measurement of the energy required to maintain the temperature. The relative performance of the two buildings can be directly compared and the time-series data can be compared to computer simulation model prediction.

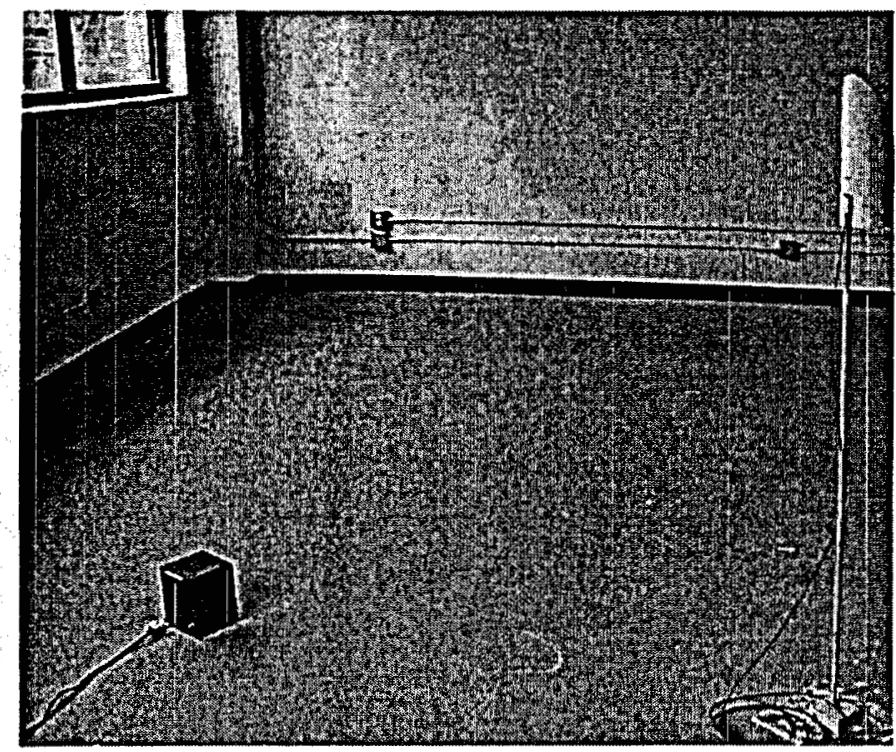

(a) Electric Heater (left) and Temperature Sensor (right) 


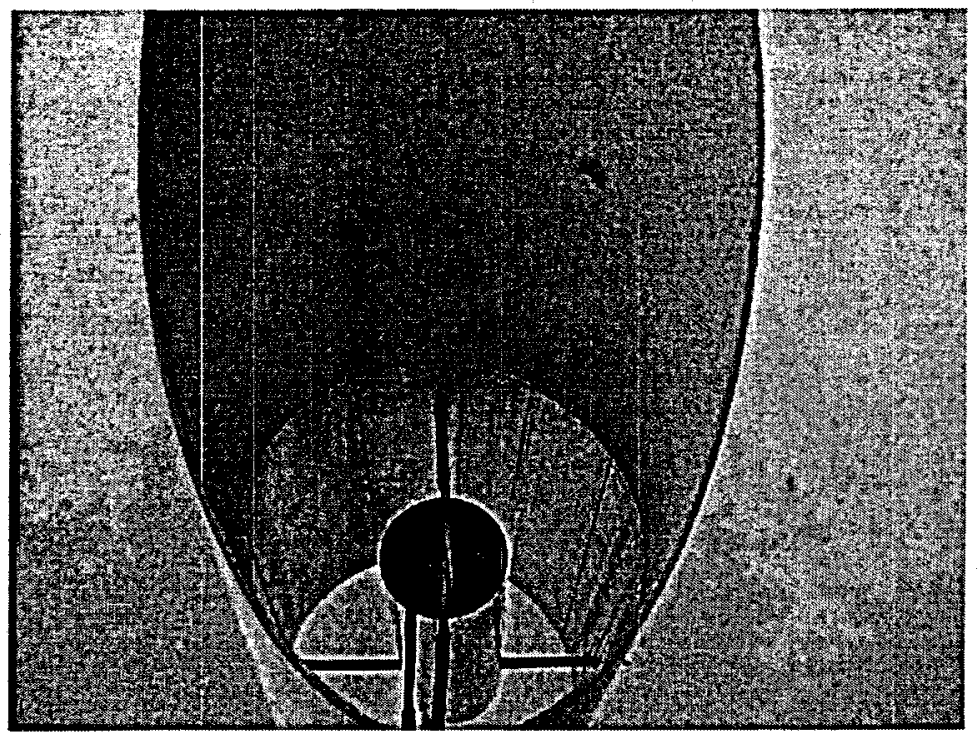

(b) Temperature Sensor

Figure 45. Electric Heating and Temperature Measurement.

The weather conditions during the coheating period are shown in Figures 46 and 47. Conditions were rather sunny and warm on Friday and Saturdy, and cooler and cloudy on Sunday and Monday.

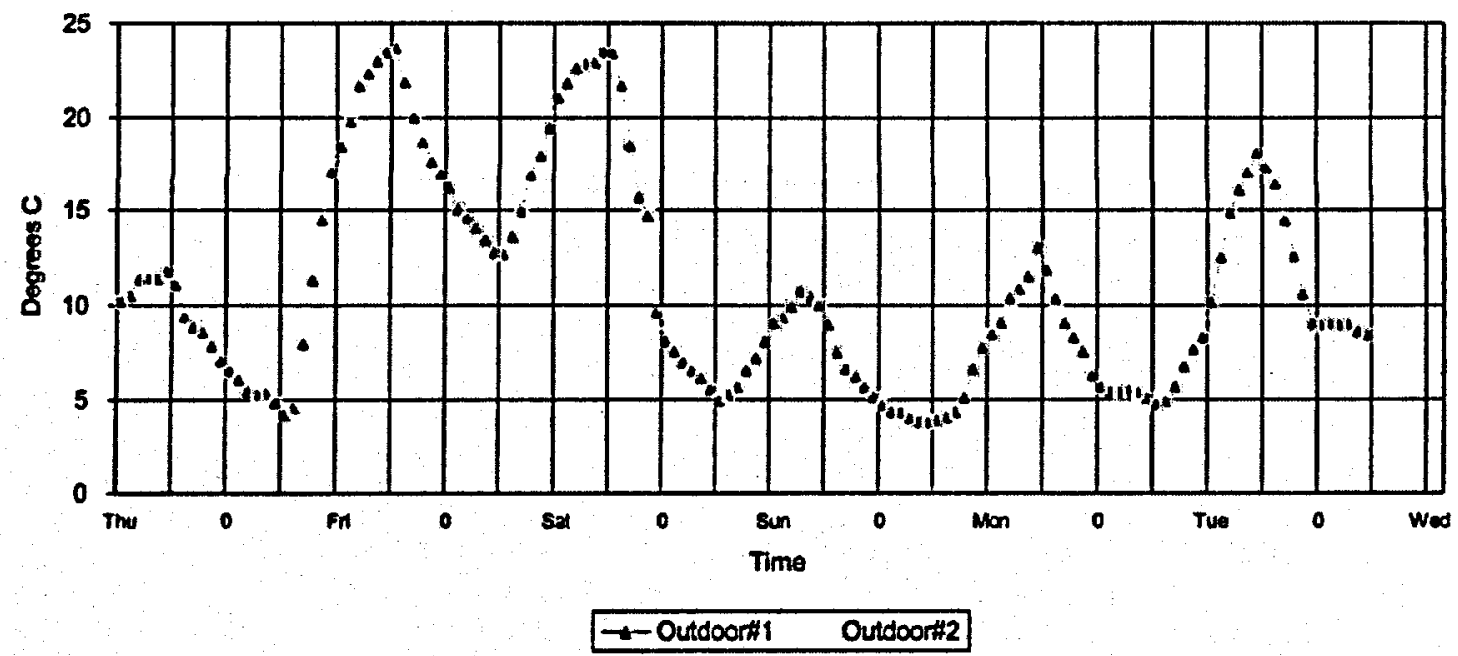

Figure 46. Outside Temperatures During the Coheating Period. 


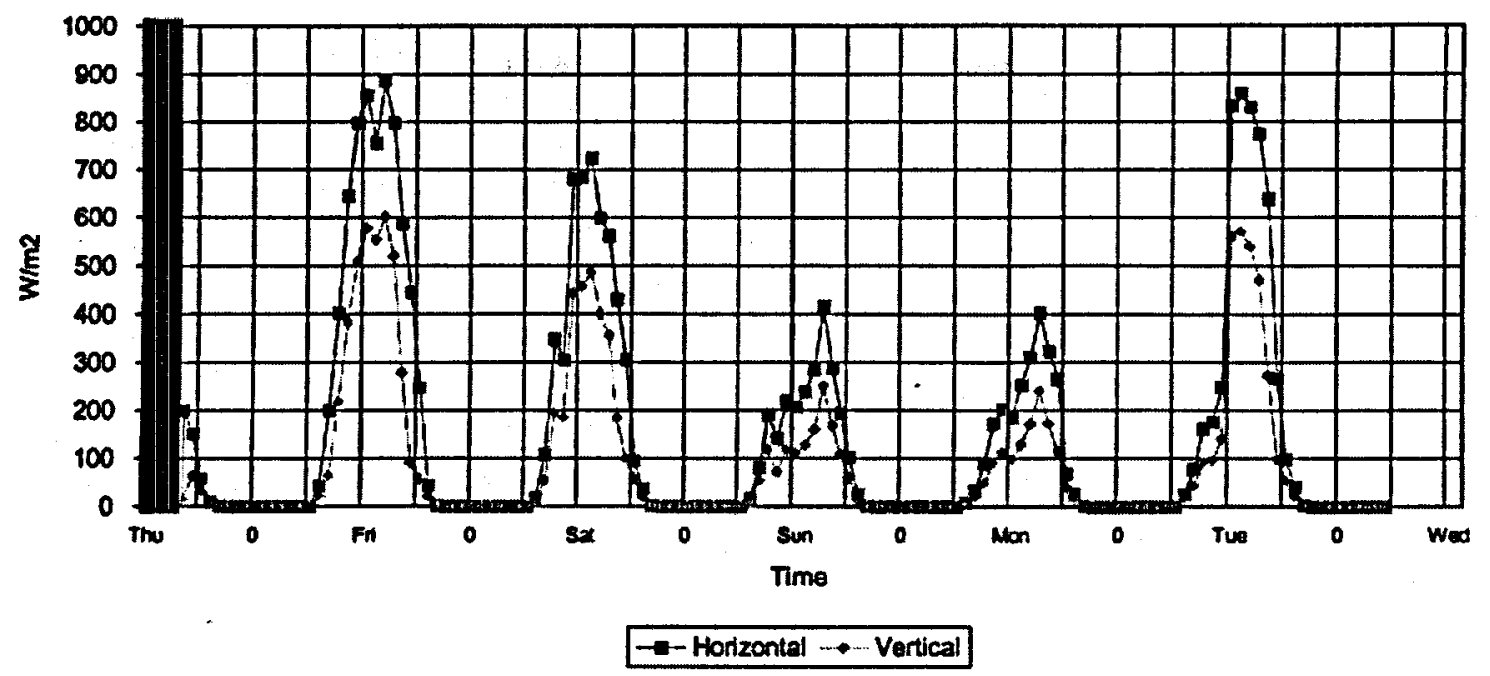

Figure 47. Solar Radiation During the Coheating Period.

The interior temperatures for six locations in the South building are graphed in Figure 48. The North building temperatures are shown in Figure 49 . Both buildings have temperature excursions above the set point on Friday and Saturday, and relatively stable and uniform temperatures on Sunday and Monday. The period of diverging temperatures on Tuesday is during furnace operation. The average of the six temperatures for each building are compared in Figure 50. The South building has a slight temperature excursion on Friday and Saturday. The period of falling temperature at night in the North building on Sunday indicates that the heater capacity was inadequate to maintain the temperature. This implies that the North building requires more heating energy than the South building during this period.

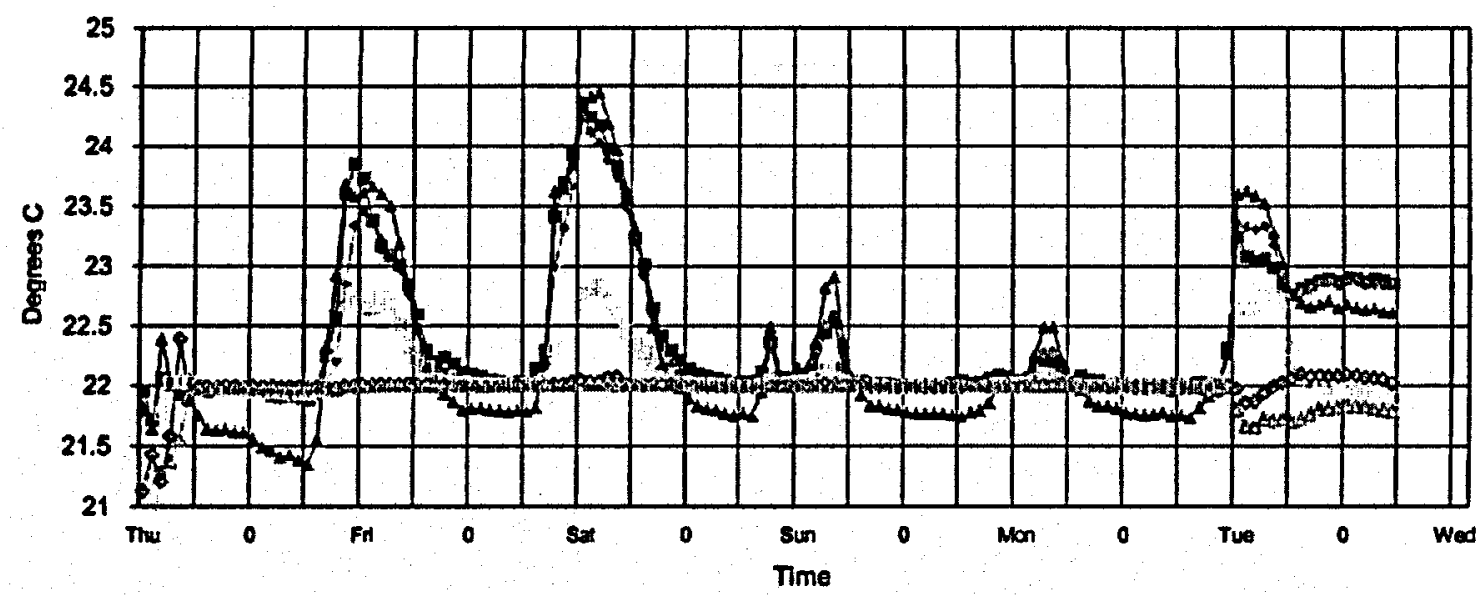

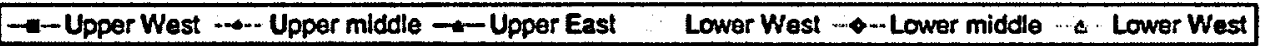

Figure 48. Interior Temepratures During the Coheating Period in the South Building. 


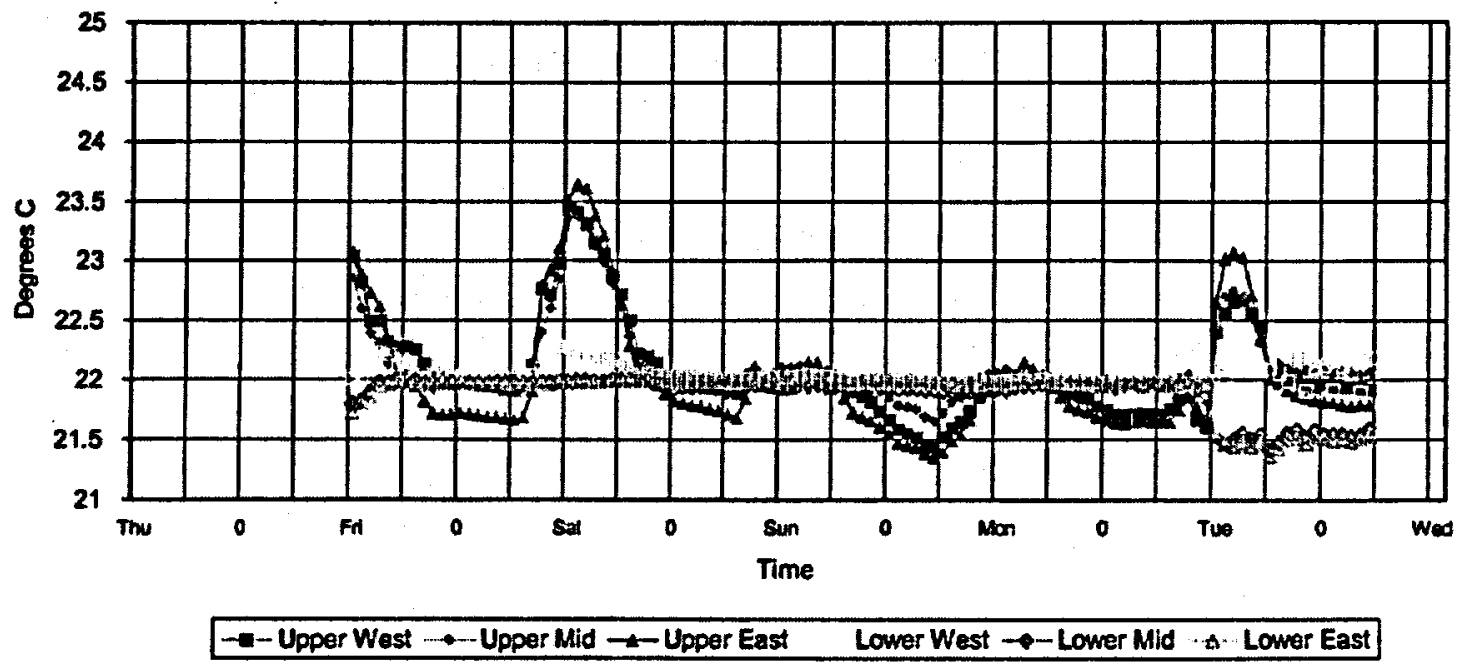

Figure 49. Interior Temperatures During the Coheating Period in the North Building.

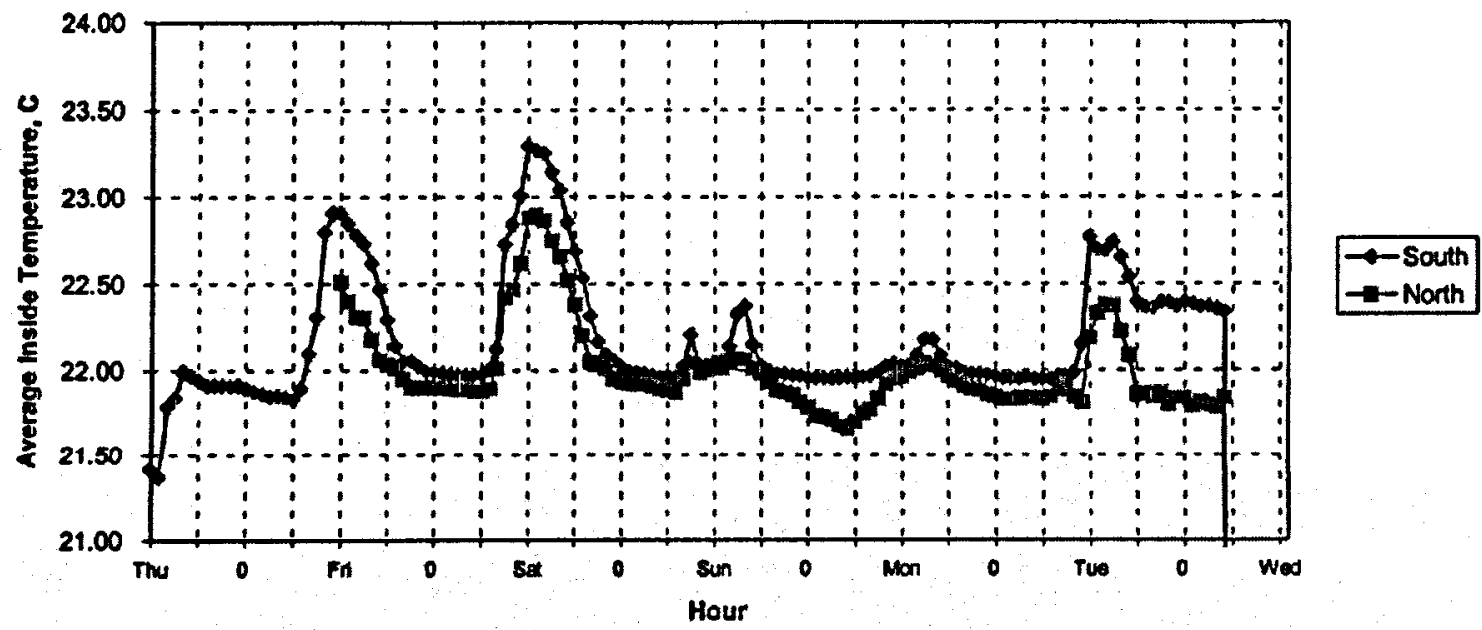

Figure 50. Comparison of Average Interior Temperatures for the South and North Buildings.

Figure 51 shows the time-series data for electric power used by both buildings during the coheating period. The North building consistently uses more electric power than the South building. The daily electric power use is about $25 \%$ less in the South building during the coheating period. 


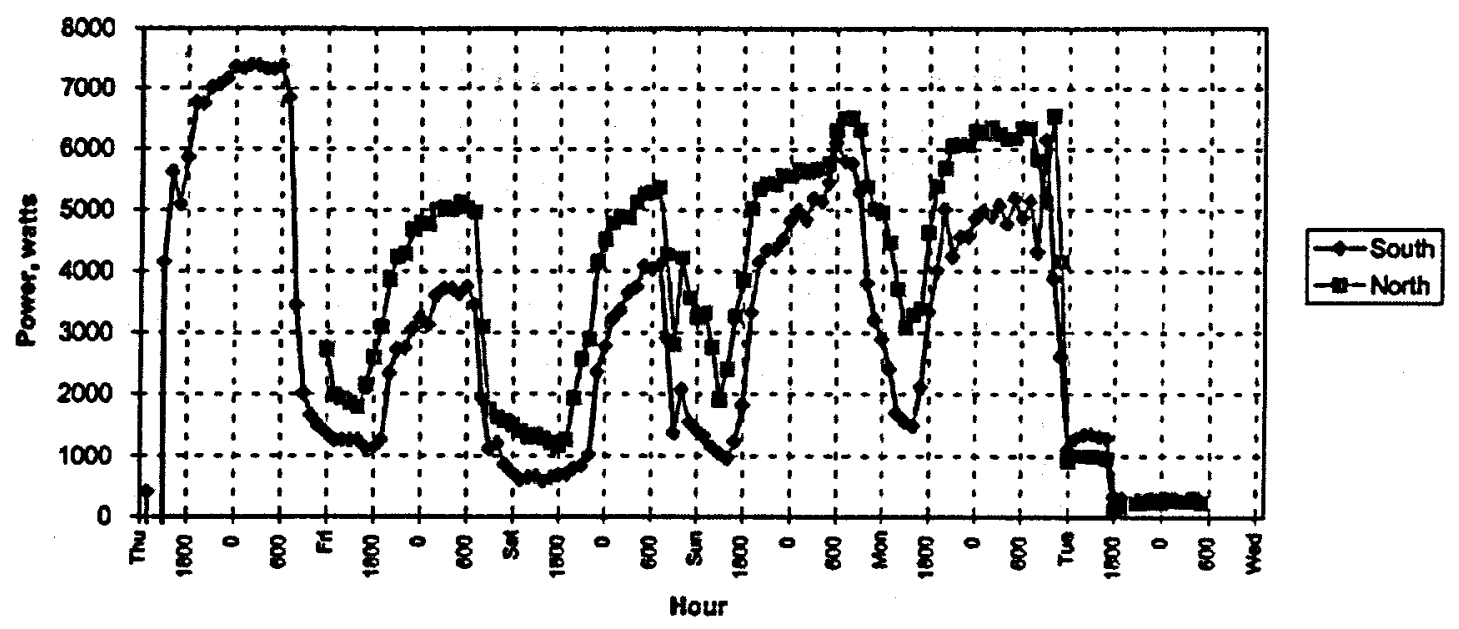

Figure 51. Comparison of Electric Power Use in Both Buildings During the Coheating Period.

\subsubsection{Lighting and Daylighting}

Illuminance from natural lighting and electric lighting was measured in the upper level of the South building using Licor photometers (see Figure 52). Interior illuminance was measured in six interior locations and for two exterior orientations as described in Table 11.

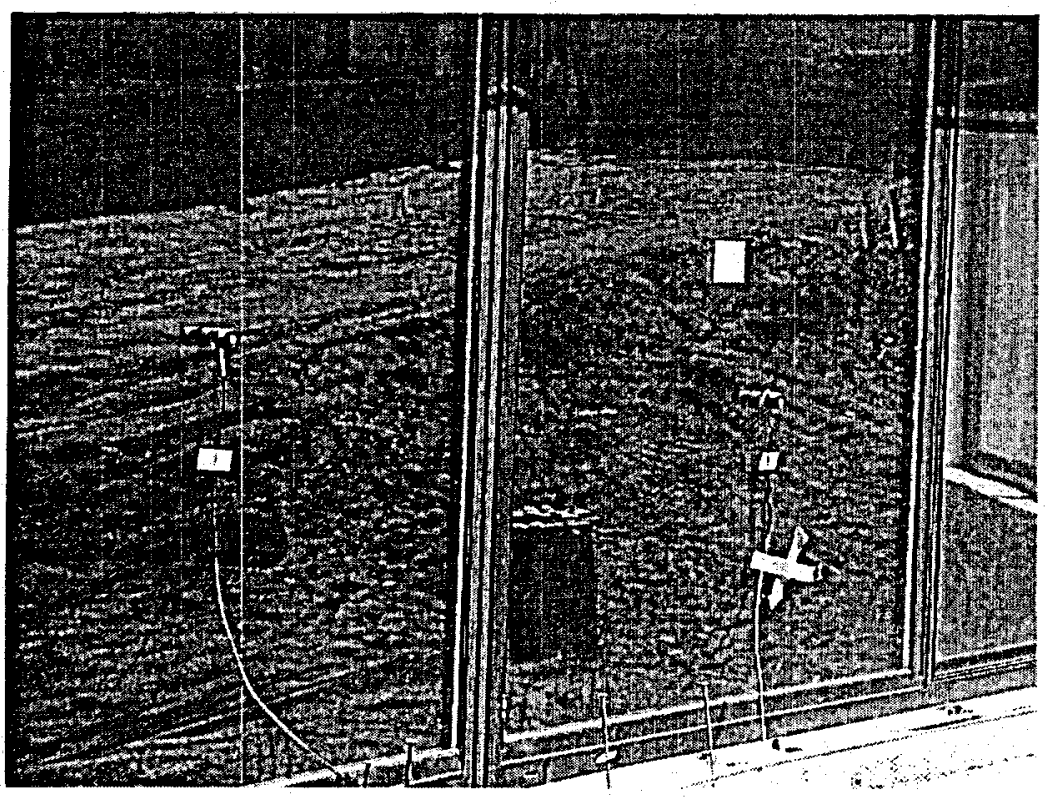

(a) Photometer Sensors Installed on Windows 


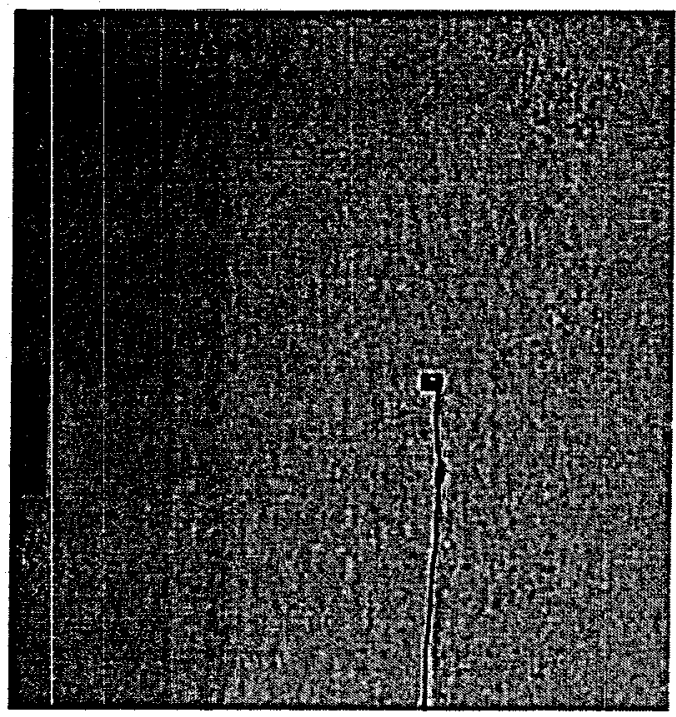

(b) Photometer Sensor Installed on Interior Wall

Figure 52. Examples of Photometer Sensors Used for the Measurement of Lighting.

Table 11. Photometer Locations.

\begin{tabular}{|c|l|l|}
\hline Number & Nane & Location \\
\hline 1 & West mid & $\begin{array}{l}30 \text { inches above floor, horizontal } \\
9 \text { feet NW of middle of SE glass, } \\
8.5 \text { feet SE of interior wall, } \\
20 \text { feet E of W wall }\end{array}$ \\
\hline 2 & East mid & $\begin{array}{l}30 \text { inches above floor, horizontal } \\
10 \text { feet N of S wall, } \\
10 \text { feet S of N wall, } \\
15 \text { W of E wall }\end{array}$ \\
\hline 3 & West, S wall & $\begin{array}{l}7 \text { feet above floor } \\
\text { on window frame facing N } \\
\text { in line with sensor } 1\end{array}$ \\
\hline 4 & West, N wall & $\begin{array}{l}7 \text { feet above floor, } \\
\text { on wall facing S, } \\
\text { in line with sensor 1 }\end{array}$ \\
\hline 5 & East, S wall & $\begin{array}{l}7 \text { feet above floor, } \\
\text { on SE window frame facing NW, } \\
\text { in line with sensor } 2\end{array}$ \\
\hline 6 & East, N wall & $\begin{array}{l}7 \text { feet above floor, } \\
\text { on interior wall facing SE, } \\
\text { in line with sensor } 2\end{array}$ \\
\hline 7 & Horizontal outside & $\begin{array}{l}18 \text { inches above ground, } \\
15 \text { feet S of building }\end{array}$ \\
\hline & Vertical S outside & $\begin{array}{l}\text { on lower floor glass, } \\
30 \text { inches above ground }\end{array}$ \\
\hline & & \\
\hline
\end{tabular}


Figures 53 and 54 show the time-series data for the outside and inside illuminance, respectively. Saturday was mostly sunny with periodic scattered clouds. Sunday and Monday were mostly overcast but still with relatively high illuminance levels. There is a period of very high illuminance on the east end of the building in the morning due to the east facing window. Much of the room receives direct sun and the illuminance exceeds 10,000 Lux on sunny days. On the completely overcast day, the illuminance is generally constant and uniform, and exceeds 500 Lux on all surfaces from 08:00 until 17:00.

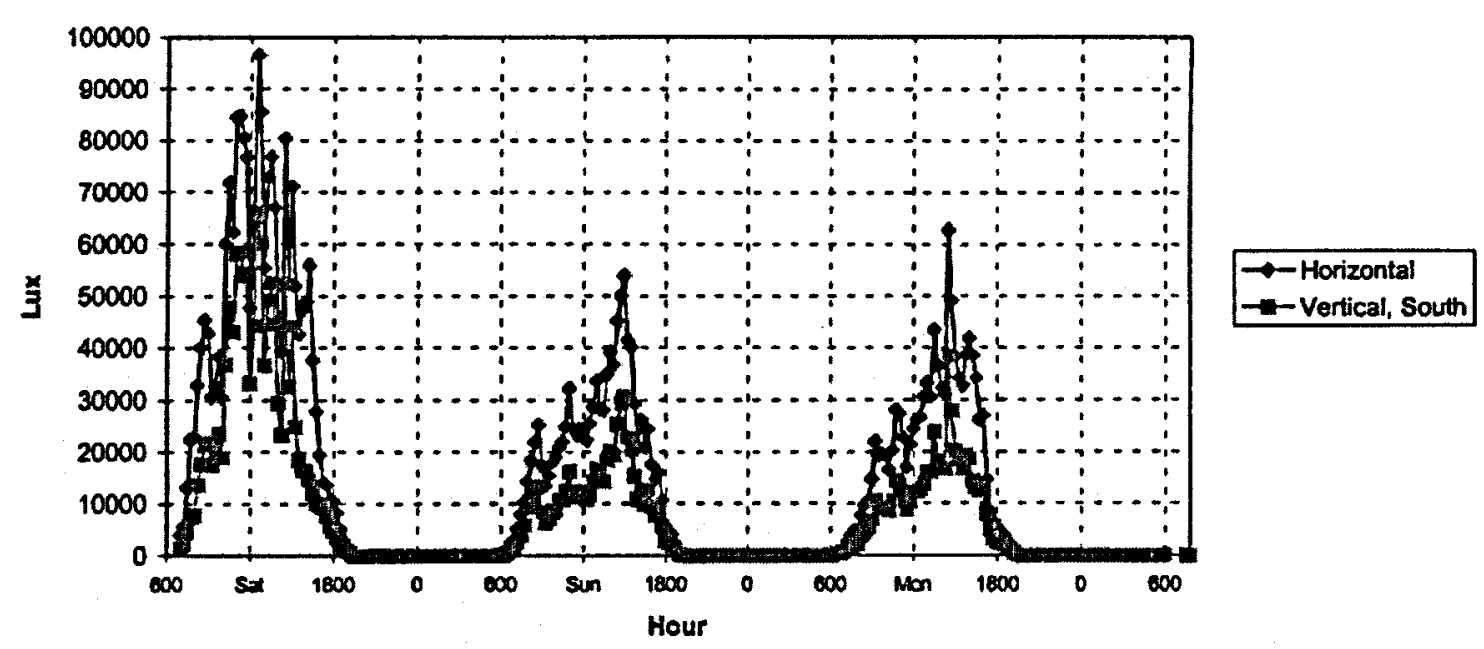

Figure 53. Measured Values of Outside Illuminance

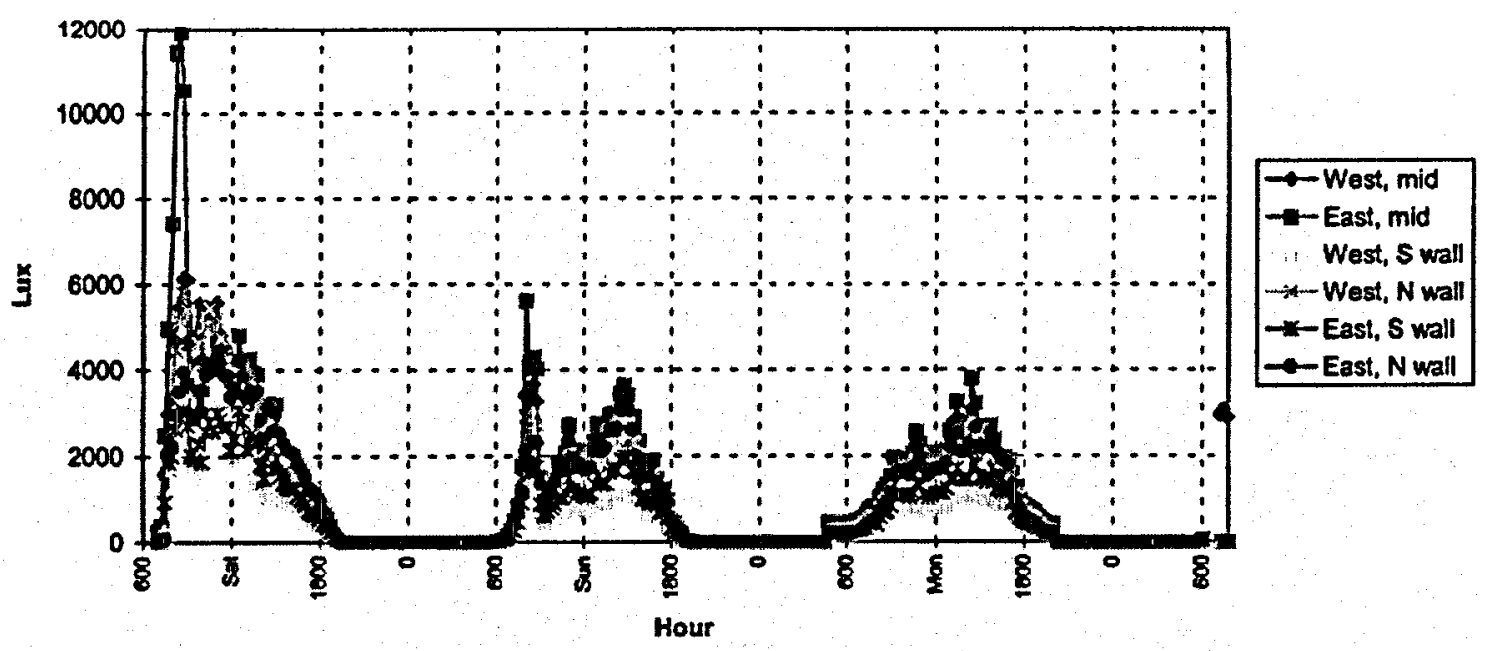

Figure 54. Measured Values of Interior Illuminance. 
On Sunday, the electric lights were activated and placed under the control of the dimming control all day from about 05:30 until 20:00. Figure 55 shows a plot of the illuminance in the room and the electric power used by the lights. When it was dark outside, the electric lights provided about 400 lux with the east end about $10 \%$ lighter than the west. THe electric power for lighting when the lighting control system operated at $100 \%$ (i.e., it was dark outside) was about 980 watts. As the illuminance level exceeded about 1000 lux, the dimming control began to reduce electric power to the lights until it reached a minimum of about 280 watts. The behavior of the lighting controller is clearly illustrated in the graph, noting that the protective plastic covering on the reflective fixtures could not be removed to make these measurements. The illuminance can be expected to be slightly higher than reported here during normal operation.

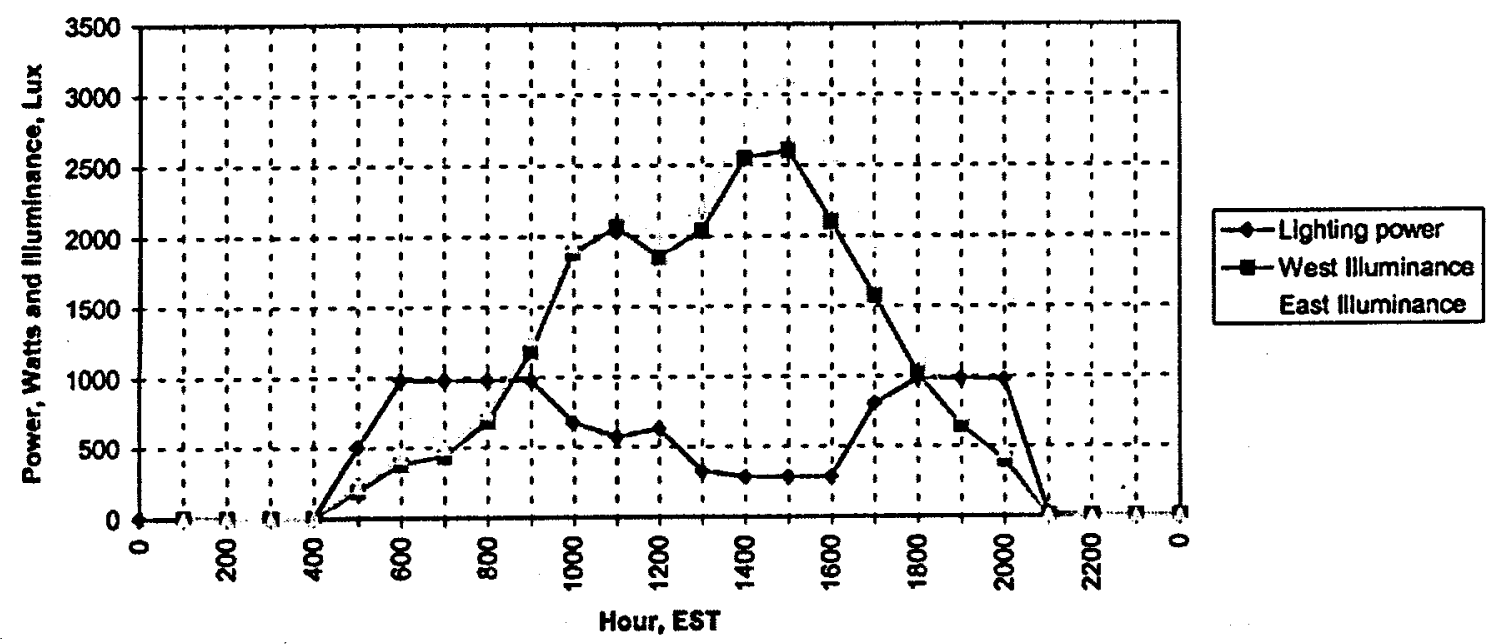

Figure 55. Interior Illuminance and Lighting Electric Power Demonstrating Dimming Control. 


\subsection{Conclusions}

1. A refined procedure was developed for proportioning of concrete mixtures incorporating relatively large volumes of recycled materials as coarse aggregate and natural sand as fine aggregate; this procedure was successfully verified in laboratory using the following recycled materials: granulated plastics (HDPE, PVC, PP and mixed plastics), chipped hardwood, granulated tire, steel, and crushed concrete. Recycled materials, as replacement for coarse aggregate, occupy close to half of concrete volume.

2. Based on bulk specific gravity, concrete materials incorporating crushed concrete as coarse aggregate can be categorized as normal-weight, those incorporating recycled plastics, tire and wood as light-weight, and those incorporating steel as heavy-weight. Concrete materials incorporating recycled or virgin coarse aggregates provide comparable levels of water absorption per unit volume, except for wood coarse aggregates which yield relatively high water absorption capacity.

3. There is a drop in compressive strength of normal concrete when crushed limestone coarse aggregate is replaced with plastics and especially with tire and wood. Recycled plastics and expanded clay produce comparable levels of compressive strength. Recycled steel and crushed concrete coarse aggregates provide compressive strengths comparable to that produced by crushed limestone.

4. Concrete materials with recycled plastics and even with recycled wood as coarse aggregate provide reasonable levels of flexural strength. Recycled steel and crushed concrete produce flexural strengths comparable to that provided by crushed limestone. Recycled plastics produce flexural strengths comparable to that provided by expanded clay lightweight aggregate. In general, concrete materials incorporating recycled plastics, tire and especially wood provided higher flexural strength-to-compressive strength ratios when compared with concrete materials with limestone, crushed concrete, recycled steel and lightweight expanded clay coarse aggregate.

5. Recycled plastics, wood and tire provide for a ductile mode of failure in flexure; this reflects on the ability of these recycled particles to bridge across cracks and prevent brittle modes of failure which are exhibited by crushed limestone and also by crushed concrete and recycled steel. This would have positive implications in terms of restrained shrinkage crack control.

6. Recycled plastic, wood and steel coarse aggregates proved to be effective in restrained shrinkage crack control.

7. Concrete materials incorporating recycled plastics and crushed concrete as coarse aggregate provide reasonable levels of impact strength.

8. Recycled plastic coarse aggregates produce concretes which, at comparable bulk specific gravity, compete well with virgin lightweight aggregate (expanded clay) in terms of flexural strength and, to some extent, compressive strength, and are superior to virgin lightweight aggregate concrete in terms of impact resistance.

9. The specific heat of concrete (per unit weight and even per unit volume) benefited greatly from the introduction of recycled plastic, tire and wood coarse aggregate. 
Concretes with higher specific heat increase produce a greater "thermal mass" and thus benefit energy-efficiency and comfort level of buildings.

10. Recycled plastic, wood and tire coarse aggregates yielded lower levels of thermal conductivity, which also benefits energy-efficiency of buildings. Still, highrecycled-content concrete provides only a fraction of the high levels of exterior insulation needed for effective use of the "thermal mass" of concrete for energyefficiency.

11. The high-recycled-content concrete materials designed and investigated in this project exhibited desirable durability characteristics reflected in their ability to retain their flexural strength and energy absorption capacity after exposure to repeated wetting-drying and temperature cycles; these materials also performed satisfactorily when exposed to elevated temperatures.

12. The capillary sorption of high-recycled-content concrete materials was comparable to that of control concrete, except for wood and tire coarse aggregates which increased the capillary sorption of concrete.

13. A reinforced concrete building was designed, from both structural and energy points of view, and constructed with concrete incorporating recycled mixed plastic coarse aggregate. The recycled plastic concrete building exhibited higher levels of energy-efficiency and comfort when compared with the control normal concrete building. Recycled plastic concrete in combination with energy-efficient building design techniques proved to be of tremendous value in lowering the cooling and heating loads of buildings and also in enhancing the comfort level of building interior.

14. Concrete masonry materials incorporating recycled coarse aggregates were also investigated. Mix proportioning and processing techniques were developed for incorporating recycled coarse aggregates into concrete masonry units. Highrecycled-content concrete masonry materials, when compared with control normal- and light- weight concrete masonry, provided competitive levels of flexural strength and superior levels of flexural energy absorption capacity. Physical attributes of high-recycled-content concrete were also satisfactory. Durability tests involveing repeated wetting-drying and freezing-thawing, extended immersion in hog water, exposure to elevated temperatures and repeated temperature cycled suggested that all high-recycled-content concrete masonry materials, except for those made with recycled wood and tire, suit exterior applications in diverse climatic conditions. High-recycled-content concrete masonry materials also provided desirable thermal attributes, marked by high specific heat values, for energy-efficient building construction. 